International Journal of Fatigue

Elsevier Editorial system(tm) for

Manuscript Draft

Manuscript Number: IJFATIGUE-D-19-00599R1

Title: Characterization of cyclic behavior, deformation mechanisms, and microstructural evolution of MarBN steels under high temperature conditions

Article Type: Original Research Paper

Keywords: MarBN steel; Low cycle fatigue; High temperature

viscoplasticity; Martensitic substructure; Sub-grain formation.

Corresponding Author: Dr. Adil Benaarbia,

Corresponding Author's Institution: Arts et Métiers ParisTech ENSAM

First Author: Adil Benaarbia

Order of Authors: Adil Benaarbia; Xu Xu, DR.; Wei Sun, PROF.; Adib Becker, PROF.; Steve Osgerby, DR.

Manuscript Region of Origin: Europe

Abstract: In this paper, the low cycle fatigue behaviour of MarBN steels at elevated temperatures is discussed. Four cyclic loading waveforms were applied to investigate both the mechanical and microstructural features. The mechanical results exhibit continuous cyclic softening and

decelerated stress relaxation, recoverable viscoelasticity at both short and long time scales and irrecoverable viscoplastic mechanisms. Detailed microstructural characterisation was also conducted

to investigate the rupture behaviour of the investigated steel. The microstructural findings indicate typical transgranular and ductile fracture behaviour, extensive sub-grain formation and structural refinement as well as significant decrease in hardness close to the fracture surface.

Response to Reviewers: Responses to reviewers: IJFATIGUE-S-19-00764

The authors are grateful to both the editors and reviewers for their constructive comments and suggestions, and have addressed each of these as indicated below and trust that these have resulted in a much-improved manuscript.

Replies to the reviewers: The authors' responses are highlighted in blue, while all the major changes in the paper are in red. The minor typos have been corrected without being highlighted.

Reviewer \#1:

Results of low cycle fatigue tests with MarBN steel at temperatures between $400^{\circ} \mathrm{C}$ and $675^{\circ} \mathrm{C}$ are presented. Different cyclic loading waveforms were employed with fully reversed, strain-controlled tests with and without hold periods as well as stress-controlled tests at different stress ranges with different hold periods in tensile region and at zero 
stress. Variations in hysteresis loops were discussed and the deformation mechanisms were analysed by microstructural investigations using SEM, EBSD and hardness mapping.

The mechanical investigations are based on well-considered experiments leading to profound descriptions of the cyclic degradation. For all temperatures, continuous cyclic softening accompanied with decelerating stress relaxation was observed. Both recoverable viscoelastic and irrecoverable viscoplastic mechanisms could be identified. Microstructural transformation caused by cyclic loading at high temperature was observed by EBSD analysis. However, there are flaws in the fractographic analysis and a lack of information on the mechanical properties of the investigated material. The main concerns are listed in the following:

Comment No. 1: The fractographic images shown in Figure 8 do not serve well to comprehend some statements in section 3.2.1. The scale bars indicate that the magnification of the fractographic images in (a), (b) and (c) should be identical. This is obviously not the case (unless different specimen shapes were used or failure did not occur in the gauge section of specimens). Please use the same magnification for Fig. 8(b) and (c) as in (a) .

The authors acknowledge that the micrograph as shown in Figure 8b was collected at a different magnification as Figures $8 \mathrm{a}$ and 8c. However, Figures $8 \mathrm{a}$ and $8 \mathrm{c}$ were collected at the identical magnification, with the CRT specimen appears to have a small gauge dimension. The authors have double checked the CRT specimen and can confirm that the specimen dimension is the same as SWT and DWT, whereas the rupture surface shows a smaller area due to significant necking occurred in the final stage of testing. Therefore, Figure 8 has been amended accordingly based on the comment from the reviewer.

The following text has been added in pages 16 and 17 in the revised version:

The specimen experiencing DWT at $625^{\circ} \mathrm{C}$ (Figure 8b) was ruptured in a similar manner as compared to the specimen experiencing SWT. This is evidenced by the presence of striations and dimples on rupture surface Figure $8(\mathrm{~b}$ and e). A larger interspacing distance between striations was observed after DWT testing as a result of holding period in each loading cycle.

Comment No. 2: This would facilitate to see if the DWT specimen (b) also exhibits fatigue crack initiation from the surface (as might be considered from the current fractograph).

Many thanks to the reviewer for this comment. The authors would like to mention that additional attempts have been made to identify the location of crack initiation sites. However, no clear evidence showing the initiation site of the major crack was obtained. This is probably attributed to a small area of the initiation site as facilitated by a rapid crack propagation at a high level of the applied stress in low cycle fatigue experiments. 
Comment No. 3: Also, the specimens should be cleaned before observation in SEM since the features marked as "dimples" in Figure 8(b) rather look like contaminants.

It is worth noting that the dimple like features in Figure 8b were checked in the SEM at a higher magnification. The figures as below show that these features are not contaminants and exhibit a similar topography as dimples. The bright particles within each dimple are non-conductive inclusions particles such as Al203 and secondary phase particles such as $\mathrm{BN}$.

Supplement 1 (see the attached RTR file): A secondary electron micrograph showing the dimples containing secondary phase particles in the DWT specimen $\left(625^{\circ} \mathrm{C}\right)$.

Comment No. 4: The region marked as "Crack propagation area" in Figure 8 (a) seems to be the final fracture region. Further, it is stated that fatigue striations are visible in Figure $8(d)$, but the magnification is too low to identify striations.

Many thanks to the reviewer in highlighting this point. The authors acknowledge that the label for the area of crack propagation was misleading. Figure 8 a has been amended accordingly.

The authors have confirmed the topography of the SWT specimen and can confirm that the surface topography is similar to the observations as in the existing studies on low cycle fatigue behaviour of similar 9\% $\mathrm{Cr}$ steels $(e \cdot g \cdot[1,2])$.

[1] V. Shankar, M. Valsan, K.B.S. Rao, R. Kannan, S.L. Mannan, S.D. Pathak, Low cycle fatigue behavior and microstructural evolution of modified 9Cr-1Mo ferritic steel, Mater. Sci. Eng. A. 437 (2006) 413-422. [2] P. Verma, N.C.S. Srinivas, S.R. Singh, V. Singh, Low cycle fatigue behavior of modified $9 \mathrm{Cr}-1 \mathrm{Mo}$ steel at room temperature, Mater. Sci. Eng. A. 652 (2016) 30-41.

Comment No. 5: The mechanical properties of the testing material should be indicated. Some of the tests relate the stress level to percentage of the yield strength. Is this the yield strength at room temperature or at the respective testing temperature?

The reviewer is correct in indicating that it would be interesting if the mechanical properties of the testing material could be indicated. This point has been addressed and the following table has been added in page 7 of section 2 in the revised version:

Table: The mechanical properties of the investigated MarBN steel. E stands for the Young's modulus, while o_k denotes the initial yield strength measured through the first loading cycle at the selected test temperature.

Temperature $\left({ }^{\circ} \mathrm{C}\right) \quad 400 \quad 625 \quad 650 \quad 675$

$\mathrm{E}(\mathrm{GPa}) \quad 395.2163 .8155 .3106 .3$

$\sigma \mathrm{k}(\mathrm{MPa}) \quad 187.3129 .6120 .594 .7$

In the manuscript, the yield strength is measured through the first loading cycle at the testing temperature. This has been indicated in the caption of Table2 in the revised version. 
Comment No. 6: The Vickers hardness of the as-received material should be indicated in order to allow comparison with hardness values presented in Section 3.2 .3 .

The authors acknowledge that a comparison between the as-received material and the specimens with SWT and DWT exposure is important and have conducted additional characterisation using the same experimental instrument. The value of hardness has been measured from the as-received material and included in the corresponding section of the revised version (page20).

Hardness measurement was firstly performed in the as-received MarBN steel prior to LCF testing at a loading weight of $10 \mathrm{~kg}$ and $0.2 \mathrm{~kg}$. The values of hardness obtained from the as-received material are measuring $249 \pm 2$ HV1O and $261 \pm 8$ HVO.2 at different testing conditions. Hardness measurement was further conducted close to the boundary between gauge and head portions of SWT and DWT specimens at a loading weight of $10 \mathrm{~kg}$.

The variation of hardness in the region close to fracture surface was further characterised using hardness mapping analysis at a loading weight of $0.2 \mathrm{~kg}$ after SWT and DWT at $625^{\circ} \mathrm{C}$, Figure 10 .

Comment No. 7: Section 3.2.3, second paragraph: "The hardness in the region $<1.5 \mathrm{~mm}$ from the rupture surface is lower and in the range between 218 and $232 \mathrm{HVO} .2$, whereas the hardness in the regions $>1.5 \mathrm{~mm}$ from the rupture surface is increased to above 230 HVO.2, Figure 10 (b)." This statement should be reconsidered since the increase in hardness is rather low and hardly visible in Figure $10(\mathrm{~b})$.

The authors acknowledge that the increase in hardness is not evident. Considering the scattering of data, the hardness variation in the DWT specimen is trivial. To highlight these points, the following texts have been added in page 20:

The variation of hardness is not evident without a clear trend in the specimen experiencing DWT, Figure $10(\mathrm{~b})$. Hardness varies between 218 and $247 \mathrm{HVO} .2$ in the gauge portion of the specimen experiencing DWT.

The hardness values measured from the gauge portion are considerably lower than the values measured from the as-received material (i.e. 261 8 HVO.2).

Comment No. 8: Also: "...in the range between 242 and 291 HV0.2 in the same specimen, Figure 10(a)". The range in the color scale bar range in Figure 10 (a) is only between 200 and $270 \mathrm{HV}$. Please check.

The authors acknowledge that the colour scale of Figure 10 should be amended and the manuscript is updated accordingly.

Comment No. 9: It should be considered to perform additional hardness measurements with a CRT specimen. This might be interesting due to high amount of refined microstructure.

The authors acknowledge that it is important to further characterise the hardness variation in the CRT specimen to compare with the other samples. Additional measurement was therefore conducted and Figure 10 has been amended accordingly. 
Figure (see the figure in the revised version): Hardness maps collected from the regions close to fracture surfaces in the specimens experiencing (a) SWT, (b) DWT and (c) CRT at $625^{\circ} \mathrm{C}$.

The corresponding text has been added in page 20 in the revised manuscript:

The value of hardness as measured from the region close to the rupture surface of the CRT specimen is evidently higher than the region further away. This can be attributed to a higher volume density of dislocations in the region close to the rupture surface upon the occurrence of necking due to localised plasticity instability [Ref: Benaarbia, A., Xu, X., Sun, W., Becker, A., Jepson, M.A., 2018b]. This is further evidenced by the observation of significantly distorted and refined martensitic microstructure as shown in Figure 9.

Further minor comments:

The tick labels of the abscissae in Figure 3 should be uniform. Many thanks to the reviewer. This point has been corrected in the revised manuscript.

Some abbreviations need to be defined: Figure 5(b): Ah (hysteresis area?), Figure 9(a) PAGB (PAG?)

These points have been corrected in the revised version.

Consider to use the commonly used term "fracture surface" instead of

"rupture surface".

This has been corrected in the revised manuscript.

Reviewer \#2:

This paper entitled "Characterization of cyclic behavior, deformation mechanisms, and microstructural evolution of MarBN steels under high temperature conditions" investigated the low cycle fatigue behavior of MarBN steels at elevated temperatures. Notably, the author has done many work and analyzed systematically in this paper. Thus, the paper can be accepted due to its high novelty and the reasonable theoretical analysis. The questions we summarized as these points:

Comment No. 1: The second sentence of the first paragraph in the part of the "Material and experimental program", are these specimens used for low cycle fatigue fabricated in accordance with the international standards or not? This point should be stated.

Many thanks to the reviewer for this remark. The samples used for the experiments were made to ISO 12106 standard. To highlight this point, the following text has been added in page 4 of the manuscript:

These were fabricated according to the specification given in ISO 12106 for metallic materials, fatigue testing and axial strain controlled methods.

Comment No. 2: The last sentence of the second paragraph in the part of the "Material and experimental program", the temperature interval between 625 and 675? is 25?, but why add an experimental temperature of 400 ?? The temperature interval between the 400? and 625? are very large! This point should be explained. 
Many thanks to the reviewer in asserting this point. The authors would like to mention that for high temperature steels, the creep mechanisms become increasingly significant at temperatures above $300-400^{\circ} \mathrm{C}$ (see for example Rae et al, IJF2019). The reason for having the $400^{\circ} \mathrm{C}$ temperature is i) to emphasize the fatigue plasticity effects as dominant mechanisms in the deformation process and ii) to ensure that the interaction between time-dependent (creep viscosity) and time-independent deformation (fatigue plasticity) mechanisms is less pronounced. To highlight this point within the manuscript, the following text has been added in page 5 of section 2 .

It is worth nothing that for high temperature steels, the creep mechanisms become increasingly significant at temperatures above 300$400^{\circ} \mathrm{C}$ (see for example Rae et al, IJF2019). The reason for having the temperature gap between $400^{\circ} \mathrm{C}$ and $625^{\circ} \mathrm{C}$ is i) to emphasize the fatigue plasticity effects as dominant mechanisms in the deformation process and ii) to ensure that the interaction between time-dependent (creep viscosity) and time-independent deformation (fatigue plasticity) mechanisms is less pronounced.

Comment No. 3: The first sentence of the first paragraph in the part of the "3.1.2 Fatigue-Relaxation Behavior", why not do the measurement of the fatigue-relaxation responses of the MarBN steel at 400?? This point should be addressed.

Many thanks to the reviewer for his/her remark. The authors would like to mention that the MarBN steel is developed to undergo elevated temperatures and to be used in ultra-supercritical power plant. In this research work, the targeted test temperature range is between 625 and $675^{\circ} \mathrm{C}$. The authors have added the $400^{\circ} \mathrm{C}$ case in the SWT example in order i) to emphasize a "purely" plasticity case and ii) to try to decouple the viscous effects from the plasticity effect. This has been addressed in question 2 of the reviewer. 
Dr. Adil Benaarbia

Arts et Métiers ParisTech, CER ENSAM de Metz

$+33(0) 387375452$

adil.benaarbia@ensam.eu

Professor M.N. James,

Professor David McDowell,

Professor G. Kang

Editors-in-Chief

International Journal of Fatigue

September 9, 2019

Dear Editors-in-Chief,

We would like to thank you and the reviewers for your effort in providing us constructive comments. Your suggestions and questions allowed us to improve our article.

Please find attached the revised version of the manuscript entitled "Characterization of cyclic behavior, deformation mechanisms, and microstructural evolution of MarBN steels under high temperature conditions" by Dr. Xu, Prof. Sun, Prof. Becker, Dr. Osgerby and I. We hope that you and the reviewers will deem the new version worthy of publication in IJF journal.

Thank you for your consideration.

Sincerely,

Dr. Adil Benaarbia

Arts et Métiers ParisTech, Campus de Metz 


\section{Responses to reviewers:}

\section{IJFATIGUE-S-19-00764}

The authors are grateful to both the editors and reviewers for their constructive comments and suggestions, and have addressed each of these as indicated below and trust that these have resulted in a much-improved manuscript.

Replies to the reviewers: The authors' responses are highlighted in blue, while all the major changes in the paper are in red. The minor typos have been corrected without being highlighted.

\section{Reviewer \#1:}

Results of low cycle fatigue tests with MarBN steel at temperatures between $400^{\circ} \mathrm{C}$ and $675^{\circ} \mathrm{C}$ are presented. Different cyclic loading waveforms were employed with fully reversed, strain-controlled tests with and without hold periods as well as stress-controlled tests at different stress ranges with different hold periods in tensile region and at zero stress. Variations in hysteresis loops were discussed and the deformation mechanisms were analysed by microstructural investigations using SEM, EBSD and hardness mapping.

The mechanical investigations are based on well-considered experiments leading to profound descriptions of the cyclic degradation. For all temperatures, continuous cyclic softening accompanied with decelerating stress relaxation was observed. Both recoverable viscoelastic and irrecoverable viscoplastic mechanisms could be identified. Microstructural transformation caused by cyclic loading at high temperature was observed by EBSD analysis. However, there are flaws in the fractographic analysis and a lack of information on the mechanical properties of the investigated material. The main concerns are listed in the following:

- The fractographic images shown in Figure 8 do not serve well to comprehend some statements in Section 3.2.1. The scale bars indicate that the magnification of the fractographic images in (a), (b) and (c) should be identical. This is obviously not the case (unless different specimen shapes were used or failure did not occur in the gauge section of specimens). Please use the same magnification for Fig. 8(b) and (c) as in (a).

The authors acknowledge that the micrograph as shown in Figure $8 \mathrm{~b}$ was collected at a different magnification as Figures $8 \mathrm{a}$ and $8 \mathrm{c}$. However, Figures $8 \mathrm{a}$ and $8 \mathrm{c}$ were collected at the identical magnification, with the CRT specimen appears to have a small gauge dimension. The authors have double checked the CRT specimen and can confirm that the specimen dimension is the same as SWT and DWT, whereas the rupture surface shows a smaller area due to significant necking occurred in the final stage of testing. Therefore, Figure 8 has been amended accordingly based on the comment from the reviewer.

The following text has been added in pages 16 and 17 in the revised version: 
The specimen experiencing DWT at $625^{\circ} \mathrm{C}$ (Figure $8 \mathrm{~b}$ ) was ruptured in a similar manner as compared to the specimen experiencing SWT. This is evidenced by the presence of striations and dimples on rupture surface Figure $8(\mathrm{~b}$ and e). A larger interspacing distance between striations was observed after DWT testing as a result of holding period in each loading cycle.

This would facilitate to see if the DWT specimen (b) also exhibits fatigue crack initiation from the surface (as might be considered from the current fractograph).

Many thanks to the reviewer for this comment. The authors would like to mention that additional attempts have been made to identify the location of crack initiation sites. However, no clear evidence showing the initiation site of the major crack was obtained. This is probably attributed to a small area of the initiation site as facilitated by a rapid crack propagation at a high level of the applied stress in low cycle fatigue experiments.

Also, the specimens should be cleaned before observation in SEM since the features marked as "dimples" in Figure 8(b) rather look like contaminants.

It is worth noting that the dimple like features in Figure 8b were checked in the SEM at a higher magnification. The figures as below show that these features are not contaminants and exhibit a similar topography as dimples. The bright particles within each dimple are non-conductive inclusions particles such as $\mathrm{Al}_{2} \mathrm{O}_{3}$ and secondary phase particles such as BN.

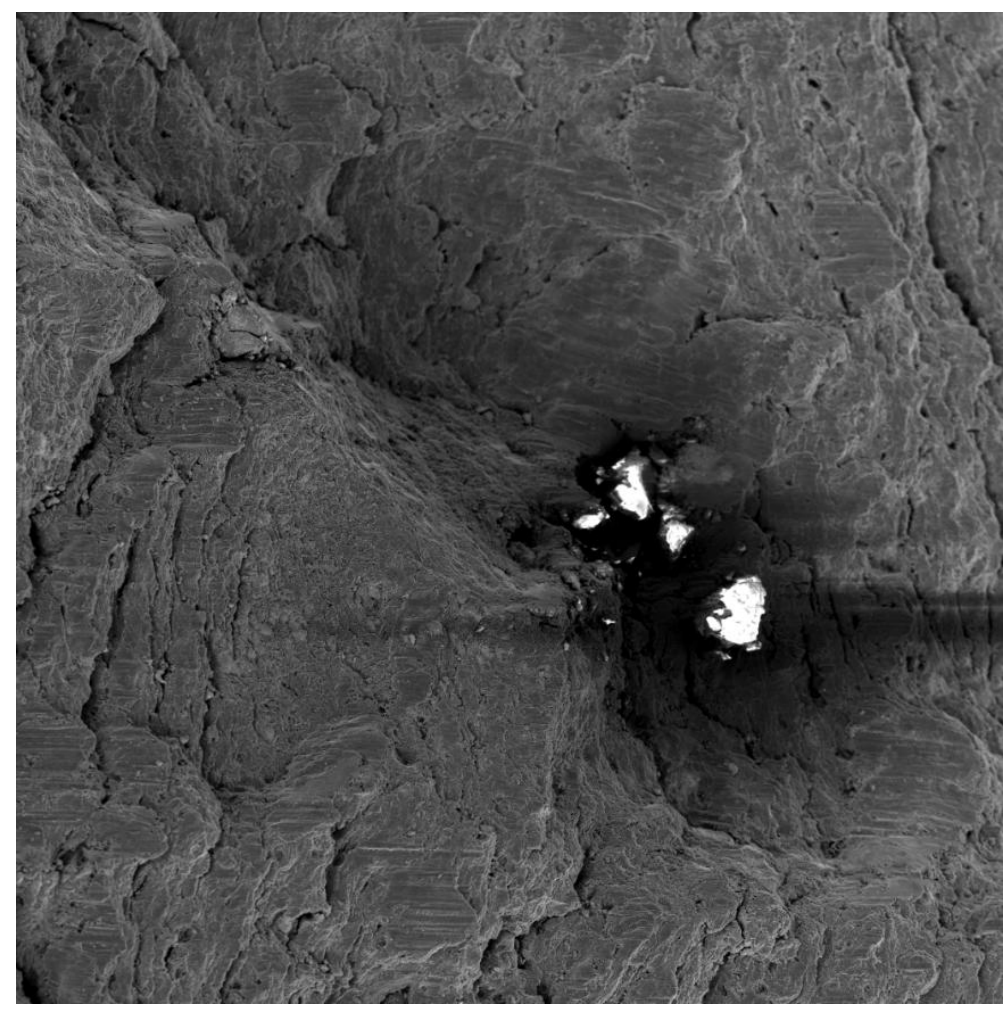

Supplement 1: A secondary electron micrograph showing the dimples containing secondary phase particles in the DWT specimen $\left(625^{\circ} \mathrm{C}\right)$. 
- The region marked as "Crack propagation area" in Figure 8(a) seems to be the final fracture region. Further, it is stated that fatigue striations are visible in Figure $8(d)$, but the magnification is too low to identify striations.

Many thanks to the reviewer in highlighting this point. The authors acknowledge that the label for the area of crack propagation was misleading. Figure 8a has been amended accordingly.

The authors have confirmed the topography of the SWT specimen and can confirm that the surface topography is similar to the observations as in the existing studies on low cycle fatigue behaviour of similar $9 \% \mathrm{Cr}$ steels (e.g. $[1,2])$.

[1] V. Shankar, M. Valsan, K.B.S. Rao, R. Kannan, S.L. Mannan, S.D. Pathak, Low cycle fatigue behavior and microstructural evolution of modified $9 \mathrm{Cr}-1 \mathrm{Mo}$ ferritic steel, Mater. Sci. Eng. A. 437 (2006) 413-422.

[2] P. Verma, N.C.S. Srinivas, S.R. Singh, V. Singh, Low cycle fatigue behavior of modified $9 \mathrm{Cr}-1 \mathrm{Mo}$ steel at room temperature, Mater. Sci. Eng. A. 652 (2016) 30-41.

- The mechanical properties of the testing material should be indicated. Some of the tests relate the stress level to percentage of the yield strength. Is this the yield strength at room temperature or at the respective testing temperature?

The reviewer is correct in indicating that it would be interesting if the mechanical properties of the testing material could be indicated. This point has been addressed and the following table has been added in page 7 of section 2 in the revised version:

Table: The mechanical properties of the investigated MarBN steel. $E$ stands for the Young's modulus, while $\sigma_{k}$ denotes the initial yield strength measured through the first loading cycle at the selected test temperature.

\begin{tabular}{|l|c|c|c|c|}
\hline Temperature $\left({ }^{\circ} \mathrm{C}\right)$ & 400 & 625 & 650 & 675 \\
\hline$E(\mathrm{GPa})$ & 395.2 & 163.8 & 155.3 & 106.3 \\
\hline$\sigma_{k}(\mathrm{MPa})$ & 187.3 & 129.6 & 120.5 & 94.7 \\
\hline
\end{tabular}

In the manuscript, the yield strength is measured through the first loading cycle at the testing temperature. This has been indicated in the caption of Table 2 in the revised version.

- The Vickers hardness of the as-received material should be indicated in order to allow comparison with hardness values presented in Section 3.2.3.

The authors acknowledge that a comparison between the as-received material and the specimens with SWT and DWT exposure is important and have conducted additional characterisation using the same experimental instrument. The value of hardness has been measured from the as-received material and included in the corresponding section of the revised version (page20). 
Hardness measurement was firstly performed in the as-received MarBN steel prior to LCF testing at a loading weight of $10 \mathrm{~kg}$ and $0.2 \mathrm{~kg}$. The values of hardness obtained from the

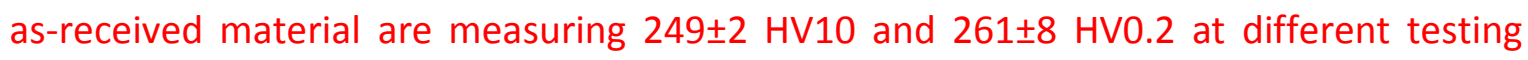
conditions. Hardness measurement was further conducted close to the boundary between gauge and head portions of SWT and DWT specimens at a loading weight of 10 $\mathrm{kg}$.

The variation of hardness in the region close to fracture surface was further characterised using hardness mapping analysis at a loading weight of $0.2 \mathrm{~kg}$ after SWT and DWT at $625^{\circ} \mathrm{C}$, Figure 10.

- Section 3.2.3, second paragraph: "The hardness in the region $<1.5 \mathrm{~mm}$ from the rupture surface is lower and in the range between 218 and $232 \mathrm{HVO} 0.2$, whereas the hardness in the regions $>1.5 \mathrm{~mm}$ from the rupture surface is increased to above $230 \mathrm{HVO} 0.2$, Figure 10(b)." This statement should be reconsidered since the increase in hardness is rather low and hardly visible in Figure 10(b).

The authors acknowledge that the increase in hardness is not evident. Considering the scattering of data, the hardness variation in the DWT specimen is trivial. To highlight these points, the following texts have been added in page 20 :

The variation of hardness is not evident without a clear trend in the specimen experiencing DWT, Figure 10(b). Hardness varies between 218 and 247 HV0.2 in the gauge portion of the specimen experiencing DWT.

The hardness values measured from the gauge portion are considerably lower than the values measured from the as-received material (i.e. 261 \pm 8 HVO.2).

Also: "...in the range between 242 and 291 HV0.2 in the same specimen, Figure 10(a)". The range in the color scale bar range in Figure 10(a) is only between 200 and $270 \mathrm{HV}$. Please check.

The authors acknowledge that the colour scale of Figure 10 should be amended and the manuscript is updated accordingly.

- It should be considered to perform additional hardness measurements with a CRT specimen. This might be interesting due to high amount of refined microstructure.

The authors acknowledge that it is important to further characterise the hardness variation in the CRT specimen to compare with the other samples. Additional measurement was therefore conducted and Figure 10 has been amended accordingly. 
(a)

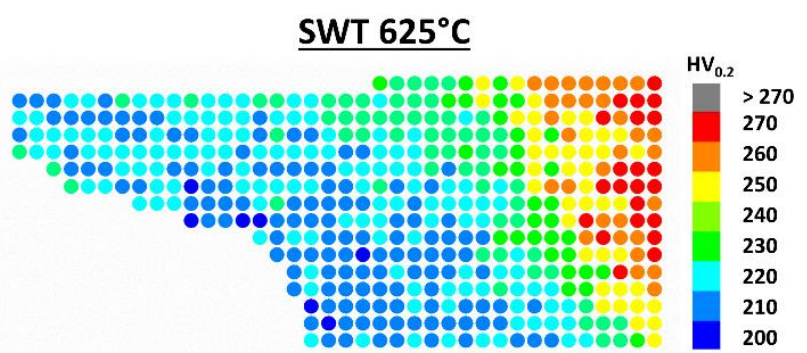

(a)

$\underline{1 \mathrm{~mm}}$

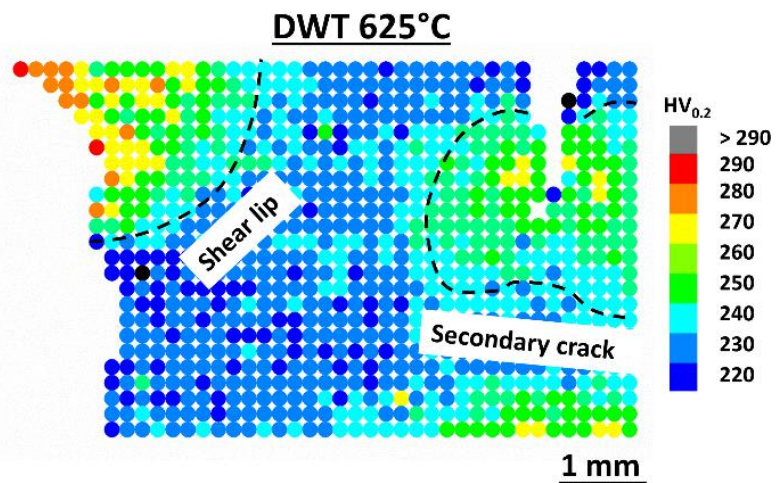

(b)

$\underline{1 \mathrm{~mm}}$

\section{CRT $625^{\circ} \mathrm{C}$}

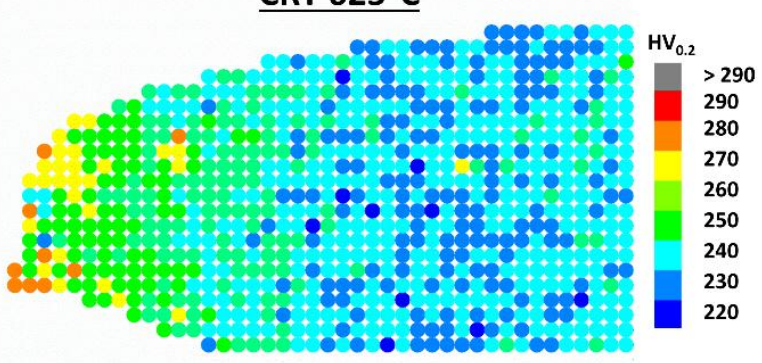

(c)

$\underline{1 \mathrm{~mm}}$

Principal stress direction

Figure: Hardness maps collected from the regions close to fracture surfaces in the specimens experiencing (a) SWT, (b) DWT and (c) CRT at $625^{\circ} \mathrm{C}$.

The corresponding text has been added in page 20 in the revised manuscript:

The value of hardness as measured from the region close to the rupture surface of the CRT specimen is evidently higher than the region further away. This can be attributed to a higher volume density of dislocations in the region close to the rupture surface upon the occurrence of necking due to localised plasticity instability [Ref: Benaarbia, A., Xu, X., Sun, W., Becker, A., Jepson, M.A., 2018b]. This is further evidenced by the observation of significantly distorted and refined martensitic microstructure as shown in Figure 9.

\section{Further minor comments:}

The tick labels of the abscissae in Figure 3 should be uniform.

Many thanks to the reviewer. This point has been corrected in the revised manuscript.

Some abbreviations need to be defined: Figure 5(b): Ah (hysteresis area?), Figure 9(a) PAGB (PAG?) 
These points have been corrected in the revised version.

Consider to use the commonly used term "fracture surface" instead of "rupture surface".

This has been corrected in the revised manuscript.

\section{Reviewer \#2:}

This paper entitled "Characterization of cyclic behavior, deformation mechanisms, and microstructural evolution of MarBN steels under high temperature conditions" investigated the low cycle fatigue behavior of MarBN steels at elevated temperatures. Notably, the author has done many work and analyzed systematically in this paper. Thus, the paper can be accepted due to its high novelty and the reasonable theoretical analysis. The questions we summarized as these points:

- The second sentence of the first paragraph in the part of the "Material and experimental program", are these specimens used for low cycle fatigue fabricated in accordance with the international standards or not? This point should be stated.

Many thanks to the reviewer for this remark. The samples used for the experiments were made to ISO 12106 standard. To highlight this point, the following text has been added in page 4 of the manuscript:

These were fabricated according to the specification given in ISO 12106 for metallic materials, fatigue testing and axial strain controlled methods.

- The last sentence of the second paragraph in the part of the "Material and experimental program", the temperature interval between 625 and 675? is 25?, but why add an experimental temperature of 400 ?? The temperature interval between the 400 ? and 625 ? are very large! This point should be explained.

Many thanks to the reviewer in asserting this point. The authors would like to mention that for high temperature steels, the creep mechanisms become increasingly significant at temperatures above $300-400^{\circ} \mathrm{C}$ (see for example Rae et al, IJF2019). The reason for having the $400^{\circ} \mathrm{C}$ temperature is i) to emphasize the fatigue plasticity effects as dominant mechanisms in the deformation process and ii) to ensure that the interaction between time-dependent (creep viscosity) and time-independent deformation (fatigue plasticity) mechanisms is less pronounced.

To highlight this point within the manuscript, the following text has been added in page 5 of section 2 .

It is worth nothing that for high temperature steels, the creep mechanisms become increasingly significant at temperatures above $300-400^{\circ} \mathrm{C}$ (see for example Rae et al, IJF2019). The reason for having the temperature gap between $400^{\circ} \mathrm{C}$ and $625^{\circ} \mathrm{C}$ is i) to emphasize the fatigue plasticity effects as dominant mechanisms in the deformation 
process and ii) to ensure that the interaction between time-dependent (creep viscosity) and time-independent deformation (fatigue plasticity) mechanisms is less pronounced.

- The first sentence of the first paragraph in the part of the "3.1.2 Fatigue-Relaxation Behavior", why not do the measurement of the fatigue-relaxation responses of the MarBN steel at 400?? This point should be addressed.

Many thanks to the reviewer for his/her remark. The authors would like to mention that the MarBN steel is developed to undergo elevated temperatures and to be used in ultrasupercritical power plant. In this research work, the targeted test temperature range is between 625 and $675^{\circ} \mathrm{C}$. The authors have added the $400^{\circ} \mathrm{C}$ case in the SWT example in order i) to emphasize a "purely" plasticity case and ii) to try to decouple the viscous effects from the plasticity effect. This has been addressed in question 2 of the reviewer. 


\section{Highlights:}

- An extensive experimental work has been conducted to investigate the high temperature low cycle fatigue behaviour of a novel MarBN steel at bulk and microscales.

- The mechanical investigations were combined with microstructural analyses (through SEM, EBSD and hardness mapping) to emphasize the leading deformation mechanisms.

- The results exhibit continuous cyclic softening and decelerated stress relaxation, recoverable viscoelasticity at different time scales and irrecoverable viscoplastic mechanisms. 


\title{
Characterization of cyclic behavior, deformation mechanisms, and microstructural evolution of MarBN steels under high temperature conditions
}

\author{
A. Benaarbia ${ }^{a, *}$, X. Xu ${ }^{b, *}$, W. Sun ${ }^{c}$, A.A. Becker ${ }^{c}$, S. Osgerby ${ }^{d}$ \\ ${ }^{a}$ Arts et Métiers ParisTech, CNRS, Université de Lorraine, LEM3, F-57000 Metz, France \\ ${ }^{b}$ Department of Materials, Loughborough University, Loughborough, Leicestershire LE11 3TU, UK \\ ${ }^{c}$ Department of Mechanical, Materials and Manufacturing Engineering, University of Nottingham, Nottingham, \\ Nottinghamshire, NG7 2RD, UK \\ ${ }^{d}$ GE Power, Newbold Road, Rugby, Warwickshire, CV21 2NH, UK
}

\begin{abstract}
In this paper, the low cycle fatigue behaviour of MarBN steels at elevated temperatures is discussed. Four cyclic loading waveforms were applied to investigate both the mechanical and microstructural features. The mechanical results exhibit continuous cyclic softening and decelerated stress relaxation, recoverable viscoelasticity at both short and long time scales and irrecoverable viscoplastic mechanisms. Detailed microstructural characterisation was also conducted to investigate the rupture behaviour of the investigated steel. The microstructural findings indicate typical transgranular and ductile fracture behaviour, extensive sub-grain formation and structural refinement as well as significant decrease in hardness close to the fracture surface.

Keywords: MarBN steel, Low cycle fatigue, High temperature viscoplasticity, Martensitic substructure, Sub-grain formation.
\end{abstract}

\section{Introduction}

Most power plant components are subjected to repeated thermomechanical stresses as a result of temperature and pressure gradients that occur on heating and cooling during startup and shutdown or during temperature transients. These loading operations lead to both

\footnotetext{
*Corresponding author.

Email addresses: adil.benaarbia@ensam.eu (A. Benaarbia), xu.xu@manchester.ac.uk (X. Xu), w. sun@nottingham.ac.uk (W. Sun), a.a.becker@nottingham.ac.uk (A.A. Becker), steve.osgerby@ge.com (S. Osgerby)
} 
creep and fatigue deformations which can cause premature failures (Wang et al., 2018; Zhu et al., 2019; Bassi et al., 2015; Pineau and Antolovich, 2015). An in-depth assessment of the creep-fatigue interaction is thus vital to ensure safe operation of the power plant component during its lifetime. Components such as gas turbines and heat exchangers need to withstand temperatures in excess of $650^{\circ} \mathrm{C}$, and thus require high strength materials with excellent creep, fatigue and oxidation/corrosion resistance. One material type used in this application are the $9 \mathrm{Cr}$ creep resistant martensitic steels which have a good combination of creep strength, weldability, hardenability and corrosion resistance (Viswanathan et al., 2005; Gianfrancesco, 2017; Fournier et al., 2011; Swindeman et al., 2004; Chen et al., 2011). The recently developed tempeblack martensitic MarBN family of steels (9CR-3W-3Co- VNbBN) is a promising candidate for the replacement of conventional materials used in the power plants due to superior creep resistance (Abe et al., 2008). However, the creep-fatigue performance of the MarBN steel is yet to be assessed, and an extensive assessment of the (thermo)-mechanical behaviour is requiblack.

Classical strain-controlled tests with and without dwell periods are often conducted under isothermal (and/or anisothermal) conditions to understand and calibrate the "hysteretic" mechanical response of power plant materials (Saad et al., 2013; Benaarbia et al., 2018a; Rae et al., 2019). A large amount of creep and fatigue properties of $9 \mathrm{Cr}$ steels is available in the literature, and much progress has been made with the interpretation of experimental fatigue-creep data (Zhang et al., 2017; Benaarbia et al., 2018b). Through examination of past research, two major features are commonly observed within $9 \mathrm{Cr}$ steels under high temperature fatigue conditions. The first is accelerated cyclic softening which is attributed to the accumulated inelastic transformation from the creep mechanism during the dwell period at the peak tensile strain of the fatigue cycle (Zhang and Xuan, 2017). The second is the decelerated stress relaxation behaviour which is ascribed to the blackuction in the viscous stress due to continuous cyclic softening. As interest developed in high temperature fatigue, it was found that in the creep range fatigue endurances are significantly shorter, particularly when hold periods are introduced (Rae et al., 2019). The reason for the blackuced fatigue life is that, in addition to fatigue damage due to cyclic loading, creep damage is also accumulated during hold periods. 
The softening behaviour of these alloys has been demonstrated to be linked with the instability of the martensitic substructure upon cyclic mechanical loading at elevated temperature (Pineau, 2014; Mishnev et al., 2016; Guguloth et al., 2014). In these cases, lath coarsening or the replacement of the initial lath microstructure by a cellular structure accompanied with the formation of sub-grains have been extensively reported after low cycle fatigue testing (Mishnev et al., 2016; Shankar et al., 2012; Mannan and Valsan, 2006). The transformation of the martensitic substructure is also commonly accompanied with a decrease in dislocation density due to the rearrangement of dislocation structure and the annihilation of mobile dislocations, which contributes to a decrease in stress amplitude during cyclic fatigue testing (Pineau and Antolovich, 2015; Shankar et al., 2006). The increase in stress amplitude and the time period of stress duration have been shown to accelerate the coarsening of the martensitic substructure (Shankar et al., 2006; Verma et al., 2016).

The initiation of fatigue damage is commonly observed at the martensitic substructure boundaries and coarse secondary phase particles due to strain localisation and strain irreversibility as a consequence of dislocation pile-up (Batista et al., 2015). This is commonly followed by the propagation of cracks in a transgranular manner upon cyclic loading (Shankar et al., 2012; Fournier et al., 2008). In addition, damage nucleation may occur from any oxide layer formed on the outer surface of the specimen at the elevated temperature (Shankar et al., 2012; Mannan and Valsan, 2006). An increase in the time period of stress duration in a compression regime has been shown to be detrimental by maintaining a sharp crack tip after its initiation upon tensile loading (Shankar et al., 2006). However, the presence of creep induced cavitation is rarely observed upon creep-fatigue exposure due to the excellent creep resistance of tempeblack martensitic microstructure in 9-12\% Cr steels (Abe et al., 2008; Yan et al., 2013).

The current experimental work aims to provide an analysis of the fatigue behaviour of a recently developed MarBN steel, IBN1, tested at high temperatures in different cyclic mechanical conditions. Experimental findings are split into two parts: the first deals with the overall mechanical responses, whereas the second focuses on microstructure investigations conducted on ruptublack samples. The tests applied utilise several cyclic loading waveforms in order to 
investigate the dominating deformation mechanisms which are commonly observed in MarBN steels. These include fully reversed tests with or without hold periods, anhysteretic tensile tests with loading-unloading hold periods, and cyclic creep-recovery tests. Mechanical findings are thus presented in forms of (i) stress amplitude to investigate the accelerated cyclic softening, (ii) viscous stress to study the decelerated stress relaxation behaviour and (iii) hysteresis area to account for the deformation energy variations. These mechanical data are analysed in conjunction with post-mortem analysis of microstructure using Scanning Electron Microscopy (SEM), Electron Backscatter Diffraction (EBSD) and micro-hardness mapping.

\section{Material and experimental programme}

The investigated material was a tempeblack martensitic IBN-1 steel with chemical components listed in Table 1. The specimens used for low cycle fatigue (LCF) tests were cylindrical with a diameter of $5 \mathrm{~mm}$ and a gauge length of $10 \mathrm{~mm}$ as shown in Figure 1. These were fabricated according to the specification given in ISO 12106 for metallic materials, fatigue testing and axial strain controlled methods. They were machined from forged bars normalised at $1200^{\circ} \mathrm{C}$ for 4 hours and tempeblack at $765^{\circ} \mathrm{C}$ for 3 hours.

Table 1: Chemical composition of the investigated material (all elements are in wt. \%, B and $\mathrm{N}$ are in ppm).

\begin{tabular}{lllllllllllllllll}
\hline $\mathbf{C}$ & $\mathbf{S i}$ & $\mathbf{M n}$ & $\mathbf{P}$ & $\mathbf{S}$ & $\mathbf{C r}$ & $\mathbf{M o}$ & $\mathbf{N i}$ & $\mathrm{Al}$ & $\mathbf{B}$ & $\mathbf{C o}$ & $\mathbf{C u}$ & $\mathbf{N b}$ & $\mathbf{V}$ & $\mathbf{W}$ & $\mathbf{N}$ \\
\hline 0.1 & 0.45 & 0.54 & 0.012 & 0.004 & 8.74 & 0.05 & 0.14 & 0.007 & 120 & 3.02 & 0.04 & 0.06 & 0.21 & 2.53 & 180 \\
\hline
\end{tabular}

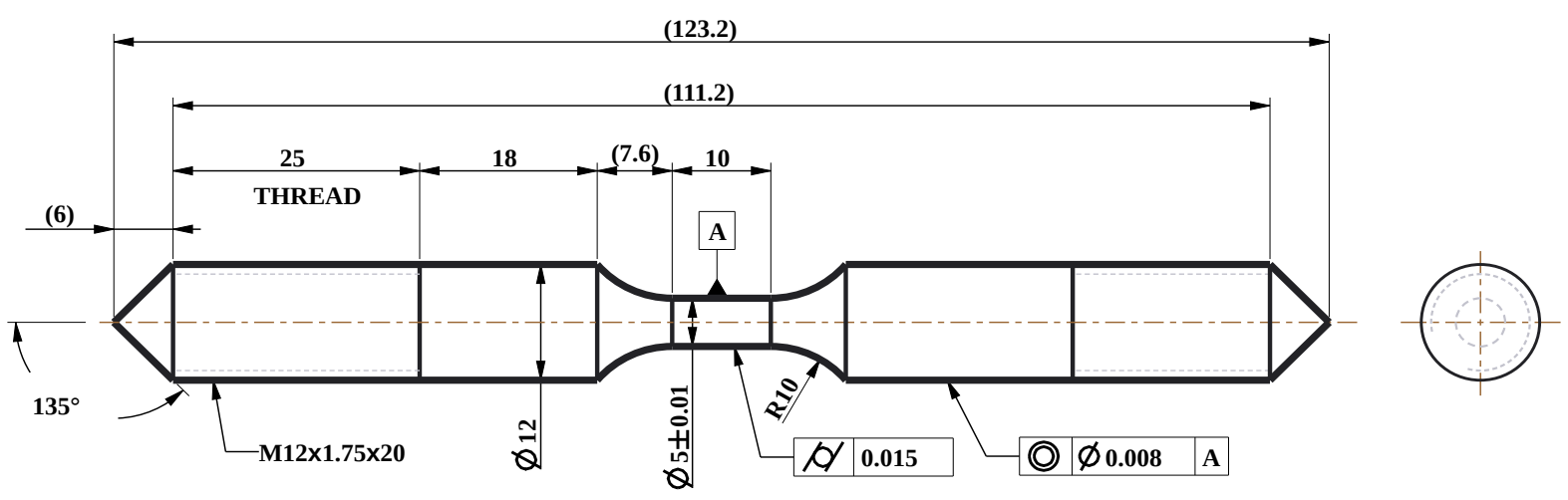

Figure 1: Uniaxial fatigue test samples used for the experimental work (all dimensions given in $\mathrm{mm}$ ). 
Fully-reversed tests with zero- and hold-tensile periods as shown in Figure 2(a-b) were conducted using a closed-loop servo hydraulic testing machine equipped with a high-temperature furnace. Standard triangular and trapezoidal strain time waveforms (namely Sawtooth, SWT, and Dwell-type, DWT, respectively) were first employed at a constant strain rate of $0.01 \% . \mathrm{s}^{-1}$ and a load ratio of - 1 to investigate the accelerated cyclic softening, the decelerated stress relaxation behaviour and deformation energy variations. For the DWT, hold durations of 3 hours at the first cycle and 30 mins at the subsequent cycles were applied to ensure a quasi-equilibrium state of the viscous stress. These hold durations were determined to be sufficient to highlight and distinguish both fatigue and relaxation induced damage. Anhysteretic waveforms wherein 45 min hold periods were applied during tensile loading at strain levels equalling to $0.1 \%, 0.2 \%$, $0.3 \%, 0.4 \%, 0.5 \%$ and $0.6 \%$. A schematic representation of these tests is given in Figure 2(c). Tests were initiated by two anhysteretic waveforms followed by 50 sawtooth waveforms, followed by two anhysteretic waveforms, and so on. Hold period durations were defined such that both short- and long-term viscoelastic material behaviours could be determined. Finally, cyclic creep-recovery tests were performed under different stress ranges for hold periods equalling to 2.5 hours in tensile region and 6 hours at zero stress (see Figure 2(d)). These tests were designed to study the long-term viscosity effects at several stress levels chosen below and above the yield strength, $\sigma_{k}$. The stress values were thus selected to be $90 \%, 120 \%, 150 \%, 180 \%$ and $210 \%$ of the yield strength which the approximate values are given in Table 2. Four temperatures were selected during the testing: $400^{\circ} \mathrm{C}, 625^{\circ} \mathrm{C}, 650^{\circ} \mathrm{C}$ and $675^{\circ} \mathrm{C}$. These were monitoblack by three thermocouples attached to the test samples, with temperature variations not exceeding $\pm 1^{\circ} \mathrm{C}$. It is worth nothing that for high temperature steels, the creep mechanisms become increasingly significant at temperatures above $300-400^{\circ} \mathrm{C}$ (Rae et al., 2019). The reason for having the temperature gap between $400^{\circ} \mathrm{C}$ and $625^{\circ} \mathrm{C}$ is i) to emphasize the fatigue plasticity effects as dominant mechanisms in the deformation process and ii) to ensure that the interaction between timedependent (creep viscosity) and time-independent deformation (fatigue plasticity) mechanisms is less pronounced. 
(a)

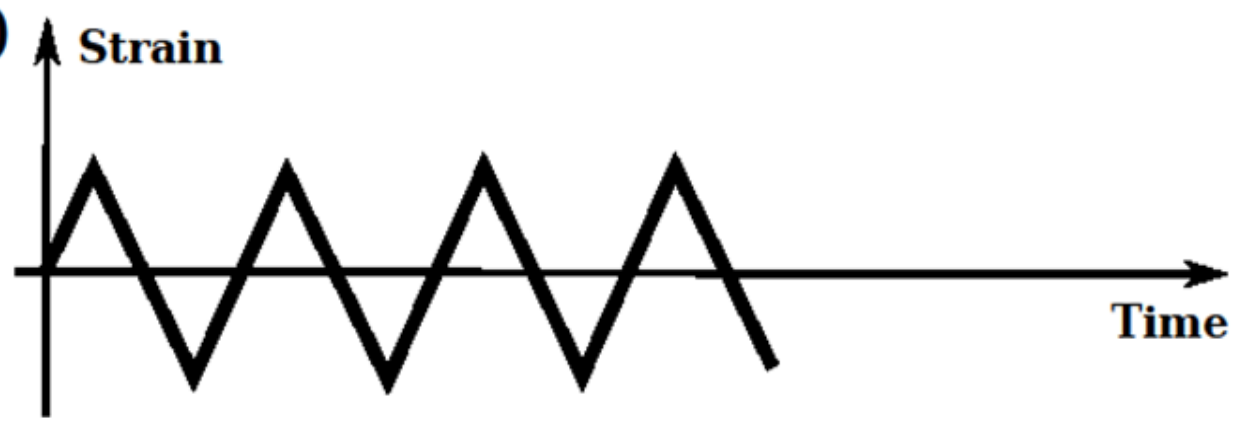

(b)

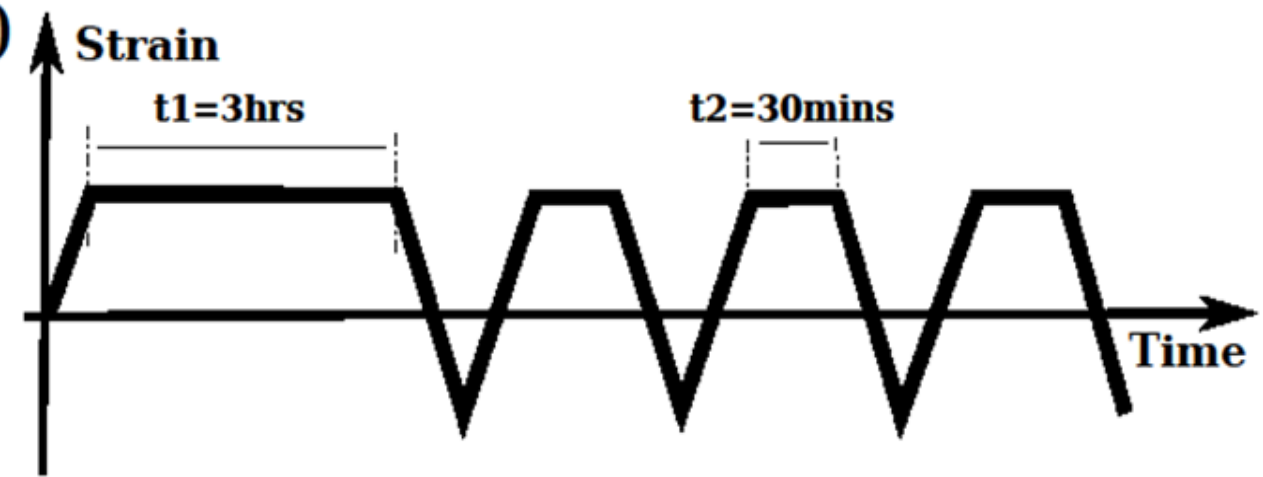

(c)
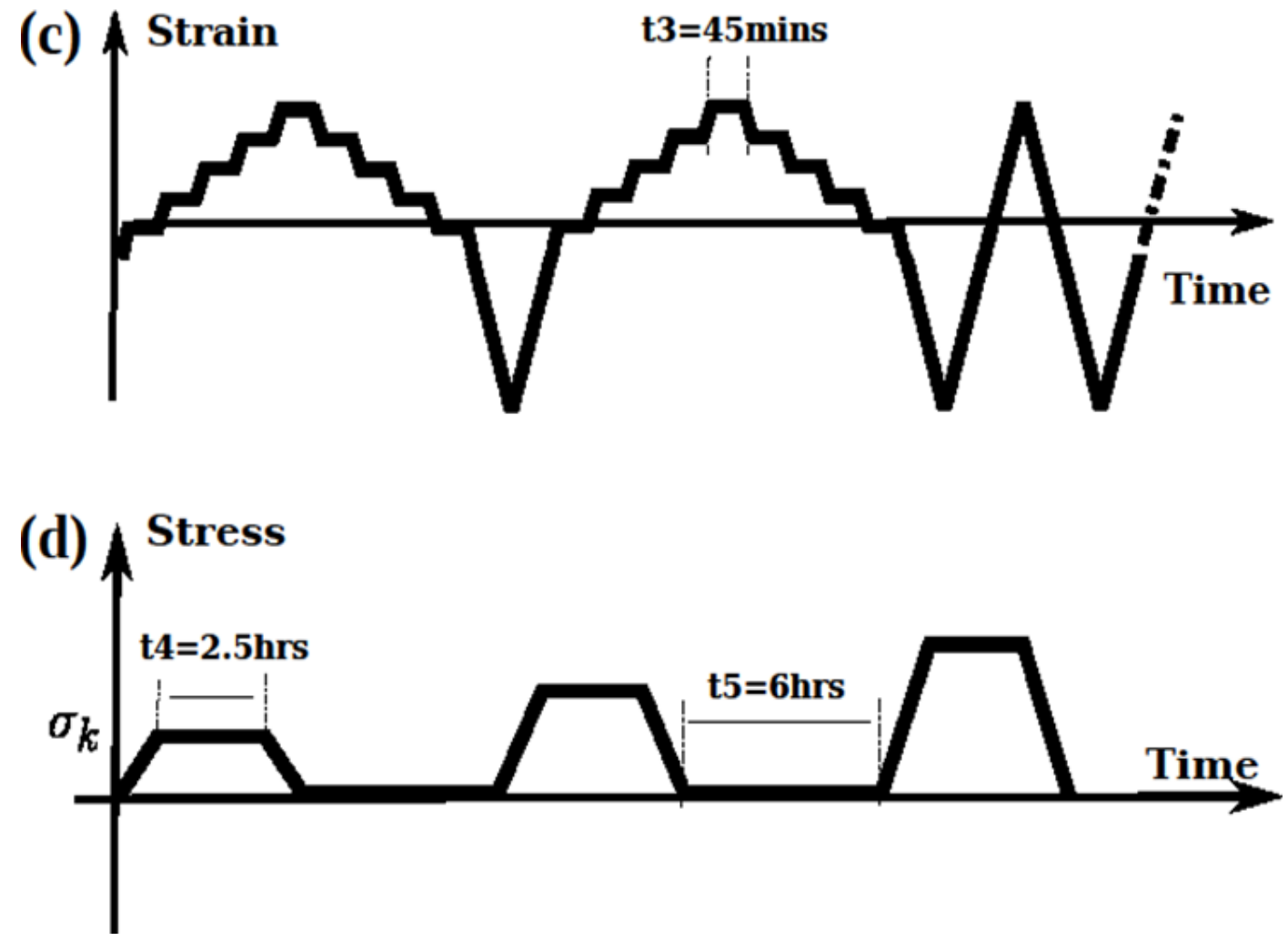

Figure 2: Mechanical waveforms used during the experiments: (a) Saw-tooth tests (SWT), (b) Dwell-type tests (DWT), (c) Anhysteretic tests (ANH) and (d) Cyclic Creep-recovery tests (CRT). 
Table 2: Mechanical properties of the investigated MarBN steel. $E$ stands for the Young's modulus, while $\sigma_{k}$ denotes the initial yield strength measublack through the first loading cycle at the selected test temperature.

\begin{tabular}{lcccc}
\hline Temperature $\left({ }^{\circ} \mathbf{C}\right)$ & $\mathbf{4 0 0}$ & $\mathbf{6 2 5}$ & $\mathbf{6 5 0}$ & $\mathbf{6 7 5}$ \\
\hline$E(\mathrm{GPa})$ & 395.2 & 163.8 & 155.3 & 106.3 \\
\hline$\sigma_{k}(\mathrm{MPa})$ & 187.3 & 129.6 & 120.5 & 94.7 \\
\hline
\end{tabular}

Topography of fracture surfaces was examined using Secondary Electron (SE) imaging in a JEOL JSM-7800F Field Emission Gun (FEG) Scanning Electron Microscope (SEM) at an accelerating voltage of $5 \mathrm{kV}$. The gauge portion was further bisected along the longitudinal direction for detailed metallographic examination and hardness mapping after standard metallographic preparation process finished with a chemomechanical polishing process using a suspension of $0.06 \mu \mathrm{m}$ colloidal silica. The microstructure close to the fracture surface was examined using Electron Backscatter Diffraction (EBSD) in the JEOL JSM-7800F FEG-SEM equipped with an Oxford Instruments Nordlys MAX2 camera. EBSD maps were collected at an accelerating voltage of $20 \mathrm{kV}$ with a step size of $1 \mu \mathrm{m}$ to provide an overview of microstructure from an area measuring $300 \times 300 \mu \mathrm{m}$. For more detailed EBSD mapping, analysis was carried out at a step size of 0.1 $\mu \mathrm{m}$ to collect maps $50 \times 50 \mu \mathrm{m}$ in size. Hardness testing was conducted on the cross-sections of ruptublack specimen using a Struers Durascan 70 hardness testing system equipped with a Vickers indenter. Ten individual measurements were conducted in the regions close to the boundary between gauge and head portions using a loading weight of $10 \mathrm{~kg}$ and a dwell time of $10 \mathrm{~s}$. A hardness map was further collected from the region close to fracture surface using a loading weight of $0.2 \mathrm{~kg}$ with an interval of $0.1 \mathrm{~mm}$ between individual indents. Each hardness map contains over 1,500 hardness indents, covering an area of $5 \times 3 \mathrm{~mm}$.

\section{Results and discussions}

\subsection{Mechanical characterization}

Three parameters were introduced to discuss and evaluate variations in hysteresis loops for both SWT and DWT: i) the hysteresis area, which represents the deformation energy lost 
during the loading, ii) the stress amplitude variations which highlight the cyclic softening related to microstructure change and damage, and iii) the viscous stress changes which reflect the relaxation behaviour.

\subsubsection{Low Cycle Fatigue Behaviour}

In order to better understand the low cycle fatigue behaviour of the MarBN steel, typical cyclic stress-strain responses for the SWT at the selected temperatures are plotted in Figure 3. In each case, the hysteresis responses are shown as engineering stress versus engineering strain at different life stages to highlight the whole low cycle fatigue life of the MarBN steel. Conclusions can be extracted from the SWT hysteresis variations as follows:

- The rate of change of deformation resistance is large during the early cycles of the tests. This rate diminishes and never reaches a stable condition after enough cycles;

- Lower temperature ranges show higher maximum stresses. At the second cycle, the hysteresis responses indicate $600 \mathrm{MPa}$ for $400^{\circ} \mathrm{C}, 360 \mathrm{MPa}$ for $625^{\circ} \mathrm{C}, 320 \mathrm{MPa}$ for $650^{\circ} \mathrm{C}$ and $290 \mathrm{MPa}$ for $675^{\circ} \mathrm{C}$. These maximum stresses decrease with increasing number of cycles highlighting the significance of cyclic softening;

- An unsymmetrical hysteresis loop in shape is observed for the mid-life cycle loops compablack with the first cycle loops;

- The hysteresis loops are crescent shaped and shrank with a point tail in the compressive region at the last stages before the macroscopic rupture. This observation has been reported for many high temperature steels (Rae et al., 2019));

- The area of hysteresis loops never stabilizes completely till the macroscopic failure. Although the changes in the hysteresis loops are less at the last stages, the later keep shifting;

- The fatigue lifetime increases when decreasing the test temperature. The mechanical responses indicate a fatigue life of 520 cycles for SWT $400^{\circ} \mathrm{C}, 480$ cycles for both SWT $625^{\circ} \mathrm{C}$ and $650^{\circ} \mathrm{C}$, and 280 cycles for SWT $675^{\circ} \mathrm{C}$. 
(a)

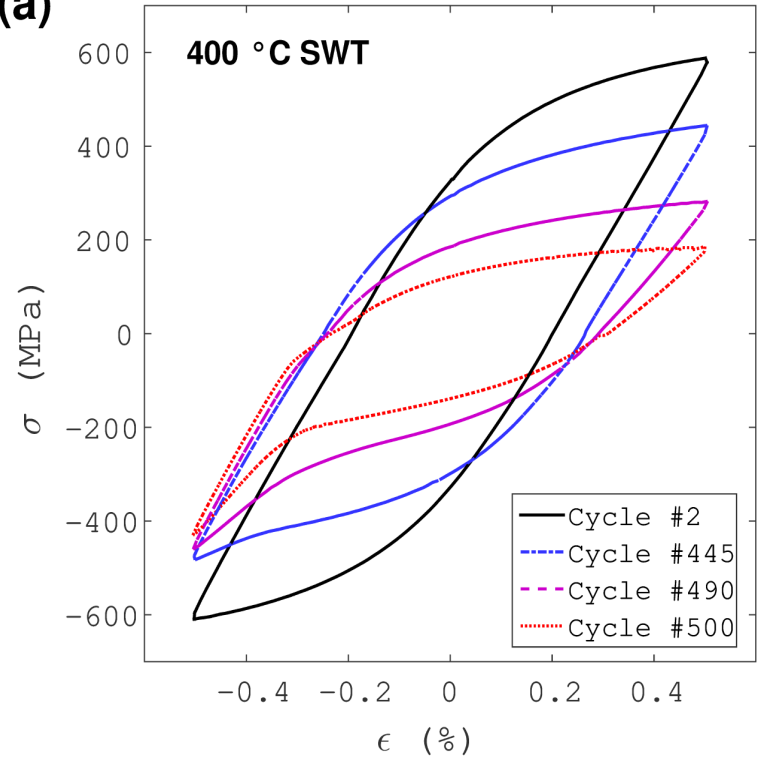

(c)

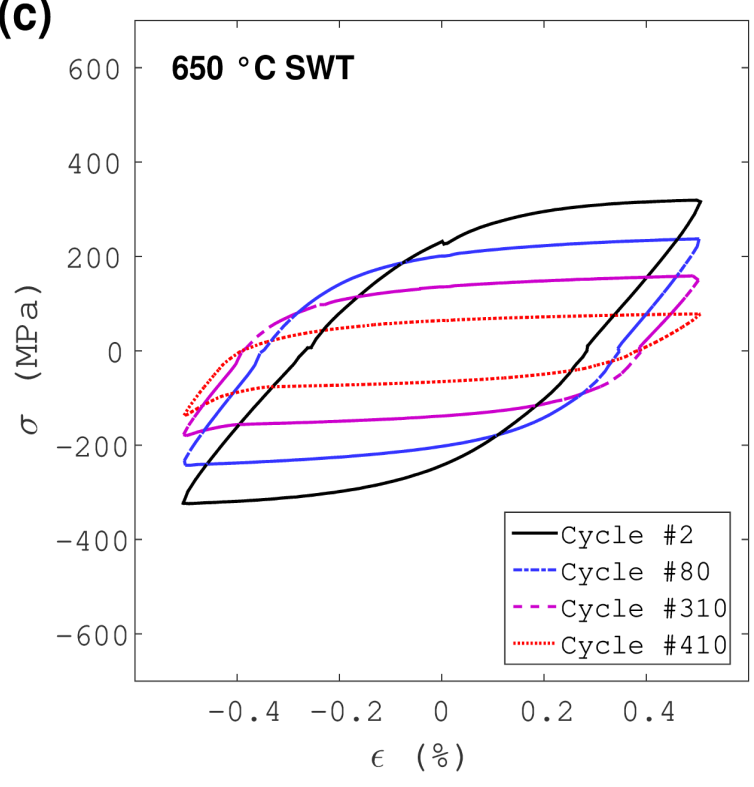

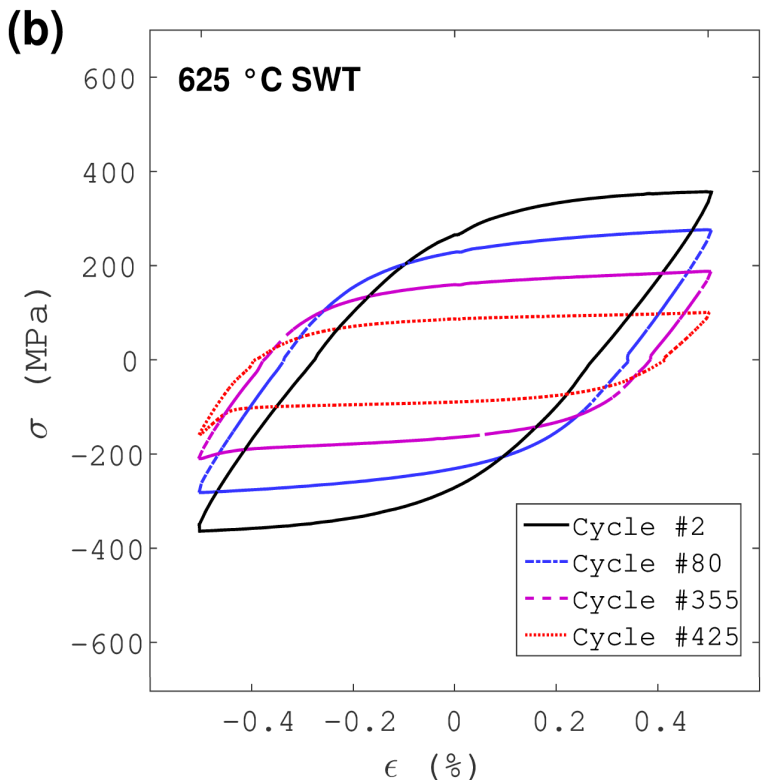

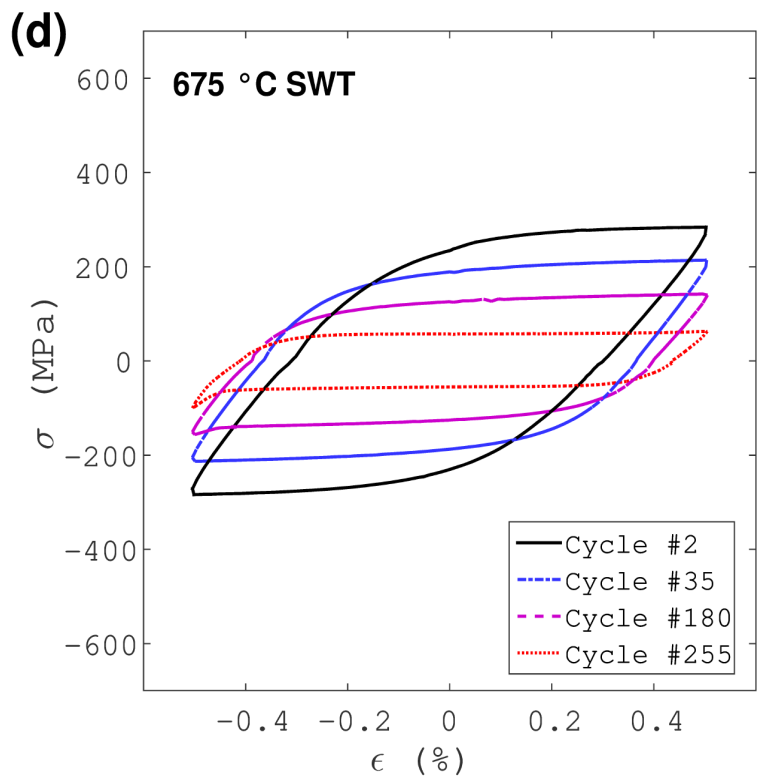

Figure 3: Stress-strain plots extracted for SWT conducted on MarBN steel under different temperatures $\left(400^{\circ} \mathrm{C}\right.$, $625^{\circ} \mathrm{C}, 650^{\circ} \mathrm{C}$ and $\left.675^{\circ} \mathrm{C}\right)$.

\subsubsection{Fatigue-Relaxation Behaviour}

Fatigue-relaxation responses of the MarBN steel have been further compablack and presented in Figure $4(\mathrm{a}-\mathrm{c})$ for applied temperatures of $625^{\circ} \mathrm{C}, 650^{\circ} \mathrm{C}$ and $675^{\circ} \mathrm{C}$. The stress relaxation responses during the first, second and middle-life tensile hold times are also plotted in Figure 4(df). Some conclusions can be drawn from the DWT hysteresis variations:

- Identical hysteresis variations to those reported for SWT are seen from Figure 4(top) with 
- The viscous stress blackuction rate is significant at the very beginning of the relaxation and then it reaches its quasi-stabilized value after 30 minutes of the holding. The stress relaxes to approximately $219 \mathrm{MPa}$ for $625^{\circ} \mathrm{C}, 178 \mathrm{MPa}$ for $650^{\circ} \mathrm{C}$ and $154 \mathrm{MPa}$ for $675^{\circ} \mathrm{C}$; it decreases with increasing temperature.

- The amount of stress relaxation during hold time varies with the number of cycles (each cycle has therefore a different average relaxation stress, see Figure 4(bottom) and Table 3). The blackuction of the viscous stress is much more pronounced for the $625^{\circ} \mathrm{C} \mathrm{DWT}$. 
(b)

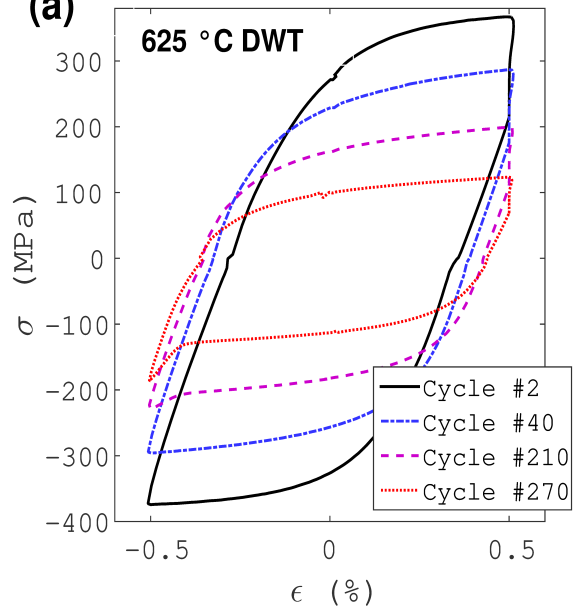

(d)

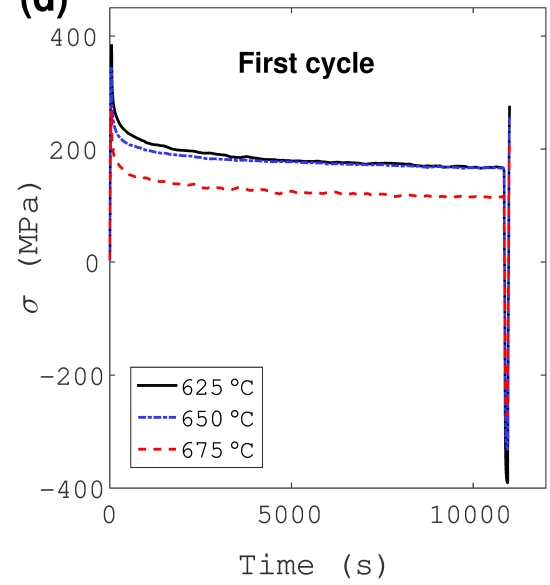

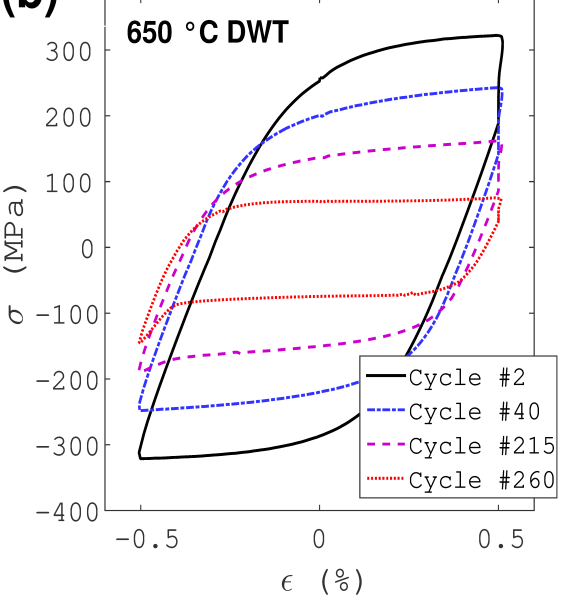

(e)

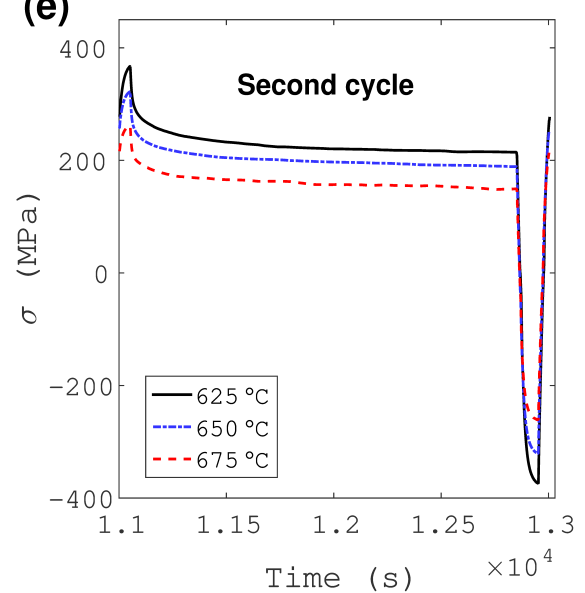

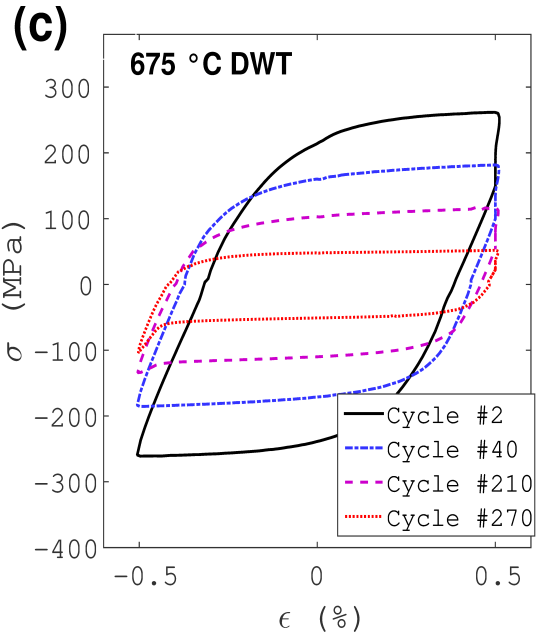

(f)

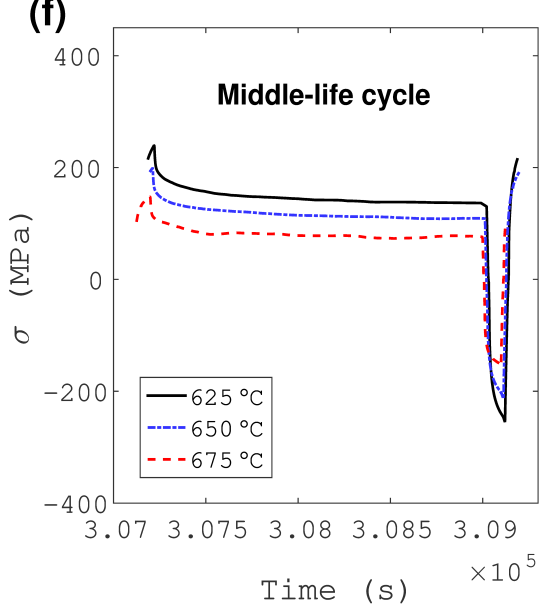

Figure 4: (top) A comparison of experimental results for DWT conducted on MarBN steel at (a) $625^{\circ} \mathrm{C}$, (b) $650^{\circ} \mathrm{C}$ and (c) $675^{\circ} \mathrm{C}$. (bottom) The stress versus time response highlighting the relaxation behaviour of the MarBN steel for (d) the first cycle, (e) second cycle and (f) middle-life cycle.

Table 3: blackuction in the viscous stress for the selected temperatures at different fatigue life stages.

\begin{tabular}{llll}
\hline Temperature & First cycle & Second cycle & Middle-life cycle \\
\hline $625^{\circ} \mathrm{C}$ & $218 \mathrm{MPa}$ & $152 \mathrm{MPa}$ & $103 \mathrm{MPa}$ \\
\hline $650^{\circ} \mathrm{C}$ & $178 \mathrm{MPa}$ & $133 \mathrm{MPa}$ & $90 \mathrm{MPa}$ \\
\hline $675^{\circ} \mathrm{C}$ & $154 \mathrm{MPa}$ & $112 \mathrm{MPa}$ & $71 \mathrm{MPa}$ \\
\hline
\end{tabular}

\subsubsection{Cyclic softening and mechanical energy variations}

To deeply characterize the low cycle fatigue behaviour of the MarBN steel, the stress range, $\Delta \sigma$, and hysteresis area, $A_{h}$, evolutions for both SWT and DWT at the test temperatures are 
compablack in Figure 5(a-b). In Figure 5(a), a continuous cyclic softening (a decrease in the stress amplitude) is observed for all test temperatures and loading conditions. A large amount of softening from the first cycle onwards occurs, after which a gradual change in the stress values under all test conditions is detected. Three stages can be distinguished in the stress amplitude plots. The first stage is characterized by a gradual decrease in both tensile and compressive peak stress (due to inelastic strain). The second stage shows a steady state with a constant rate of the cyclic softening. In the last stage, a significant decrease in the stress amplitude is observed (due to damage localizations and increase in the inelastic strain). The amount of softening and the softening rates are accelerated at higher test temperatures, while the hold has a slight impact on this behaviour. Moreover, experimental findings also indicate a gradual decrease of the deformation energy density during the fatigue process. The hysteresis area evolution reveals that the deformation energy density decreases with increasing number of cycles, and this decrease is found more pronounced for high test temperatures as shown in Figure 5(b).
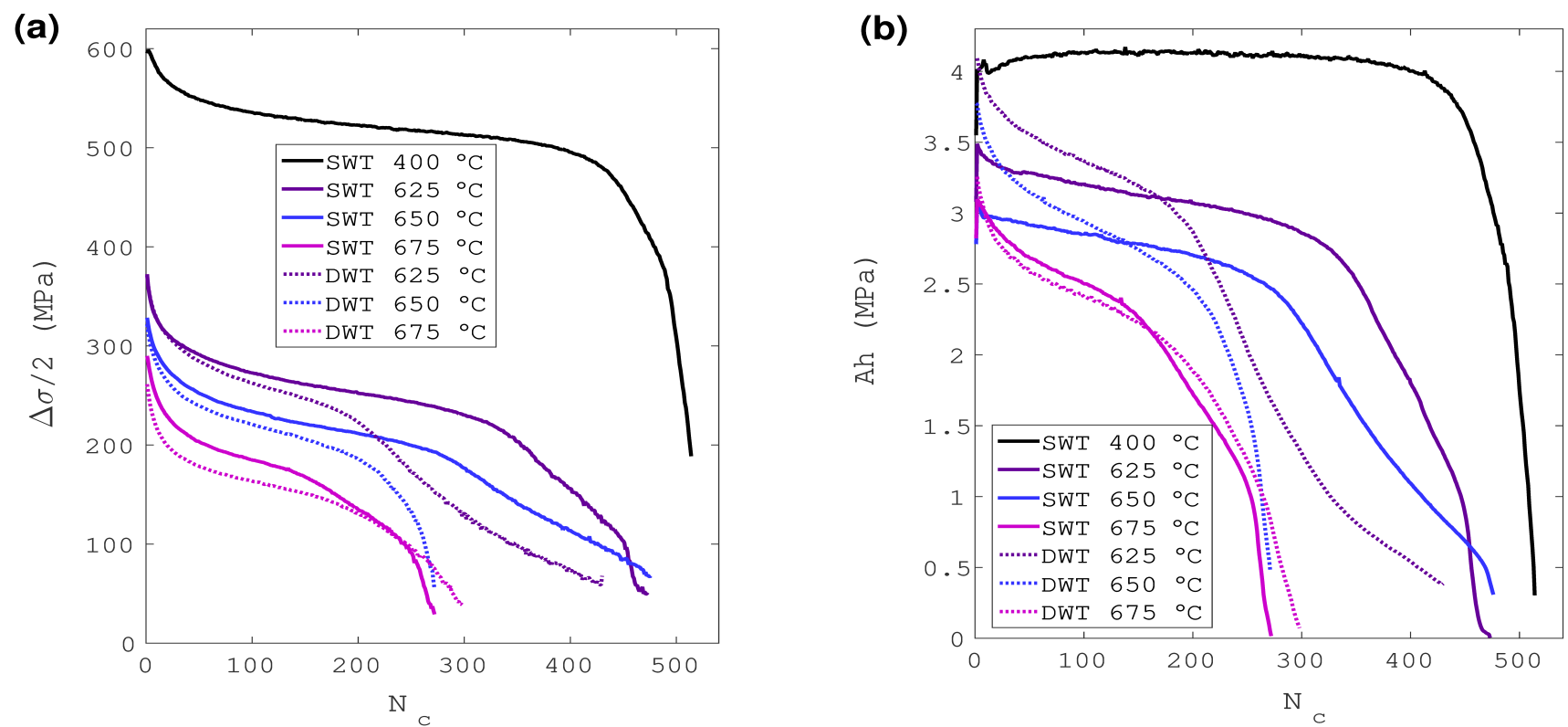

Figure 5: A comparative plot of hysteresis variations for both SWT and DWT at the selected temperatures, highlighted by (a) the stress amplitude evolution, $\Delta \sigma / 2$, and (b) the hysteresis area blackuction, $A_{h}$.

\subsubsection{Anhysteretic behaviour}

Anhysteretic tests with path symmetry during the unloading have been conducted to investigate the long-term viscous effects (below and above the yield) and also to reach and reveal the 
equilibrium stress response of the material at different strain levels. The reason of conducting such experimental investigation is motivated by the fact that some conventional power plant components are exposed to elevated temperature conditions that activate significant amounts of creep (long term viscous effects) for stress much lower than any reasonable interpretation of yield (Cortellino et al., 2017). So, it is of great interest to characterize the material behaviour below the yield and see if it remains elastic. Indeed, in many practical implementations of High-Cr steels, stress magnitudes are consideblack in the elastic regime and viscous effects are entirely attributed to viscoplastic mechanisms where viscous strain accumulation is only possible at stresses greater than the yield. This experimental investigation by conducting such advanced tests attempts to demonstrate the importance of incorporating viscoelastic effects (even below the yield) in the commonly implemented elasto-viscoplastic constitutive Chaboche type models (Chaboche, 2008).

The cyclic anhysteretic tests presented hereafter include several relaxation plateaus with strain levels that allow to work below and above the yield stress. Figure 6 shows the anhysteretic responses at the selected test temperatures studied over a large range of imposed strains. Several conclusions can be pointed out from the results:

- At the first relaxation step, the material exhibits a highly temperature dependent viscous behaviour. In Figure 6(d), the stress relaxes to approximately $98 \mathrm{MPa}$ for $625^{\circ} \mathrm{C}, 78 \mathrm{MPa}$ for $650^{\circ} \mathrm{C}$ and $75 \mathrm{MPa}$ for $675^{\circ} \mathrm{C}$, values which are below that of the yield stress of the MarBN steel (circa $130 \mathrm{MPa}$ for $625^{\circ} \mathrm{C}, 102 \mathrm{MPa}$ for $650^{\circ} \mathrm{C}$ and $94 \mathrm{MPa}$ for $675^{\circ} \mathrm{C}$ ).

- The viscous effects occur on a long-time scale. Although strain levels are increasing, the relaxation stress amplitudes at the last relaxation steps are similar, Figure 6(b-c).

- The anhysteretic loops become contracted and shrank at the second anhysteretic block with a same hardening behaviour as that observed within the previous sawtooth cycles, Figure 6(e-f).

- During the unloading, the relaxed stress amplitude is almost the same for all applied temperatures; this observation is not valid at compressive region where the relaxed stress 
variations show a highly temperature dependent response.

- The cyclic response of the investigated material shows irrecoverable strains below and above what is consideblack as the yield stress of the MarBN steel. It is however difficult to conclude whether residual strains stem from (visco-) plastic flow or from very long-term recoverable viscosity. 
(a)

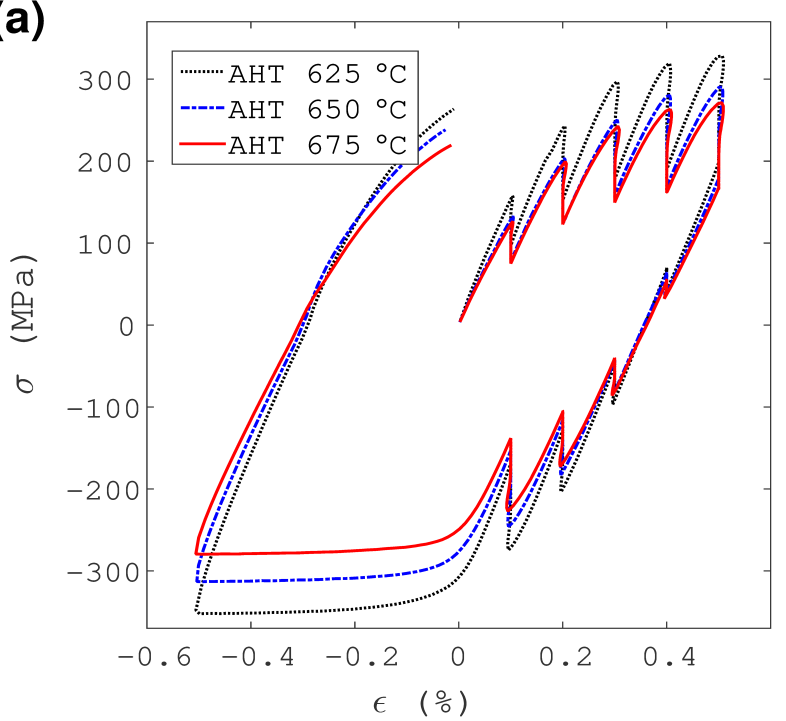

(c)

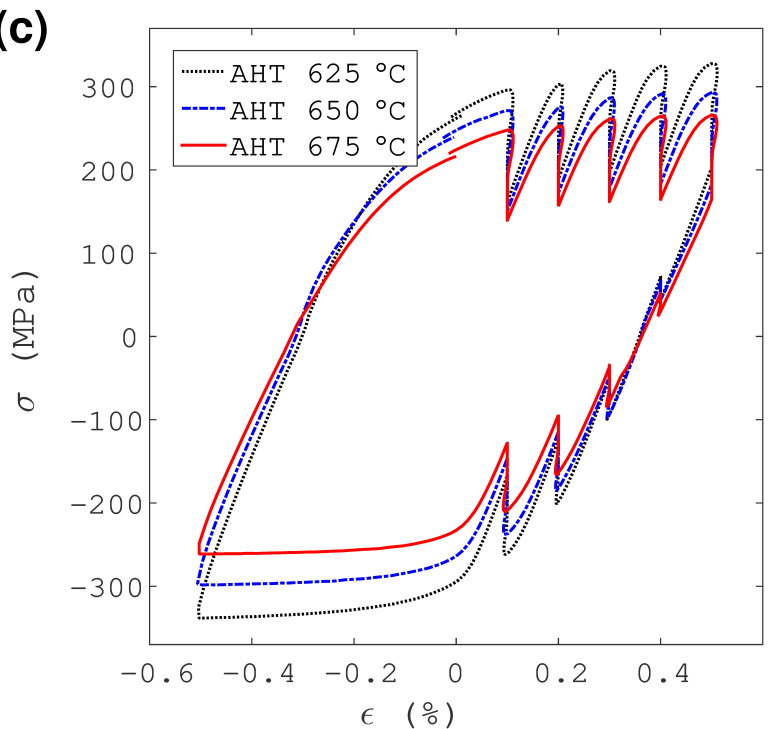

(e)

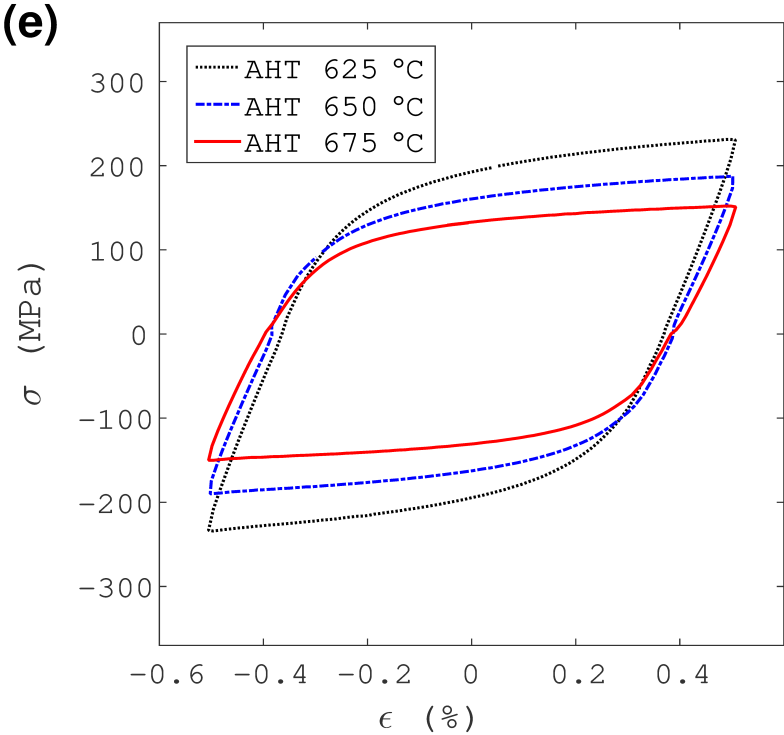

(b)

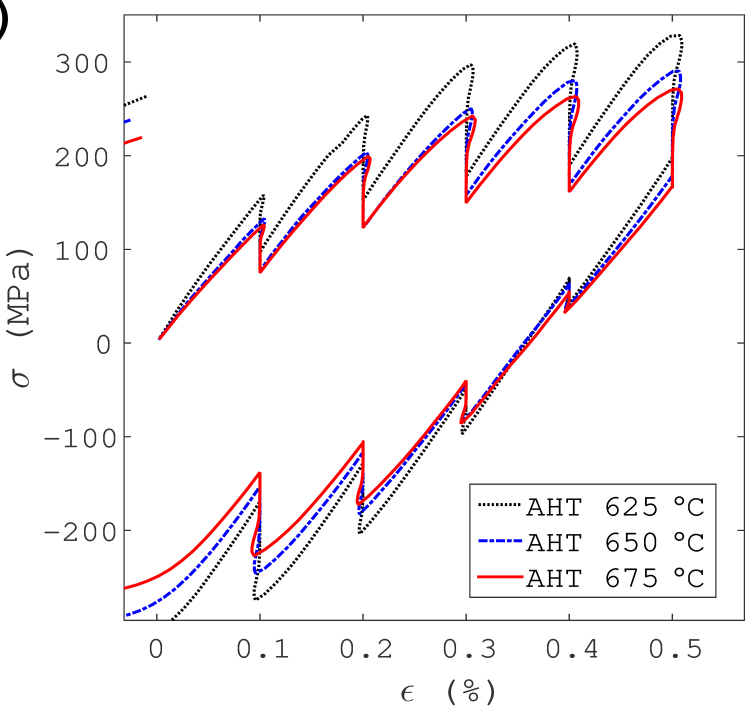

(d)

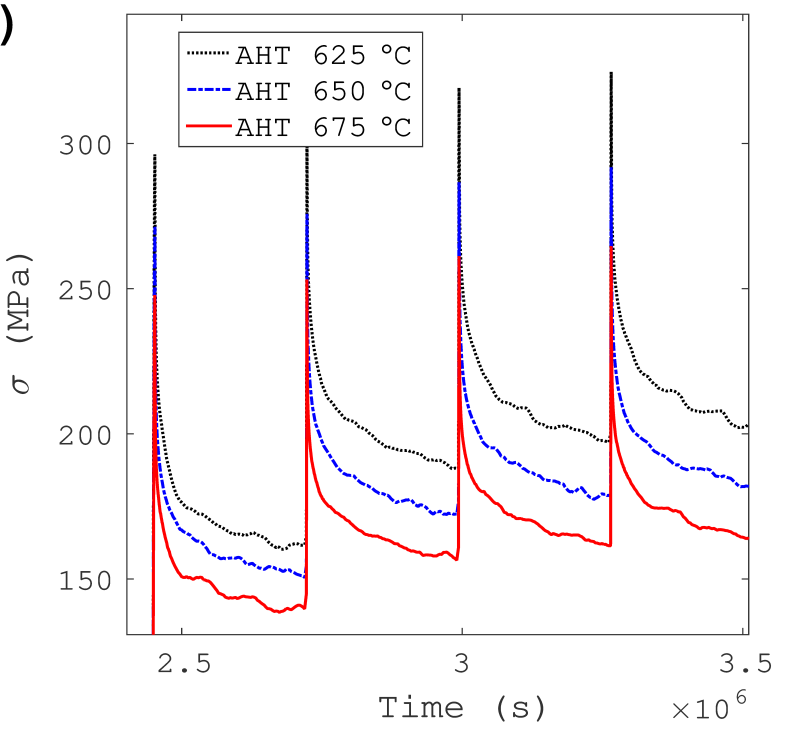

(f)

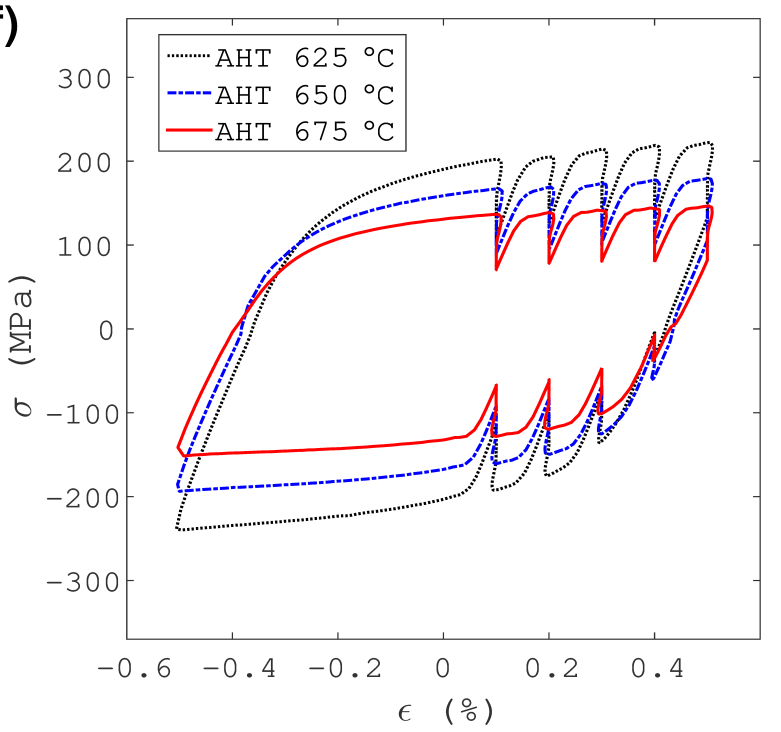

Figure 6: Anhysteretic responses of the MarBN steel at the selected temperatures. Figures are arranged to show $(a-b)$ material response at the first anhysteretic cycle, (c) material response at the second anhysteretic cycle, (d) relaxation response at the ongoing tensile region of the second anhysteretic cycle, (e) material response during the last sawtooth test of the first block and (f) anhysteretic response of the first cycle of the second block. 


\subsubsection{Cyclic creep-recovery behaviour}

Cyclic creep-recovery tests, CRT, have been performed to deeply investigate the long-term viscosity effects at several stress levels. These tests are designed to distinguish between longterm viscoelastic and viscoplastic mechanisms. Figure 7(a) shows the axial strain versus time plots of the MarBN steel extracted from CRT conducted under different stress levels for the $625^{\circ} \mathrm{C}$ test temperature. The corresponding mechanical response is given in Figure 7(b). It can be noted from the plots that at low stress levels, time-dependent effects are pronounced with inelastic strain partially recoveblack (around 0.05\%). At higher stress levels, large amounts of irrecoverable strain appear which are consideblack to be consequence of a significant viscoplastic flow. These residual strains seem to accumulate cycle after cycle with values of $0.42 \%$ at $210 \%$ of the yield strength. Finally, the ratcheting behaviour is observed in Figure 7(b) highlighted by the shifting of the hysteresis loops.
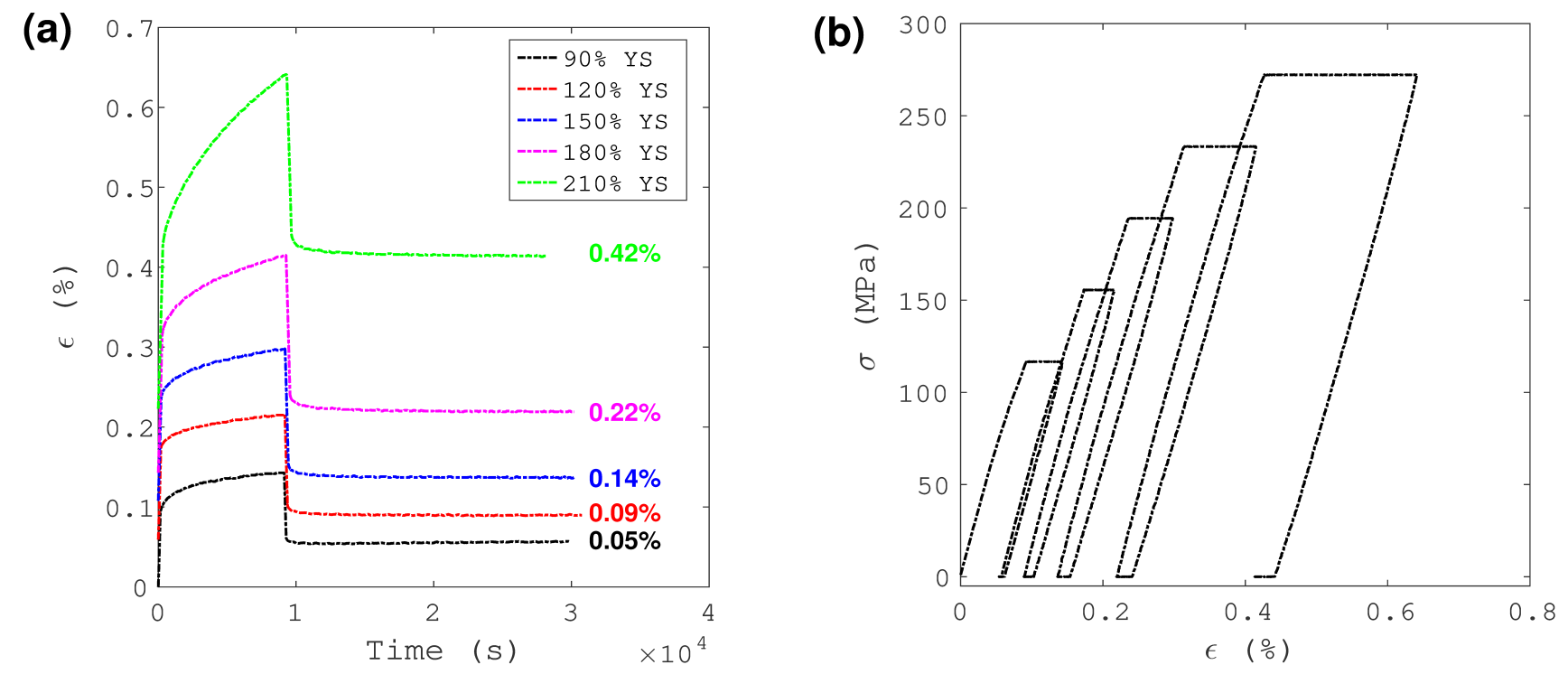

Figure 7: Cyclic creep-recovery tests for the $625^{\circ} \mathrm{C}$ test temperature conducted at several stress levels until failure: (a) the axial strain versus time plot highlighting the un-recoveblack strain stoblack within the material; (b) the associated mechanical response showing the cyclic ratcheting effect.

\subsection{Material characterisation}

Ruptublack specimens were examined in detail after SWT, DWT and CRT to investigate the variation in deformation and rupture behaviour upon different testing conditions. Fractography examination was conducted on the fracture surfaces of specimens, followed by detailed 
metallographic examination using EBSD and micro-hardness mapping.

\subsubsection{Fractography Examination}

Topography of the samples' fracture surfaces was examined using SE imaging on the specimens experiencing SWT, DWT and CRT at $625^{\circ} \mathrm{C}$, Figure 8 .
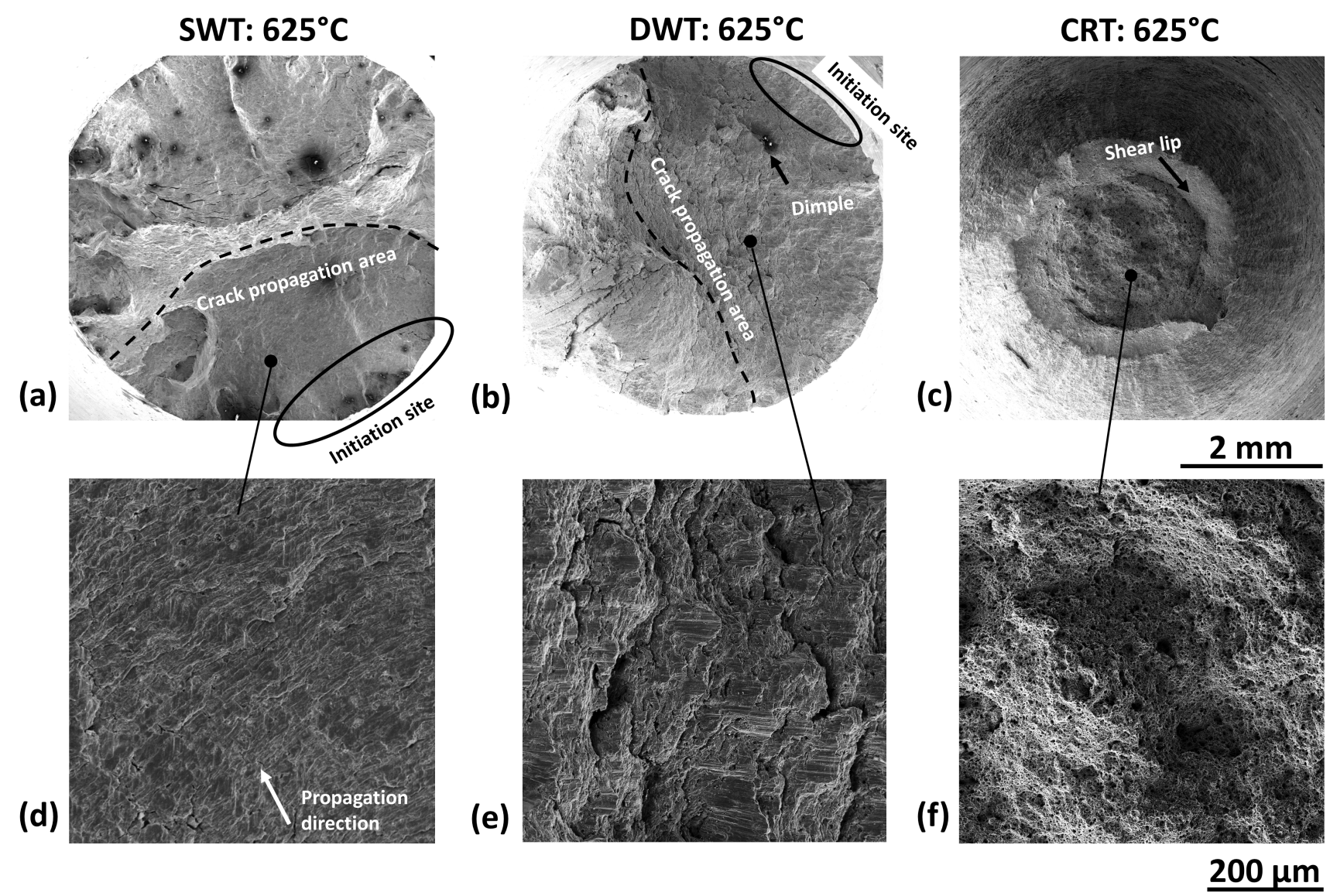

Figure 8: Topography of fracture surface after ( $a$ and d) SWT, (b and e) DWT and (c and f) CRT at $625^{\circ} \mathrm{C}$.

Figure $8\left(\mathrm{a}\right.$ and $\mathrm{d}$ ) demonstrate that the specimen experiencing SWT at $625^{\circ} \mathrm{C}$ was ruptublack as a result of fatigue crack propagation. The major crack was initiated from the outer surface of the specimen, followed by rapid crack propagation (contoublack by dashed lines) as marked by fatigue striations aligned perpendicular to the propagation direction. The regions of crack initiation are small in area and not distinctively differentiated from the area of crack propagation due to rapid crack propagation. The specimen experiencing DWT at $625^{\circ} \mathrm{C}$ (Figure $8 \mathrm{~b}$ ) was ruptublack in a similar manner as compablack to the specimen experiencing SWT. This is evidenced by the presence of striations and dimples on fracture surface, Figure 8(b and e)). A 
larger interspacing distance between striations was observed after DWT testing as a result of holding period in each loading cycle. The transgranular fracture surface observed after DWT is consistent with the previous observations from similar 9-12\% Cr martensitic steels upon stress/strain-controlled dwell fatigue testing conducted at similar conditions (Fournier et al., 2008). The transition in rupture behaviour between SWT and DWT specimens suggests that the hold duration during DWT imposes a dominating effect over the influence of cyclic loading on the manner of rupture. The specimen experiencing CRT was ruptublack in a ductile manner as evidenced by a dimpled surface, Figure 8(c and f). The dimpled topography of fracture surface has been previously observed after tensile testing (Mishnev et al., 2016) and short-term creep testing (Benaarbia et al., 2018b) conducted in the high temperature regime as a result of plasticity instability. The rupture of CRT specimen was therefore consideblack to take place in a transgranular manner via the coalescence of plasticity induced micro-voids during the hold duration at a stress level above the yield strength (Lin et al., 2005).

\subsubsection{EBSD mapping analysis}

EBSD mapping analysis was conducted in the longitudinal cross-section in the as-received state and after SWT, DWT and CRT at $625^{\circ} \mathrm{C}$ in the regions close to the fracture surface, Figure 9. The EBSD maps were collected adjacent to the crack propagation area and the dimpled region as demonstrated in Figure 9 in the SWT /DWT and CRT specimens, respectively. 


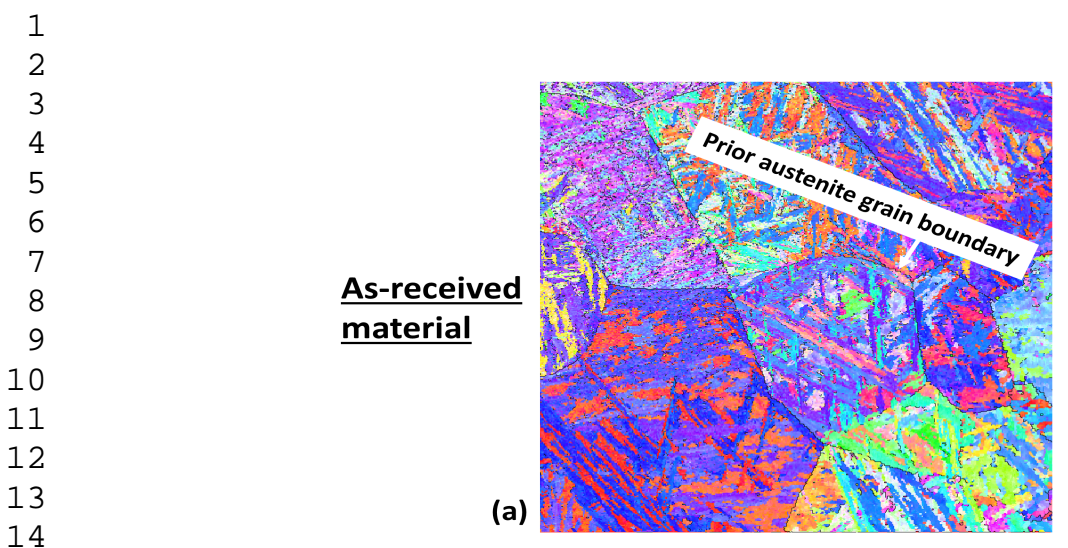

(b)
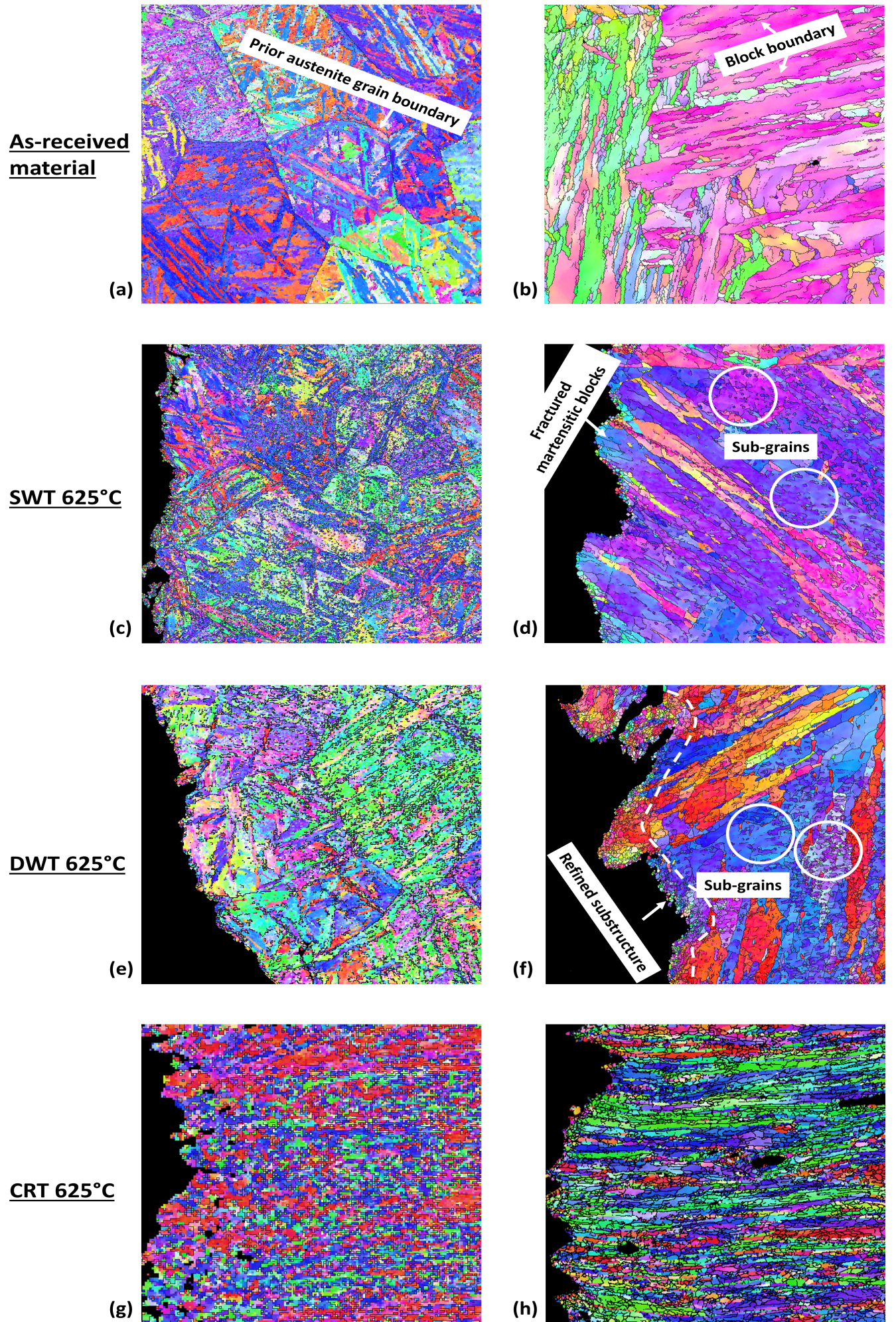

(h)

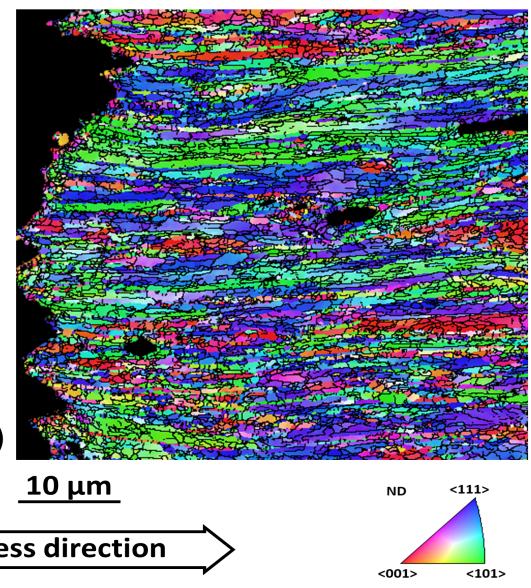

Figure 9: EBSD maps showing ( $a$ and $b$ ) the initial microstructure in the as-received state and the microstructure in the regions adjacent to the fracture surfaces after (c and d) SWT, (e and f) DWT and ( $g$ and h) CRT at $625^{\circ} \mathrm{C}$. Typical regions demonstrating a refined grain structure are indicated by white circles in (d) and (f). 
The initial microstructure in the as-received state is composed of Prior Austenite Grains (PAGs) that are $>200 \mu \mathrm{m}$ in diameter (Figure 9(a)) and elongated martensitic blocks with a width between 2 and $5 \mu \mathrm{m}$, Figure 9(b). Figure 9(c and e) demonstrate that the original PAG structure was not significantly changed during SWT and DWT, whereas the formation of sub-grains that are $<1 \mu \mathrm{m}$ in diameter was extensively observed within the martensitic blocks, Figure 9(d and f). This is consistent with existing observations from similar $9-12 \% \mathrm{Cr}$ steels demonstrating similar resultant microstructures after LCF exposure (Mishnev et al., 2016; Verma et al., 2016). The extensive formation of sub-grains within the martensitic substructure was attributed to the transformation from an unstable martensitic lath structure to a cellular substructure via the rearrangement of pre-existing dislocations at the elevated temperatures (Mishnev et al., 2016). The formation of sub- grains is therefore consideblack to result in a decrease in dislocation density and cause cyclic softening as observed in Figure 5.

In addition, significant structural refinement has been observed in the region $<5 \mu \mathrm{m}$ from the fracture surface in the DWT specimen (Figure 9(f)), whereas the refinement of the martensitic substructure was not evident in the SWT specimen. The presence of structural refinement in martensitic steels has been previously reported as a consequence of significant plastic deformation at a high strain rate (Huang et al., 2012; Zhang et al., 2015). This further suggests that the deformation and rupture of the specimen experiencing DWT is involved with plasticity related mechanisms.

The specimen experiencing CRT demonstrates a significantly refined microstructure in the region close to the fracture surface, Figure $9(\mathrm{~g}$ and $\mathrm{h})$. The original PAG structure and the martensitic substructure were both refined to an equiaxed morphology, with the vicinities corresponding to the original martensitic blocks distorted along the principal stress direction, Figure 9(h). The significant refinement of the original martensitic microstructure has been observed from similar materials upon rapid plastic deformation at elevated temperature (Huang et al., 2012; Zhang et al., 2015; Benaarbia et al., 2018b). The CRT specimen was therefore consideblack to experience significant plastic deformation prior to rupture.

\subsubsection{Hardness mapping}


Hardness measurement was firstly performed in the as-received MarBN steel prior to LCF testing at a loading weight of $10 \mathrm{~kg}$ and $0.2 \mathrm{~kg}$. The values of hardness obtained from the as-received material are measuring $249 \pm 2 \mathrm{HV} 10$ and $261 \pm 8 \mathrm{HV} 0.2$ at different testing conditions. Hardness measurement was further conducted close to the boundary between gauge and head portions of SWT and DWT specimens at a loading weight of $10 \mathrm{~kg}$. The hardness values obtained from the specimens experiencing SWT and DWT at $625^{\circ} \mathrm{C}$ are $271 \pm 3$ and $260 \pm 8$ HV10, respectively. The variation of hardness in the region close to fracture surface was further characterised using hardness mapping analysis at a loading weight of $0.2 \mathrm{~kg}$ after SWT and DWT at $625^{\circ} \mathrm{C}$, Figure 10.

Figure 10(a) demonstrates that hardness varies between 198 and 229 HV0.2 in the region < $4 \mathrm{~mm}$ away from fracture surface in the specimen experiencing SWT at $625^{\circ} \mathrm{C}$. The hardness in the regions closer to the head portion (i.e. $>4 \mathrm{~mm}$ from fracture surface) is higher and in the range between 242 and 291 HV0.2 in the same specimen, Figure 10(a). The variation of hardness is not evident without a clear trend in the specimen experiencing DWT, Figure 10(b). Hardness varies between 218 and 247 HV0.2 in the gauge portion of the specimen experiencing DWT. The hardness values measublack from the gauge portion are considerably lower than the values measublack from the as-received material (i.e. $261 \pm 8$ HV0.2). The lower hardness in the gauge regions close to the fracture surface has further confirmed the deterioration of matrix properties upon LCF exposure at both the SWT and DWT conditions. The transformation of martensitic substructure and the decrease of dislocation density accompanied by the formation of sub-grains may cause a decrease in the hardness and the stress amplitude measublack from cyclic fatigue testing, Figure 10. The value of hardness as measublack from the region close to the fracture surface of the CRT specimen is evidently higher than the region further away. This can be attributed to a higher volume density of dislocations in the region close to the fracture surface upon the occurrence of necking due to localised plasticity instability (Benaarbia et al., 2018b). This is further evidenced by the observation of significantly distorted and refined martensitic microstructure as shown in Figure 9. 
(a)

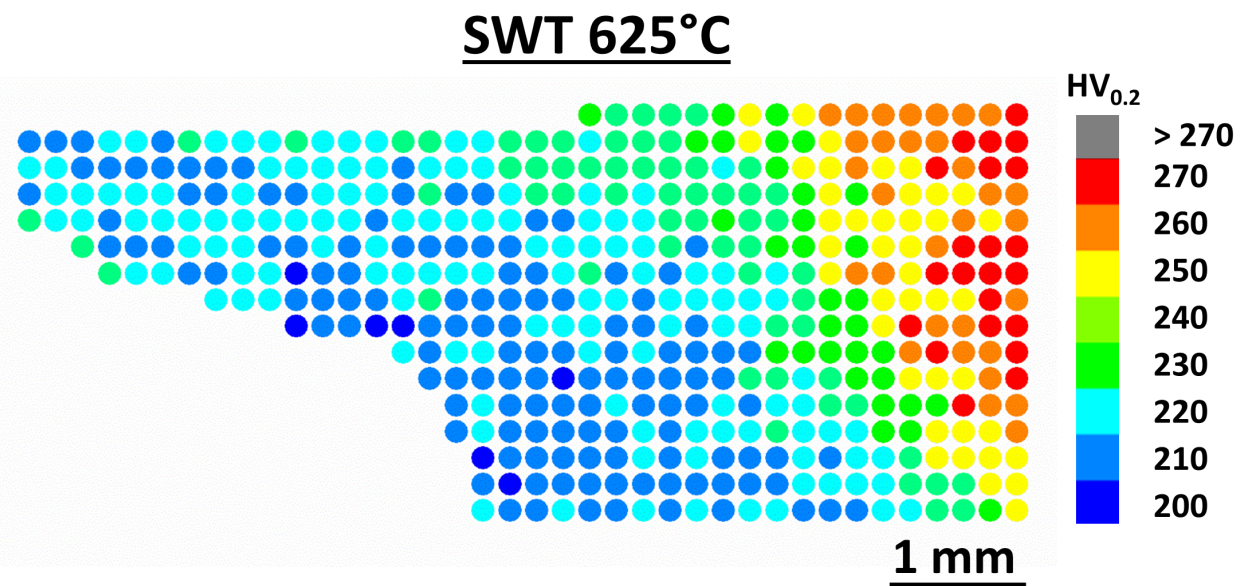

(b)

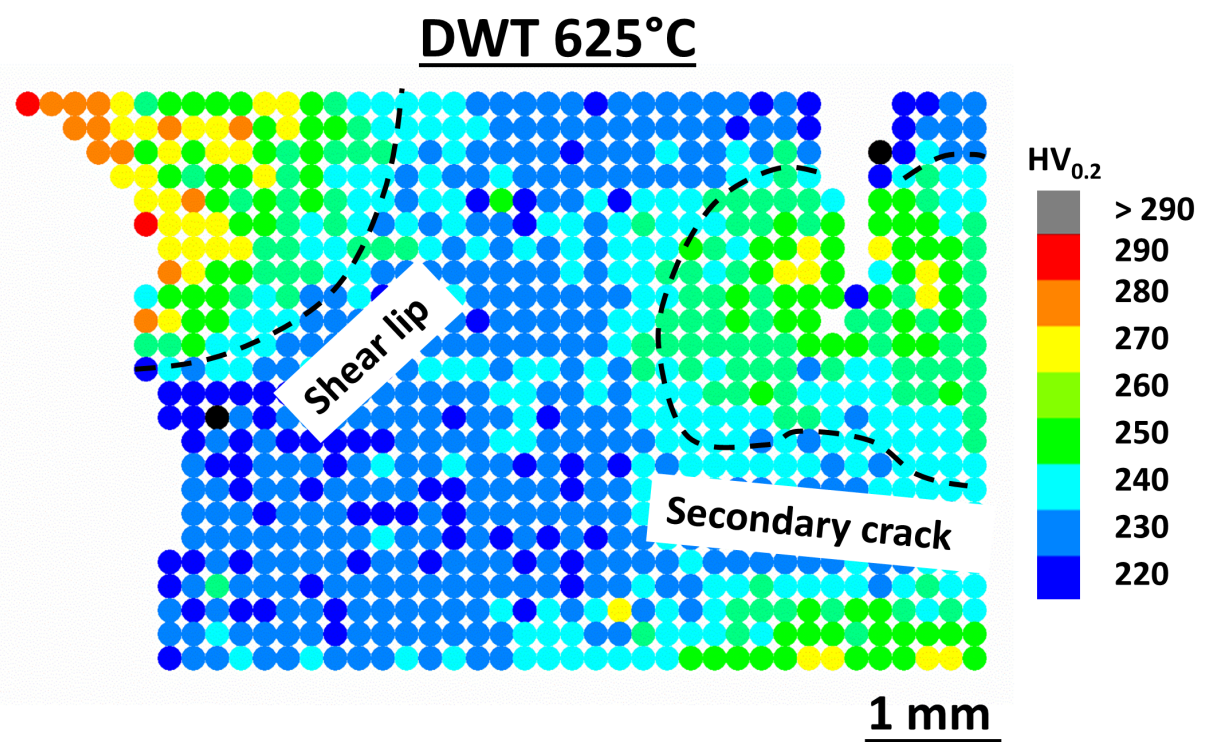

(c)

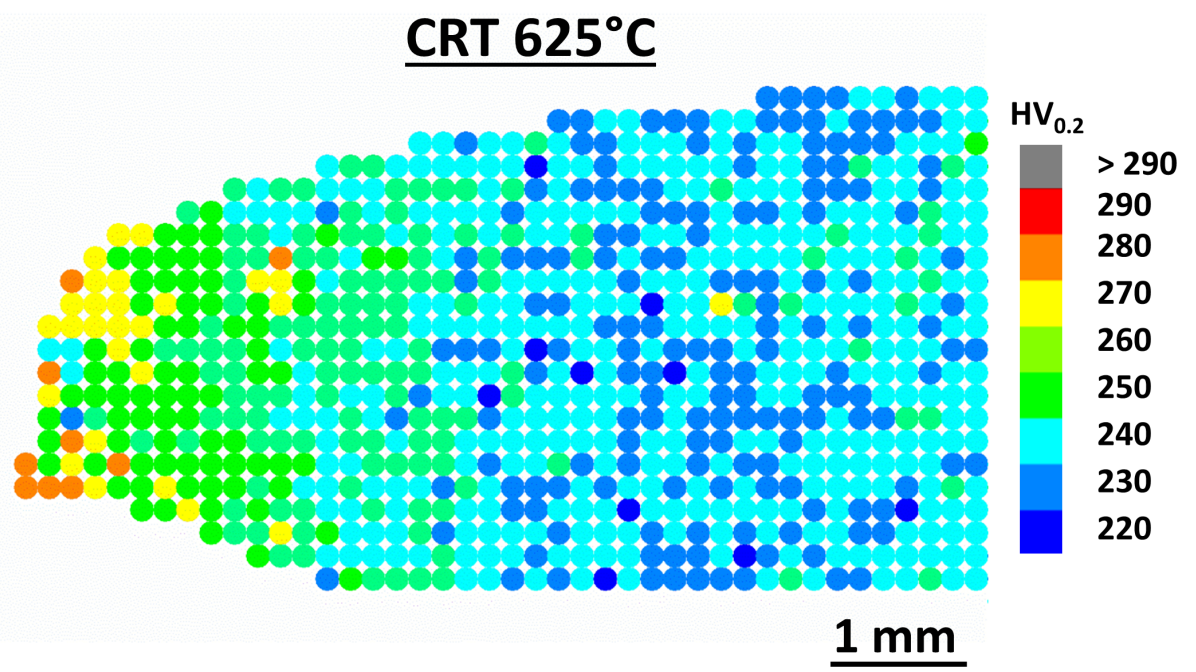

\section{Principal stress direction}

Figure 10: Hardness maps collected from the regions close to fracture surfaces in the specimens experiencing (a) SWT, (b) DWT and (c) CRT at $625^{\circ} \mathrm{C}$. 


\section{Conclusions and future work}

Extensive experimental work has been conducted to investigate the high temperature low cycle fatigue behaviour of MarBN steel at bulk and micro-scales. Fully-reversed tests with zero- and hold-tensile periods, anhysteretic tests with hold- tensile periods at ascending strain levels, and cyclic creep-recovery tests at different stress ranges, were conducted. The mechanical investigations were combined with microstructural analyses (through SEM, EBSD and hardness mapping) to further emphasize the leading deformation mechanisms. The main conclusions are listed below:

- A continuous accelerated cyclic softening and a decelerated stress relaxation behaviour were observed for all test temperatures. The first was attributed to the accumulated inelastic transformation from the creep mechanism during the dwell period at the peak tensile strain of the fatigue cycle, while the second was ascribed to the blackuction in the viscous stress due to the continuous cyclic softening.

- Large amounts of irrecoverable strains below and above the yield were highlighted through AHT, while the viscous effects were found to occur on a long time-scale. The irreversible strains were attributed to either viscoplastic and/or long-term viscous effects.

- Time-dependent effects at low stress levels were pronounced with inelastic strain partially recoveblack (see the cyclic creep-recovery tests). At higher stress levels large amounts of irrecoverable strains appeablack.

- Specimens experiencing SWT were ruptublack as a result of fatigue crack propagation. The rupture for specimens experiencing DWT and CRT was consideblack to take place in a transgranular and ductile manner (evidenced by a dimpled surface) via the coalescence of plasticity induced micro-voids during the hold duration.

- An extensive formation of sub-grains within the martensitic substructure was observed for all test conditions. This was further related with a decrease in dislocation density that causes cyclic softening. A significant structural refinement for the martensitic substructure 
was also observed for both DWT and CRT conditions. This refinement was attributed to the plastic deformation.

- Same hardness variations for both SWT and DWT conditions were reported. The decrease in hardness values was essentially due to the transformation in martensitic substructure.

Based on the conclusions drawn above, future work will focus on the modelling of the viscoplastic behaviour of the MarBN steel at high temperature conditions. This should be undertaken focusing on the incorporation of microstructural features in the model constitutive equations. The inclusion of such microstructural information will undoubtedly enhance the fundamental understanding that the model can provide. Models based on dislocation density should have an enhanced physical meaning. Dislocation densities can thus be incorporated as internal state variables, and their evolution can be modelled based on the storage and annihilation processes for dislocations.

\section{Acknowledgments}

This work is supported by the Engineering and Physical Sciences Research Council (grant numbers: EP/N509991/1 and EP/N509942/1).

The authors gratefully acknowledge the following partners for their valuable contributions: Doosan Babcock, GE Power, Uniper Technologies, Metrode Products, Goodwin Steel Castings and Wyman-Gordon. Specific acknowledgments to GE Power for providing the test material and to Mr. Shane Maskill (University of Nottingham) for his support in the experimental testing.

\section{References}

\section{References}

Abe, F., Tabuchi, M., Semba, H., Igarashi, M., Yoshizawa, M., Komar, N., Fujita, A., 2008. Feasibility of marbn steel for application to thick section boiler components in usc power plant at $650^{\circ} \mathrm{C}$. 5th International Conference on Advances in Materials Technology for Fossil Power Plants, Marco Island, FL, Oct. 3-5 , 92-106. 
Bassi, F., Foletti, S., Conte, A.L., 2015. Creep fatigue crack growth and fracture mechanisms of t/p91 power plant steel. Materials at High Temperatures 32, 250-255.

Batista, M., Marinelli, M., Herenu, S., Alvarez-Armas, I., 2015. The role of microstructure in fatigue crack initiation of $9-12 \% \mathrm{cr}$ reduced activation ferritic-martensitic steel. International Journal of Fatigue $72,75-79$.

Benaarbia, A., Rouse, J., Sun, W., 2018a. A thermodynamically-based viscoelastic-viscoplastic model for the high temperature cyclic behaviour of $9-12 \%$ cr steels. International Journal of Plasticity 107, $100-121$.

Benaarbia, A., Xu, X., Sun, W., Becker, A., Jepson, M.A., 2018b. Investigation of short-term creep deformation mechanisms in marbn steel at elevated temperatures. Materials Science and Engineering: A 734, $491-505$.

Chaboche, J., 2008. A review of some plasticity and viscoplasticity constitutive theories. International Journal of Plasticity 24, 1642 - 1693. Special Issue in Honor of Jean-Louis Chaboche.

Chen, R., Armaki, H.G., Maruyama, K., Igarashi, M., 2011. Long-term microstructural degradation and creep strength in gr.91 steel. Materials Science and Engineering: A 528, 4390 4394.

Cortellino, F., Rouse, J.P., Cacciapuoti, B., Sun, W., Hyde, T.H., 2017. Experimental and numerical analysis of initial plasticity in p91 steel small punch creep samples. Experimental Mechanics $57,1193-1212$.

Fournier, B., Dalle, F., Sauzay, M., Longour, J., Salvi, M., Caës, C., Tournié, I., Giroux, P.F., Kim, S.H., 2011. Comparison of various $9-12 \%$ cr steels under fatigue and creep-fatigue loadings at high temperature. Materials Science and Engineering: A 528, 6934- 6945.

Fournier, B., Sauzay, M., Caës, C., Noblecourt, M., Mottot, M., Bougault, A., Rabeau, V., Pineau, A., 2008. Creep-fatigue-oxidation interactions in a 9cr-1mo martensitic steel. part i: Effect of tensile holding period on fatigue lifetime. International Journal of Fatigue 30, 649 - 662. 
Gianfrancesco, D., 2017. Materials for ultra-supercritical and advanced ultra- supercritical power plants. Woodhead Publishing, 1-49.

Guguloth, K., Sivaprasad, S., Chakrabarti, D., Tarafder, S., 2014. Low-cyclic fatigue behavior of modified 9cr-1mo steel at elevated temperature. Materials Science and Engineering: A 604, $196-206$.

Huang, X., Morito, S., Hansen, N., Maki, T., 2012. Ultrafine structure and high strength in cold-rolled martensite. Metallurgical and Materials Transactions A 43, 3517-3531.

Lin, J., Liu, Y., Dean, T.A., 2005. A review on damage mechanisms, models and calibration methods under various deformation conditions. International Journal of Damage Mechanics 14, 299-319.

Mannan, S., Valsan, M., 2006. High-temperature low cycle fatigue, creep-fatigue and thermomechanical fatigue of steels and their welds. International Journal of Mechanical Sciences 48, 160 - 175. 7th Asia-Pacific Symposium on Advances in Engineering Plasticity and its Applications (AEPA 2004).

Mishnev, R., Dudova, N., Kaibyshev, R., 2016. Low cycle fatigue behavior of a 10cr-2w-mo-3conbv steel. International Journal of Fatigue 83, 344 - 355.

Pineau, A., 2014. High temperature fatigue - a comprehensive review. Creep fatigue crack development symposium .

Pineau, A., Antolovich, S.D., 2015. High temperature fatigue: behaviour of three typical classes of structural materials. Materials at High Temperatures 32, 298-317.

Rae, Y., Benaarbia, A., Hughes, J., Sun, W., 2019. Experimental characterisation and computational modelling of cyclic viscoplastic behaviour of turbine steel. International Journal of Fatigue 124, $581-594$.

Saad, A., Hyde, T., Sun, W., Hyde, C., Tanner, D., 2013. Characterization of viscoplasticity 
behaviour of p91 and p92 power plant steels. International Journal of Pressure Vessels and Piping 111-112, $246-252$.

Shankar, V., Bauer, V., Sandhya, R., Mathew, M., Christ, H.J., 2012. Low cycle fatigue and thermomechanical fatigue behavior of modified $9 \mathrm{cr}-1 \mathrm{mo}$ ferritic steel at elevated temperatures. Journal of Nuclear Materials 420, $23-30$.

Shankar, V., Valsan, M., Rao, K.B.S., Kannan, R., Mannan, S., Pathak, S., 2006. Low cycle fatigue behavior and microstructural evolution of modified 9cr-1mo ferritic steel. Materials Science and Engineering: A 437, $413-422$.

Swindeman, R., Santella, M., Maziasz, P., Roberts, B., Coleman, K., 2004. Issues in replacing cr-mo steels and stainless steels with 9cr-1mo-v steel. International Journal of Pressure Vessels and Piping 81, 507 - 512. The 7th International Conference on Operating Pressure Equipment.

Verma, P., Srinivas, N.S., Singh, S., Singh, V., 2016. Low cycle fatigue behavior of modified 9cr-1mo steel at room temperature. Materials Science and Engineering: A 652, $30-41$.

Viswanathan, R., Henry, J.F., Tanzosh, J., Stanko, G., Shingledecker, J., Vitalis, B., Purgert, R., 2005. U.s. program on materials technology for ultra-supercritical coal power plants. Journal of Materials Engineering and Performance 14, 281-292.

Wang, X., Zhang, W., Gong, J., Wahab, M.A., 2018. Low cycle fatigue and creep fatigue interaction behavior of $9 \mathrm{cr}-0.5 \mathrm{mo}-1.8 \mathrm{w}-\mathrm{v}-\mathrm{nb}$ heat-resistant steel at high temperature. Journal of Nuclear Materials 505, $73-84$.

Yan, W., Wang, W., Shan, Y.Y., Yang, K., 2013. Microstructural stability of 9-12\%cr ferrite/martensite heat-resistant steels. Frontiers of Materials Science 7, 1-27.

Zhang, S.L., Xuan, F.Z., 2017. Interaction of cyclic softening and stress relaxation of 9-12\% cr steel under strain-controlled fatigue-creep condition: Experimental and modeling. International Journal of Plasticity 98, $45-64$. 
Zhang, S.L., Xuan, F.Z., Guo, S.J., Zhao, P., 2017. The role of anelastic recovery in the creep-fatigue interaction of $9-12 \% \mathrm{cr}$ steel at high temperature. International Journal of Mechanical Sciences $122,95-103$.

Zhang, Z., Mishin, O., Tao, N., Pantleon, W., 2015. Microstructure and annealing behavior of a modified 9cr-1mo steel after dynamic plastic deformation to different strains. Journal of Nuclear Materials 458, 64-69.

Zhu, X., Chen, H., Xuan, F., Chen, X., 2019. On the creep fatigue and creep rupture behaviours of 9-12\% cr steam turbine rotor. European Journal of Mechanics - A/Solids 76, 263 - 278. 


\title{
Characterization of cyclic behavior, deformation mechanisms, and microstructural evolution of MarBN steels under high temperature conditions
}

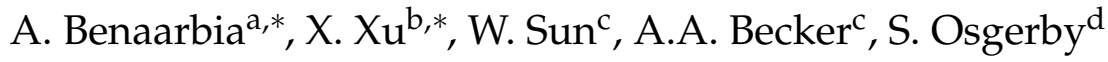 \\ ${ }^{a}$ Arts et Métiers ParisTech, CNRS, Université de Lorraine, LEM3, F-57000 Metz, France \\ ${ }^{b}$ Department of Materials, Loughborough University, Loughborough, Leicestershire LE11 3TU, UK \\ ${ }^{c}$ Department of Mechanical, Materials and Manufacturing Engineering, University of Nottingham, Nottingham, \\ Nottinghamshire, NG7 2RD, UK \\ ${ }^{d}$ GE Power, Newbold Road, Rugby, Warwickshire, CV21 2NH, UK
}

\begin{abstract}
In this paper, the low cycle fatigue behaviour of MarBN steels at elevated temperatures is discussed. Four cyclic loading waveforms were applied to investigate both the mechanical and microstructural features. The mechanical results exhibit continuous cyclic softening and decelerated stress relaxation, recoverable viscoelasticity at both short and long time scales and irrecoverable viscoplastic mechanisms. Detailed microstructural characterisation was also conducted to investigate the rupture behaviour of the investigated steel. The microstructural findings indicate typical transgranular and ductile fracture behaviour, extensive sub-grain formation and structural refinement as well as significant decrease in hardness close to the fracture surface.

Keywords: MarBN steel, Low cycle fatigue, High temperature viscoplasticity, Martensitic substructure, Sub-grain formation.
\end{abstract}

\section{Introduction}

Most power plant components are subjected to repeated thermomechanical stresses as a result of temperature and pressure gradients that occur on heating and cooling during startup and shutdown or during temperature transients. These loading operations lead to both

\footnotetext{
*Corresponding author.

Email addresses: adil.benaarbia@ensam.eu (A. Benaarbia), xu.xu@manchester.ac.uk (X. Xu), w.sun@nottingham.ac.uk (W.Sun), a.a.becker@nottingham.ac.uk (A.A. Becker), steve.osgerby@ge.com (S. Osgerby)
} 
creep and fatigue deformations which can cause premature failures (Wang et al., 2018; Zhu et al., 2019; Bassi et al., 2015; Pineau and Antolovich, 2015). An in-depth assessment of the creep-fatigue interaction is thus vital to ensure safe operation of the power plant component during its lifetime. Components such as gas turbines and heat exchangers need to withstand temperatures in excess of $650^{\circ} \mathrm{C}$, and thus require high strength materials with excellent creep, fatigue and oxidation/corrosion resistance. One material type used in this application are the $9 \mathrm{Cr}$ creep resistant martensitic steels which have a good combination of creep strength, weldability, hardenability and corrosion resistance (Viswanathan et al., 2005; Gianfrancesco, 2017; Fournier et al., 2011; Swindeman et al., 2004; Chen et al., 2011). The recently developed tempered martensitic MarBN family of steels (9CR-3W-3Co- $\mathrm{VNbBN}$ ) is a promising candidate for the replacement of conventional materials used in the power plants due to superior creep resistance (Abe et al., 2008). However, the creep-fatigue performance of the MarBN steel is yet to be assessed, and an extensive assessment of the (thermo)-mechanical behaviour is required.

Classical strain-controlled tests with and without dwell periods are often conducted under isothermal (and/or anisothermal) conditions to understand and calibrate the "hysteretic" mechanical response of power plant materials (Saad et al., 2013; Benaarbia et al., 2018a; Rae et al., 2019). A large amount of creep and fatigue properties of $9 \mathrm{Cr}$ steels is available in the literature, and much progress has been made with the interpretation of experimental fatigue-creep data (Zhang et al., 2017; Benaarbia et al., 2018b). Through examination of past research, two major features are commonly observed within $9 \mathrm{Cr}$ steels under high temperature fatigue conditions. The first is accelerated cyclic softening which is attributed to the accumulated inelastic transformation from the creep mechanism during the dwell period at the peak tensile strain of the fatigue cycle (Zhang and Xuan, 2017). The second is the decelerated stress relaxation behaviour which is ascribed to the reduction in the viscous stress due to continuous cyclic softening. As interest developed in high temperature fatigue, it was found that in the creep range fatigue endurances are significantly shorter, particularly when hold periods are introduced (Rae et al., 2019). The reason for the reduced fatigue life is that, in addition to fatigue damage due to cyclic loading, creep damage is also accumulated during hold periods. 
The softening behaviour of these alloys has been demonstrated to be linked with the instability of the martensitic substructure upon cyclic mechanical loading at elevated temperature (Pineau, 2014; Mishnev et al., 2016; Guguloth et al., 2014). In these cases, lath coarsening or the replacement of the initial lath microstructure by a cellular structure accompanied with the formation of sub-grains have been extensively reported after low cycle fatigue testing (Mishnev et al., 2016; Shankar et al., 2012; Mannan and Valsan, 2006). The transformation of the martensitic substructure is also commonly accompanied with a decrease in dislocation density due to the rearrangement of dislocation structure and the annihilation of mobile dislocations, which contributes to a decrease in stress amplitude during cyclic fatigue testing (Pineau and Antolovich, 2015; Shankar et al., 2006). The increase in stress amplitude and the time period of stress duration have been shown to accelerate the coarsening of the martensitic substructure (Shankar et al., 2006; Verma et al., 2016).

The initiation of fatigue damage is commonly observed at the martensitic substructure boundaries and coarse secondary phase particles due to strain localisation and strain irreversibility as a consequence of dislocation pile-up (Batista et al., 2015). This is commonly followed by the propagation of cracks in a transgranular manner upon cyclic loading (Shankar et al., 2012; Fournier et al., 2008). In addition, damage nucleation may occur from any oxide layer formed on the outer surface of the specimen at the elevated temperature (Shankar et al., 2012; Mannan and Valsan, 2006). An increase in the time period of stress duration in a compression regime has been shown to be detrimental by maintaining a sharp crack tip after its initiation upon tensile loading (Shankar et al., 2006). However, the presence of creep induced cavitation is rarely observed upon creep-fatigue exposure due to the excellent creep resistance of tempered martensitic microstructure in 9-12\% Cr steels (Abe et al., 2008; Yan et al., 2013).

The current experimental work aims to provide an analysis of the fatigue behaviour of a recently developed MarBN steel, IBN1, tested at high temperatures in different cyclic mechanical conditions. Experimental findings are split into two parts: the first deals with the overall mechanical responses, whereas the second focuses on microstructure investigations conducted on ruptured samples. The tests applied utilise several cyclic loading waveforms in order to 
investigate the dominating deformation mechanisms which are commonly observed in MarBN steels. These include fully reversed tests with or without hold periods, anhysteretic tensile tests with loading-unloading hold periods, and cyclic creep-recovery tests. Mechanical findings are thus presented in forms of (i) stress amplitude to investigate the accelerated cyclic softening, (ii) viscous stress to study the decelerated stress relaxation behaviour and (iii) hysteresis area to account for the deformation energy variations. These mechanical data are analysed in conjunction with post-mortem analysis of microstructure using Scanning Electron Microscopy (SEM), Electron Backscatter Diffraction (EBSD) and micro-hardness mapping.

\section{Material and experimental programme}

The investigated material was a tempered martensitic IBN-1 steel with chemical components listed in Table 1. The specimens used for low cycle fatigue (LCF) tests were cylindrical with a diameter of $5 \mathrm{~mm}$ and a gauge length of $10 \mathrm{~mm}$ as shown in Figure 1. These were fabricated according to the specification given in ISO 12106 for metallic materials, fatigue testing and axial strain controlled methods. They were machined from forged bars normalised at $1200^{\circ} \mathrm{C}$ for 4 hours and tempered at $765^{\circ} \mathrm{C}$ for 3 hours.

Table 1: Chemical composition of the investigated material (all elements are in wt. $\%, \mathrm{~B}$ and $\mathrm{N}$ are in ppm).

\begin{tabular}{lllllllllllllllll}
\hline $\mathbf{C}$ & $\mathbf{S i}$ & $\mathbf{M n}$ & $\mathbf{P}$ & $\mathbf{S}$ & $\mathbf{C r}$ & $\mathbf{M o}$ & $\mathbf{N i}$ & $\mathrm{Al}$ & $\mathbf{B}$ & $\mathbf{C o}$ & $\mathbf{C u}$ & $\mathbf{N b}$ & $\mathbf{V}$ & $\mathbf{W}$ & $\mathbf{N}$ \\
\hline 0.1 & 0.45 & 0.54 & 0.012 & 0.004 & 8.74 & 0.05 & 0.14 & 0.007 & 120 & 3.02 & 0.04 & 0.06 & 0.21 & 2.53 & 180 \\
\hline
\end{tabular}

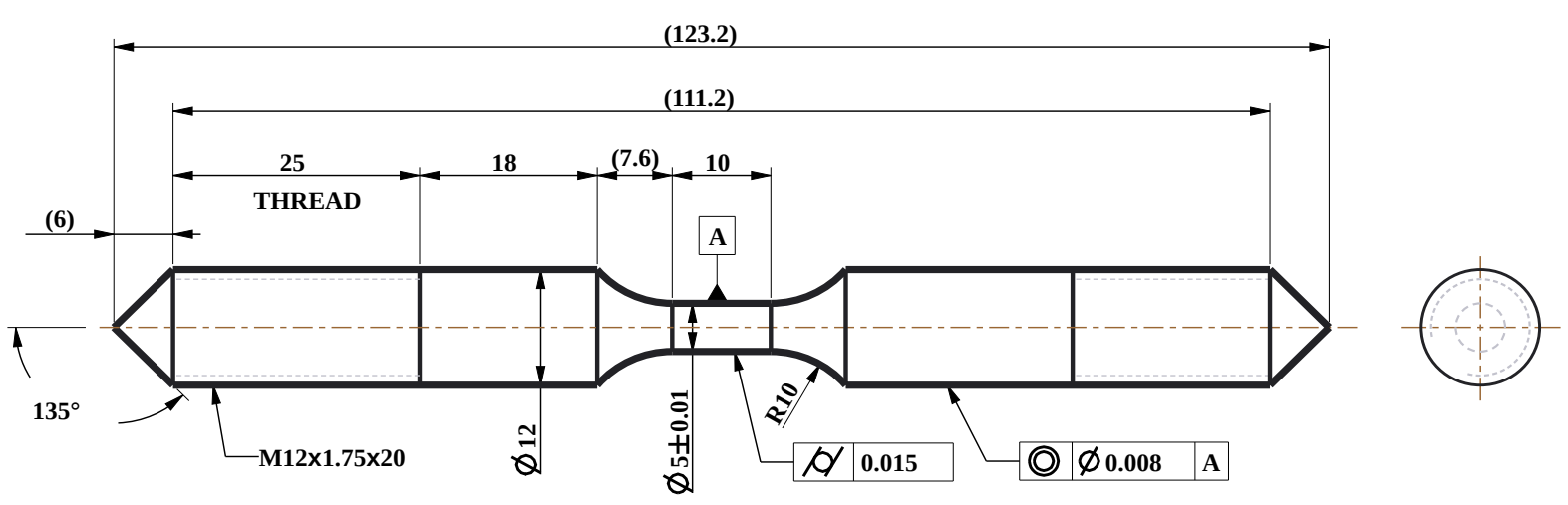

Figure 1: Uniaxial fatigue test samples used for the experimental work (all dimensions given in $\mathrm{mm}$ ). 
Fully-reversed tests with zero- and hold-tensile periods as shown in Figure 2(a-b) were conducted using a closed-loop servo hydraulic testing machine equipped with a high-temperature furnace. Standard triangular and trapezoidal strain time waveforms (namely Sawtooth, SWT, and Dwell-type, DWT, respectively) were first employed at a constant strain rate of $0.01 \% . \mathrm{s}^{-1}$ and a load ratio of - 1 to investigate the accelerated cyclic softening, the decelerated stress relaxation behaviour and deformation energy variations. For the DWT, hold durations of 3 hours at the first cycle and 30 mins at the subsequent cycles were applied to ensure a quasi-equilibrium state of the viscous stress. These hold durations were determined to be sufficient to highlight and distinguish both fatigue and relaxation induced damage. Anhysteretic waveforms wherein 45 min hold periods were applied during tensile loading at strain levels equalling to $0.1 \%, 0.2 \%$, $0.3 \%, 0.4 \%, 0.5 \%$ and $0.6 \%$. A schematic representation of these tests is given in Figure 2(c). Tests were initiated by two anhysteretic waveforms followed by 50 sawtooth waveforms, followed by two anhysteretic waveforms, and so on. Hold period durations were defined such that both short- and long-term viscoelastic material behaviours could be determined. Finally, cyclic creep-recovery tests were performed under different stress ranges for hold periods equalling to 2.5 hours in tensile region and 6 hours at zero stress (see Figure 2(d)). These tests were designed to study the long-term viscosity effects at several stress levels chosen below and above the yield strength, $\sigma_{k}$. The stress values were thus selected to be $90 \%, 120 \%, 150 \%, 180 \%$ and $210 \%$ of the yield strength which the approximate values are given in Table 2. Four temperatures were selected during the testing: $400^{\circ} \mathrm{C}, 625^{\circ} \mathrm{C}, 650^{\circ} \mathrm{C}$ and $675^{\circ} \mathrm{C}$. These were monitored by three thermocouples attached to the test samples, with temperature variations not exceeding $\pm 1^{\circ} \mathrm{C}$. It is worth nothing that for high temperature steels, the creep mechanisms become increasingly significant at temperatures above $300-400^{\circ} \mathrm{C}$ (Rae et al., 2019). The reason for having the temperature gap between $400^{\circ} \mathrm{C}$ and $625^{\circ} \mathrm{C}$ is i) to emphasize the fatigue plasticity effects as dominant mechanisms in the deformation process and ii) to ensure that the interaction between timedependent (creep viscosity) and time-independent deformation (fatigue plasticity) mechanisms is less pronounced. 
(a)

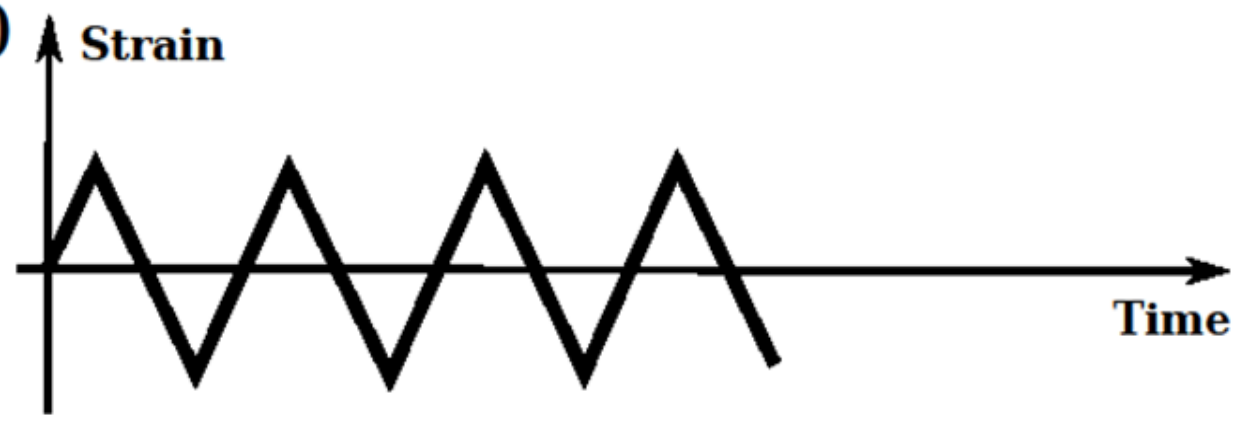

(b)

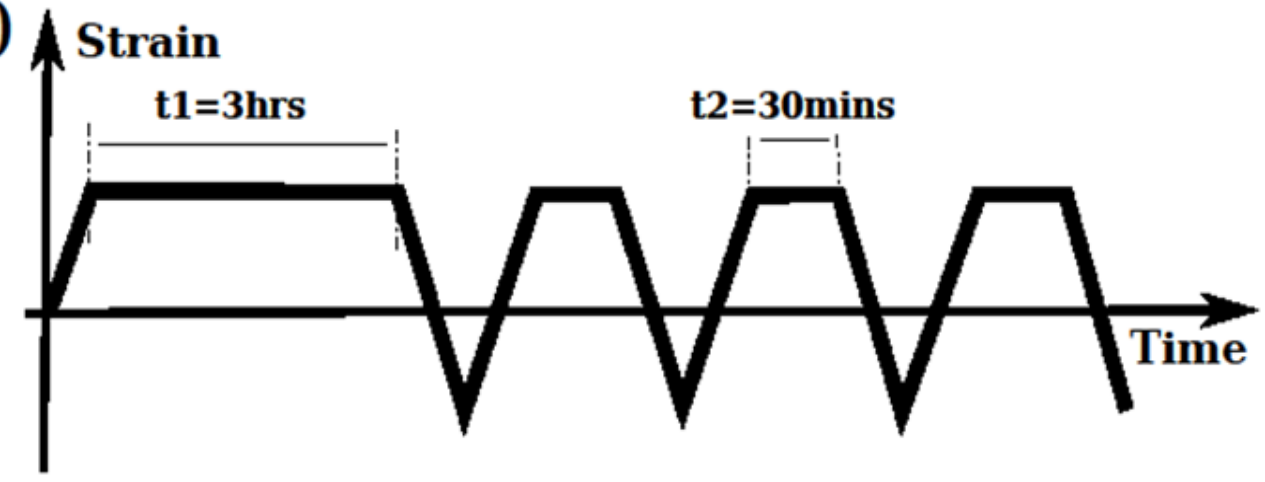

(c)

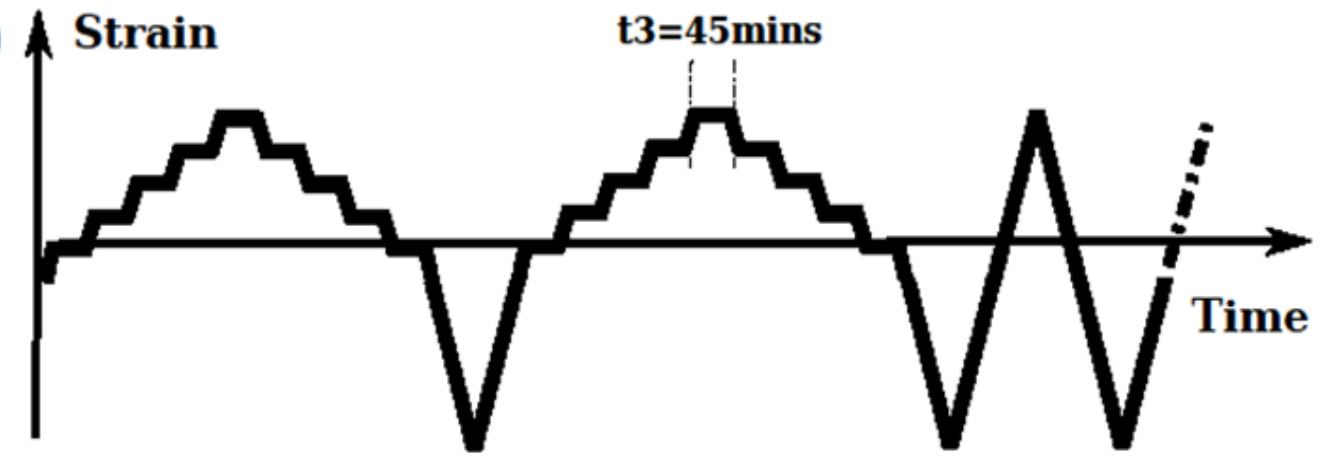

(d)

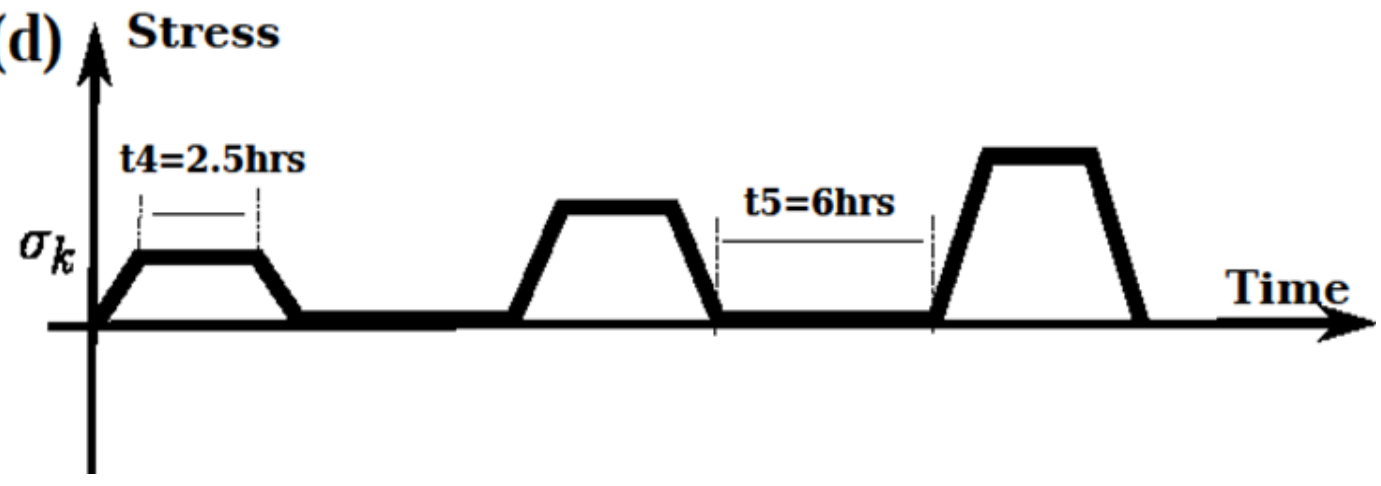

Figure 2: Mechanical waveforms used during the experiments: (a) Saw-tooth tests (SWT), (b) Dwell-type tests (DWT), (c) Anhysteretic tests (ANH) and (d) Cyclic Creep-recovery tests (CRT). 
Table 2: Mechanical properties of the investigated MarBN steel. E stands for the Young's modulus, while $\sigma_{k}$ denotes the initial yield strength measured through the first loading cycle at the selected test temperature.

\begin{tabular}{lcccc}
\hline Temperature $\left({ }^{\circ} \mathbf{C}\right)$ & $\mathbf{4 0 0}$ & $\mathbf{6 2 5}$ & $\mathbf{6 5 0}$ & $\mathbf{6 7 5}$ \\
\hline$E(\mathrm{GPa})$ & 395.2 & 163.8 & 155.3 & 106.3 \\
\hline$\sigma_{k}(\mathrm{MPa})$ & 187.3 & 129.6 & 120.5 & 94.7 \\
\hline
\end{tabular}

Topography of fracture surfaces was examined using Secondary Electron (SE) imaging in a JEOL JSM-7800F Field Emission Gun (FEG) Scanning Electron Microscope (SEM) at an accelerating voltage of $5 \mathrm{kV}$. The gauge portion was further bisected along the longitudinal direction for detailed metallographic examination and hardness mapping after standard metallographic preparation process finished with a chemomechanical polishing process using a suspension of $0.06 \mu \mathrm{m}$ colloidal silica. The microstructure close to the fracture surface was examined using Electron Backscatter Diffraction (EBSD) in the JEOL JSM-7800F FEG-SEM equipped with an Oxford Instruments Nordlys MAX2 camera. EBSD maps were collected at an accelerating voltage of $20 \mathrm{kV}$ with a step size of $1 \mu \mathrm{m}$ to provide an overview of microstructure from an area measuring $300 \times 300 \mu \mathrm{m}$. For more detailed EBSD mapping, analysis was carried out at a step size of 0.1 $\mu \mathrm{m}$ to collect maps $50 \times 50 \mu \mathrm{m}$ in size. Hardness testing was conducted on the cross-sections of ruptured specimen using a Struers Durascan 70 hardness testing system equipped with a Vickers indenter. Ten individual measurements were conducted in the regions close to the boundary between gauge and head portions using a loading weight of $10 \mathrm{~kg}$ and a dwell time of $10 \mathrm{~s}$. A hardness map was further collected from the region close to fracture surface using a loading weight of $0.2 \mathrm{~kg}$ with an interval of $0.1 \mathrm{~mm}$ between individual indents. Each hardness map contains over 1,500 hardness indents, covering an area of $5 \times 3 \mathrm{~mm}$.

\section{Results and discussions}

\subsection{Mechanical characterization}

Three parameters were introduced to discuss and evaluate variations in hysteresis loops for both SWT and DWT: i) the hysteresis area, which represents the deformation energy lost 
during the loading, ii) the stress amplitude variations which highlight the cyclic softening related to microstructure change and damage, and iii) the viscous stress changes which reflect the relaxation behaviour.

\subsubsection{Low Cycle Fatigue Behaviour}

In order to better understand the low cycle fatigue behaviour of the MarBN steel, typical cyclic stress-strain responses for the SWT at the selected temperatures are plotted in Figure 3. In each case, the hysteresis responses are shown as engineering stress versus engineering strain at different life stages to highlight the whole low cycle fatigue life of the MarBN steel. Conclusions can be extracted from the SWT hysteresis variations as follows:

- The rate of change of deformation resistance is large during the early cycles of the tests. This rate diminishes and never reaches a stable condition after enough cycles;

- Lower temperature ranges show higher maximum stresses. At the second cycle, the hysteresis responses indicate $600 \mathrm{MPa}$ for $400^{\circ} \mathrm{C}, 360 \mathrm{MPa}$ for $625^{\circ} \mathrm{C}, 320 \mathrm{MPa}$ for $650^{\circ} \mathrm{C}$ and $290 \mathrm{MPa}$ for $675^{\circ} \mathrm{C}$. These maximum stresses decrease with increasing number of cycles highlighting the significance of cyclic softening;

- An unsymmetrical hysteresis loop in shape is observed for the mid-life cycle loops compared with the first cycle loops;

- The hysteresis loops are crescent shaped and shrank with a point tail in the compressive region at the last stages before the macroscopic rupture. This observation has been reported for many high temperature steels (Rae et al., 2019));

- The area of hysteresis loops never stabilizes completely till the macroscopic failure. Although the changes in the hysteresis loops are less at the last stages, the later keep shifting;

- The fatigue lifetime increases when decreasing the test temperature. The mechanical responses indicate a fatigue life of 520 cycles for SWT $400^{\circ} \mathrm{C}, 480$ cycles for both SWT $625^{\circ} \mathrm{C}$ and $650^{\circ} \mathrm{C}$, and 280 cycles for SWT $675^{\circ} \mathrm{C}$. 

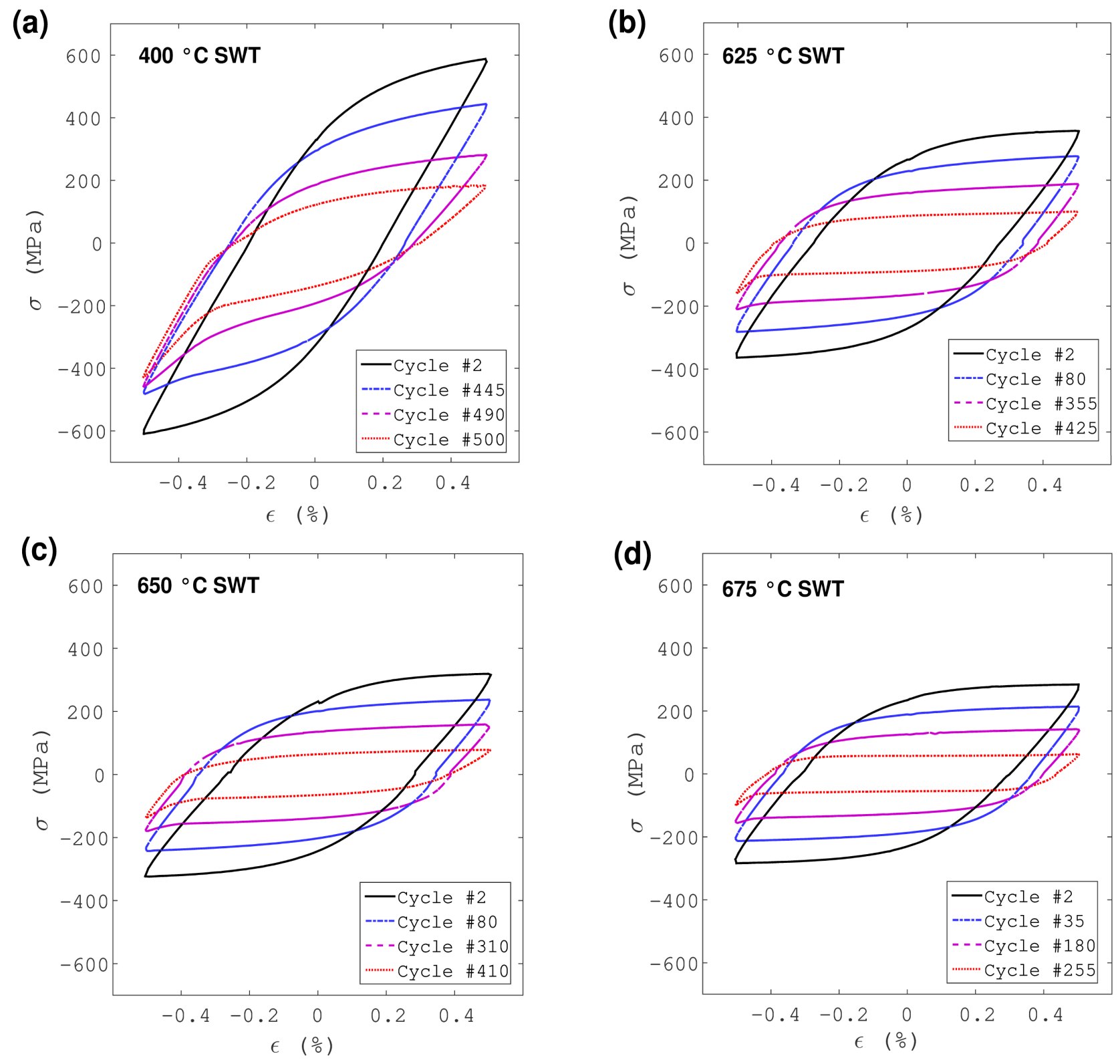

Figure 3: Stress-strain plots extracted for SWT conducted on MarBN steel under different temperatures $\left(400^{\circ} \mathrm{C}\right.$, $625^{\circ} \mathrm{C}, 650^{\circ} \mathrm{C}$ and $\left.675^{\circ} \mathrm{C}\right)$.

\subsubsection{Fatigue-Relaxation Behaviour}

Fatigue-relaxation responses of the MarBN steel have been further compared and presented in Figure $4(\mathrm{a}-\mathrm{c})$ for applied temperatures of $625^{\circ} \mathrm{C}, 650^{\circ} \mathrm{C}$ and $675^{\circ} \mathrm{C}$. The stress relaxation responses during the first, second and middle-life tensile hold times are also plotted in Figure 4(d-f). Some conclusions can be drawn from the DWT hysteresis variations:

- Identical hysteresis variations to those reported for SWT are seen from Figure 4(top) with 
slight reductions in the fatigue life. The reason for the reduced fatigue life is essentially due to application of hold. In addition to fatigue damage due to cyclic loading, viscous damage is also accumulated during the hold periods. This observation will be consolidated later by microstructure investigations conducted on ruptured MarBN samples.

- The viscous stress reduction rate is significant at the very beginning of the relaxation and then it reaches its quasi-stabilized value after 30 minutes of the holding. The stress relaxes to approximately $219 \mathrm{MPa}$ for $625^{\circ} \mathrm{C}, 178 \mathrm{MPa}$ for $650^{\circ} \mathrm{C}$ and $154 \mathrm{MPa}$ for $675^{\circ} \mathrm{C}$; it decreases with increasing temperature.

- The amount of stress relaxation during hold time varies with the number of cycles (each cycle has therefore a different average relaxation stress, see Figure 4(bottom) and Table 3). The reduction of the viscous stress is much more pronounced for the $625^{\circ} \mathrm{C}$ DWT. 

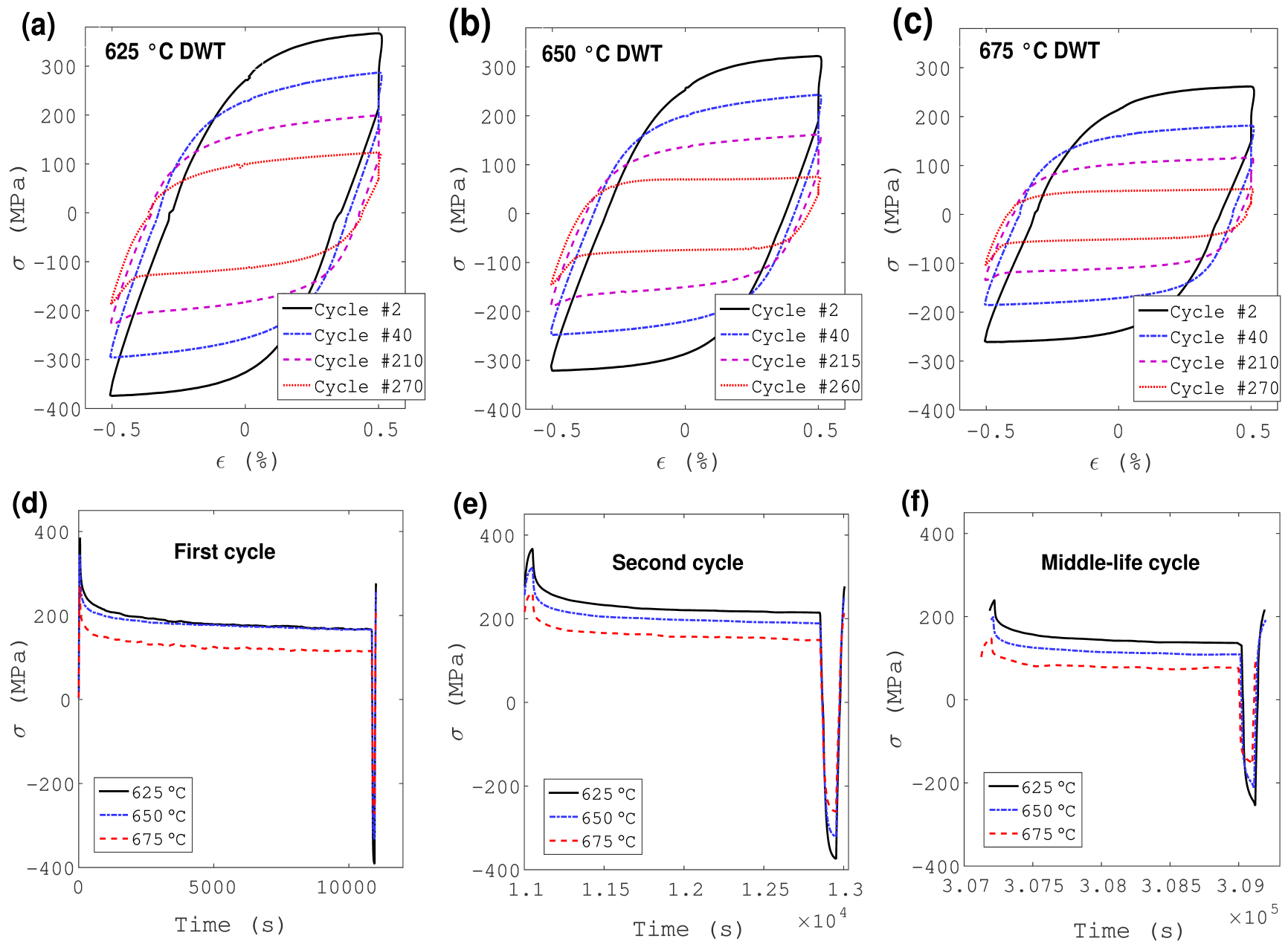

Figure 4: (top) A comparison of experimental results for DWT conducted on MarBN steel at (a) $625^{\circ} \mathrm{C}$, (b) $650^{\circ} \mathrm{C}$ and (c) $675^{\circ} \mathrm{C}$. (bottom) The stress versus time response highlighting the relaxation behaviour of the MarBN steel for (d) the first cycle, (e) second cycle and (f) middle-life cycle.

Table 3: Reduction in the viscous stress for the selected temperatures at different fatigue life stages.

\begin{tabular}{llll}
\hline Temperature & First cycle & Second cycle & Middle-life cycle \\
\hline $625^{\circ} \mathrm{C}$ & $218 \mathrm{MPa}$ & $152 \mathrm{MPa}$ & $103 \mathrm{MPa}$ \\
\hline $650^{\circ} \mathrm{C}$ & $178 \mathrm{MPa}$ & $133 \mathrm{MPa}$ & $90 \mathrm{MPa}$ \\
\hline $675^{\circ} \mathrm{C}$ & $154 \mathrm{MPa}$ & $112 \mathrm{MPa}$ & $71 \mathrm{MPa}$ \\
\hline
\end{tabular}

\subsubsection{Cyclic softening and mechanical energy variations}

To deeply characterize the low cycle fatigue behaviour of the MarBN steel, the stress range, $\Delta \sigma$, and hysteresis area, $A_{h}$, evolutions for both SWT and DWT at the test temperatures are 
compared in Figure 5(a-b). In Figure 5(a), a continuous cyclic softening (a decrease in the stress amplitude) is observed for all test temperatures and loading conditions. A large amount of softening from the first cycle onwards occurs, after which a gradual change in the stress values under all test conditions is detected. Three stages can be distinguished in the stress amplitude plots. The first stage is characterized by a gradual decrease in both tensile and compressive peak stress (due to inelastic strain). The second stage shows a steady state with a constant rate of the cyclic softening. In the last stage, a significant decrease in the stress amplitude is observed (due to damage localizations and increase in the inelastic strain). The amount of softening and the softening rates are accelerated at higher test temperatures, while the hold has a slight impact on this behaviour. Moreover, experimental findings also indicate a gradual decrease of the deformation energy density during the fatigue process. The hysteresis area evolution reveals that the deformation energy density decreases with increasing number of cycles, and this decrease is found more pronounced for high test temperatures as shown in Figure 5(b).
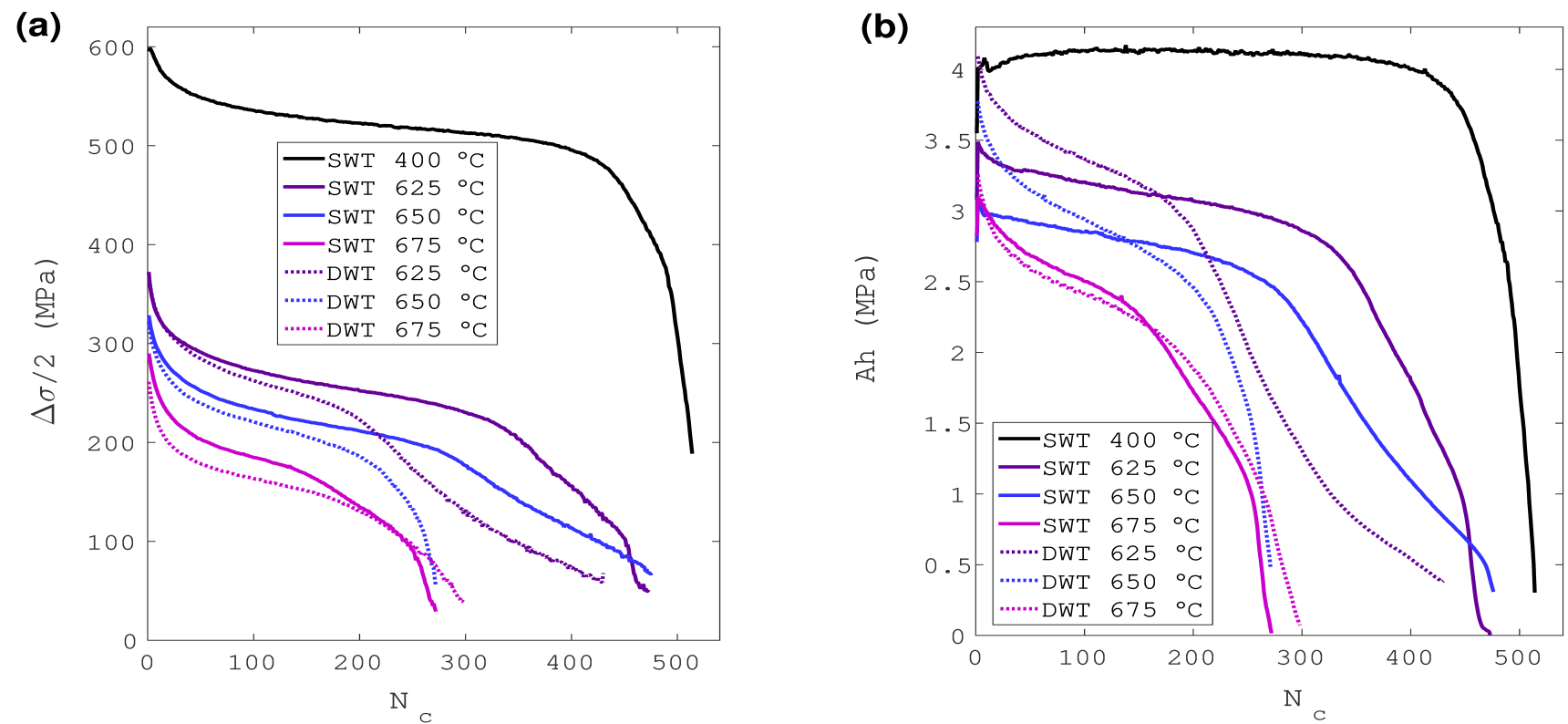

Figure 5: A comparative plot of hysteresis variations for both SWT and DWT at the selected temperatures, highlighted by (a) the stress amplitude evolution, $\Delta \sigma / 2$, and (b) the hysteresis area reduction, $A_{h}$.

\subsubsection{Anhysteretic behaviour}

Anhysteretic tests with path symmetry during the unloading have been conducted to investigate the long-term viscous effects (below and above the yield) and also to reach and reveal the 
equilibrium stress response of the material at different strain levels. The reason of conducting such experimental investigation is motivated by the fact that some conventional power plant components are exposed to elevated temperature conditions that activate significant amounts of creep (long term viscous effects) for stress much lower than any reasonable interpretation of yield (Cortellino et al., 2017). So, it is of great interest to characterize the material behaviour below the yield and see if it remains elastic. Indeed, in many practical implementations of High-Cr steels, stress magnitudes are considered in the elastic regime and viscous effects are entirely attributed to viscoplastic mechanisms where viscous strain accumulation is only possible at stresses greater than the yield. This experimental investigation by conducting such advanced tests attempts to demonstrate the importance of incorporating viscoelastic effects (even below the yield) in the commonly implemented elasto-viscoplastic constitutive Chaboche type models (Chaboche, 2008).

The cyclic anhysteretic tests presented hereafter include several relaxation plateaus with strain levels that allow to work below and above the yield stress. Figure 6 shows the anhysteretic responses at the selected test temperatures studied over a large range of imposed strains. Several conclusions can be pointed out from the results:

- At the first relaxation step, the material exhibits a highly temperature dependent viscous behaviour. In Figure $6(\mathrm{~d})$, the stress relaxes to approximately $98 \mathrm{MPa}$ for $625^{\circ} \mathrm{C}, 78 \mathrm{MPa}$ for $650^{\circ} \mathrm{C}$ and $75 \mathrm{MPa}$ for $675^{\circ} \mathrm{C}$, values which are below that of the yield stress of the MarBN steel (circa $130 \mathrm{MPa}$ for $625^{\circ} \mathrm{C}, 102 \mathrm{MPa}$ for $650^{\circ} \mathrm{C}$ and $94 \mathrm{MPa}$ for $675^{\circ} \mathrm{C}$ ).

- The viscous effects occur on a long-time scale. Although strain levels are increasing, the relaxation stress amplitudes at the last relaxation steps are similar, Figure 6(b-c).

- The anhysteretic loops become contracted and shrank at the second anhysteretic block with a same hardening behaviour as that observed within the previous sawtooth cycles, Figure 6(e-f).

- During the unloading, the relaxed stress amplitude is almost the same for all applied temperatures; this observation is not valid at compressive region where the relaxed stress 
variations show a highly temperature dependent response.

- The cyclic response of the investigated material shows irrecoverable strains below and above what is considered as the yield stress of the MarBN steel. It is however difficult to conclude whether residual strains stem from (visco-) plastic flow or from very long-term recoverable viscosity. 

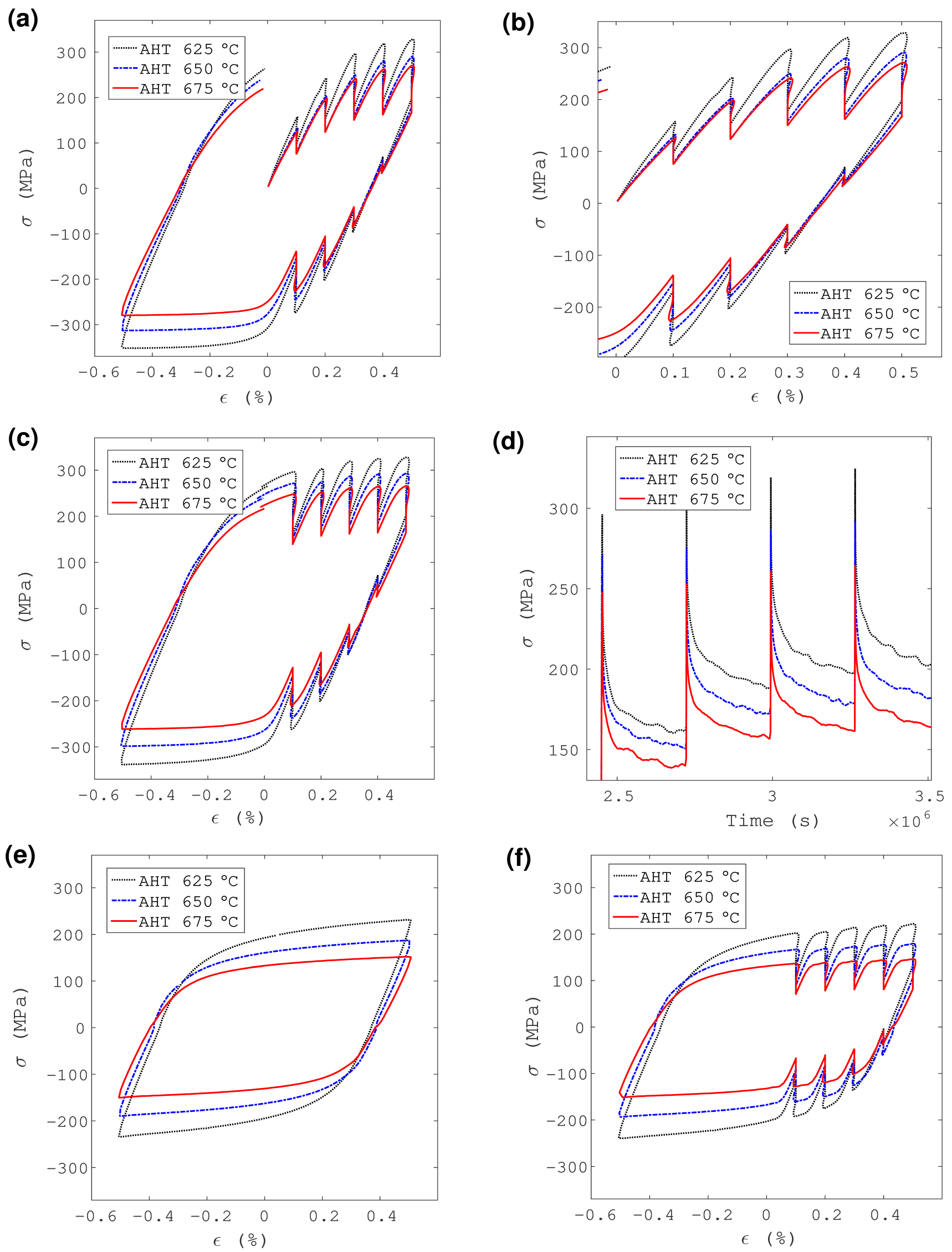

Figure 6: Anhysteretic responses of the MarBN steel at the selected temperatures. Figures are arranged to show $(a-b)$ material response at the first anhysteretic cycle, (c) material response at the second anhysteretic cycle, (d) relaxation response at the ongoing tensile region of the second anhysteretic cycle, (e) material response during the last sawtooth test of the first block and (f) anhysteretic response of the first cycle of the second block. 


\subsubsection{Cyclic creep-recovery behaviour}

Cyclic creep-recovery tests, CRT, have been performed to deeply investigate the long-term viscosity effects at several stress levels. These tests are designed to distinguish between long-term viscoelastic and viscoplastic mechanisms. Figure 7(a) shows the axial strain versus time plots of the MarBN steel extracted from CRT conducted under different stress levels for the $625^{\circ} \mathrm{C}$ test temperature. The corresponding mechanical response is given in Figure 7(b). It can be noted from the plots that at low stress levels, time-dependent effects are pronounced with inelastic strain partially recovered (around 0.05\%). At higher stress levels, large amounts of irrecoverable strain appear which are considered to be consequence of a significant viscoplastic flow. These residual strains seem to accumulate cycle after cycle with values of $0.42 \%$ at $210 \%$ of the yield strength. Finally, the ratcheting behaviour is observed in Figure 7(b) highlighted by the shifting of the hysteresis loops.
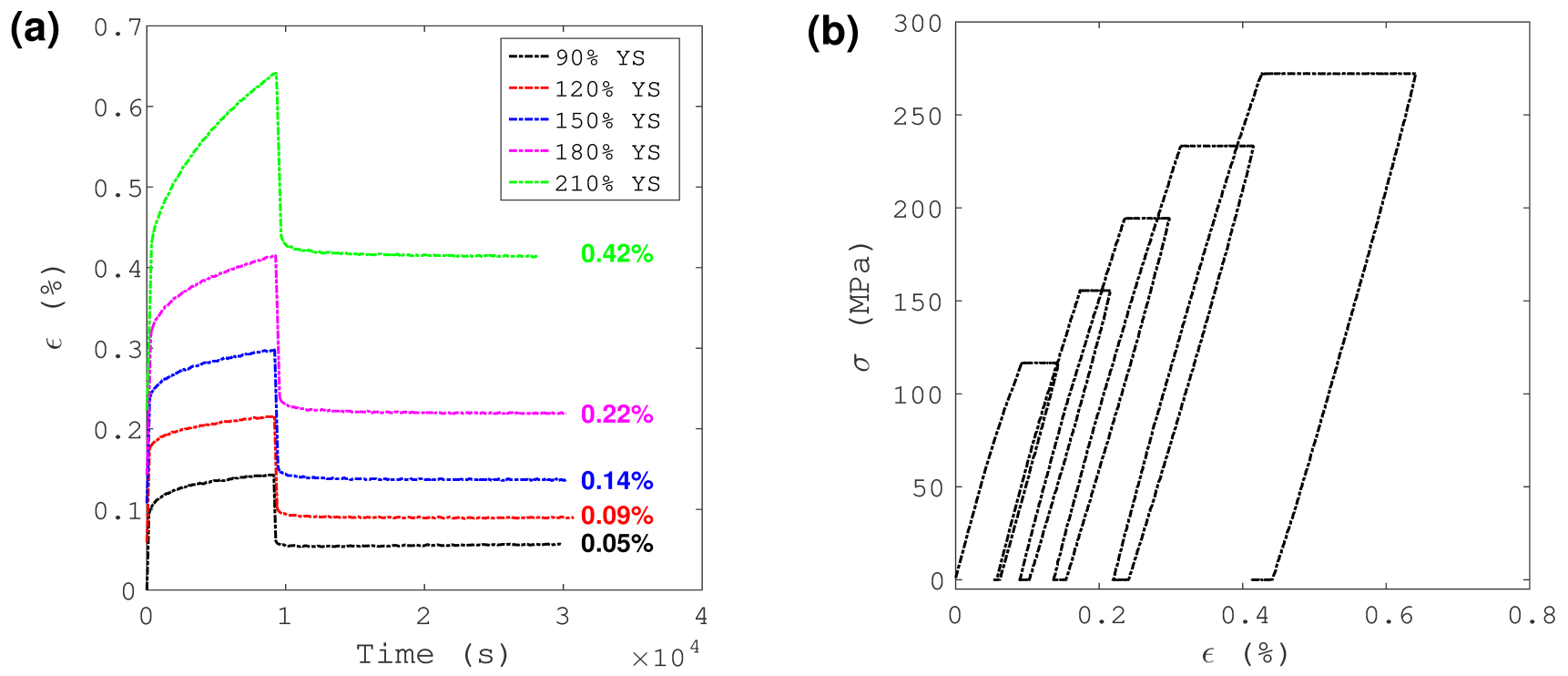

Figure 7: Cyclic creep-recovery tests for the $625^{\circ} \mathrm{C}$ test temperature conducted at several stress levels until failure: (a) the axial strain versus time plot highlighting the un-recovered strain stored within the material; (b) the associated mechanical response showing the cyclic ratcheting effect.

\subsection{Material characterisation}

Ruptured specimens were examined in detail after SWT, DWT and CRT to investigate the variation in deformation and rupture behaviour upon different testing conditions. Fractography examination was conducted on the fracture surfaces of specimens, followed by detailed metallo- 
graphic examination using EBSD and micro-hardness mapping.

\subsubsection{Fractography Examination}

Topography of the samples' fracture surfaces was examined using SE imaging on the specimens experiencing SWT, DWT and CRT at $625^{\circ} \mathrm{C}$, Figure 8 .
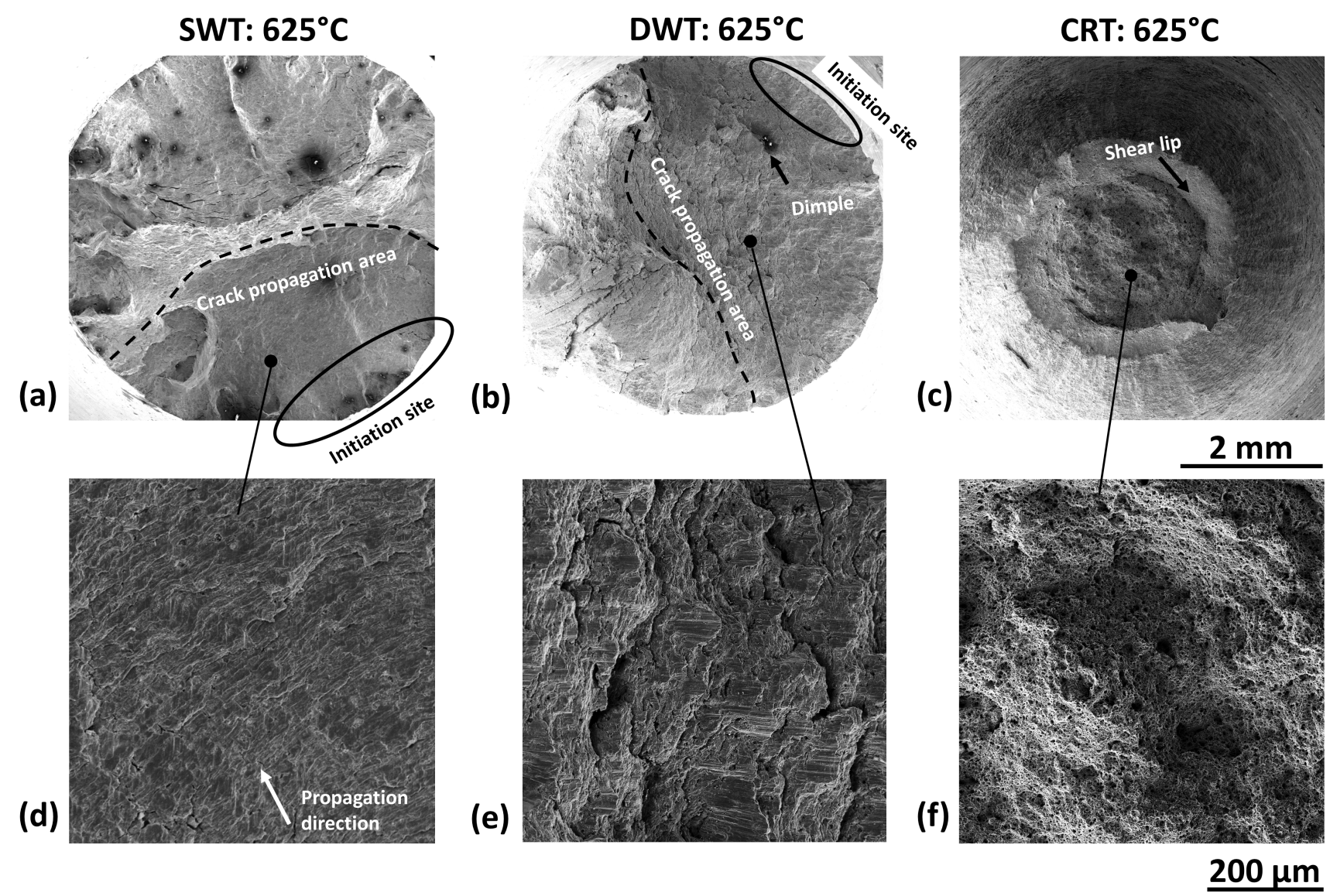

Figure 8: Topography of fracture surface after (a and d) SWT, (b and e) DWT and (c and f) CRT at $625^{\circ} \mathrm{C}$.

Figure $8\left(\mathrm{a}\right.$ and $\mathrm{d}$ ) demonstrate that the specimen experiencing SWT at $625^{\circ} \mathrm{C}$ was ruptured as a result of fatigue crack propagation. The major crack was initiated from the outer surface of the specimen, followed by rapid crack propagation (contoured by dashed lines) as marked by fatigue striations aligned perpendicular to the propagation direction. The regions of crack initiation are small in area and not distinctively differentiated from the area of crack propagation due to rapid crack propagation. The specimen experiencing DWT at $625^{\circ} \mathrm{C}$ (Figure $8 \mathrm{~b}$ ) was ruptured in a similar manner as compared to the specimen experiencing SWT. This is evidenced by the presence of striations and dimples on fracture surface, Figure 8(b and e)). A larger interspacing 
distance between striations was observed after DWT testing as a result of holding period in each loading cycle. The transgranular fracture surface observed after DWT is consistent with the previous observations from similar $9-12 \% \mathrm{Cr}$ martensitic steels upon stress/strain-controlled dwell fatigue testing conducted at similar conditions (Fournier et al., 2008). The transition in rupture behaviour between SWT and DWT specimens suggests that the hold duration during DWT imposes a dominating effect over the influence of cyclic loading on the manner of rupture. The specimen experiencing CRT was ruptured in a ductile manner as evidenced by a dimpled surface, Figure 8(c and f). The dimpled topography of fracture surface has been previously observed after tensile testing (Mishnev et al., 2016) and short-term creep testing (Benaarbia et al., 2018b) conducted in the high temperature regime as a result of plasticity instability. The rupture of CRT specimen was therefore considered to take place in a transgranular manner via the coalescence of plasticity induced micro-voids during the hold duration at a stress level above the yield strength (Lin et al., 2005).

\subsubsection{EBSD mapping analysis}

EBSD mapping analysis was conducted in the longitudinal cross-section in the as-received state and after SWT, DWT and CRT at $625^{\circ} \mathrm{C}$ in the regions close to the fracture surface, Figure 9. The EBSD maps were collected adjacent to the crack propagation area and the dimpled region as demonstrated in Figure 9 in the SWT/DWT and CRT specimens, respectively. 

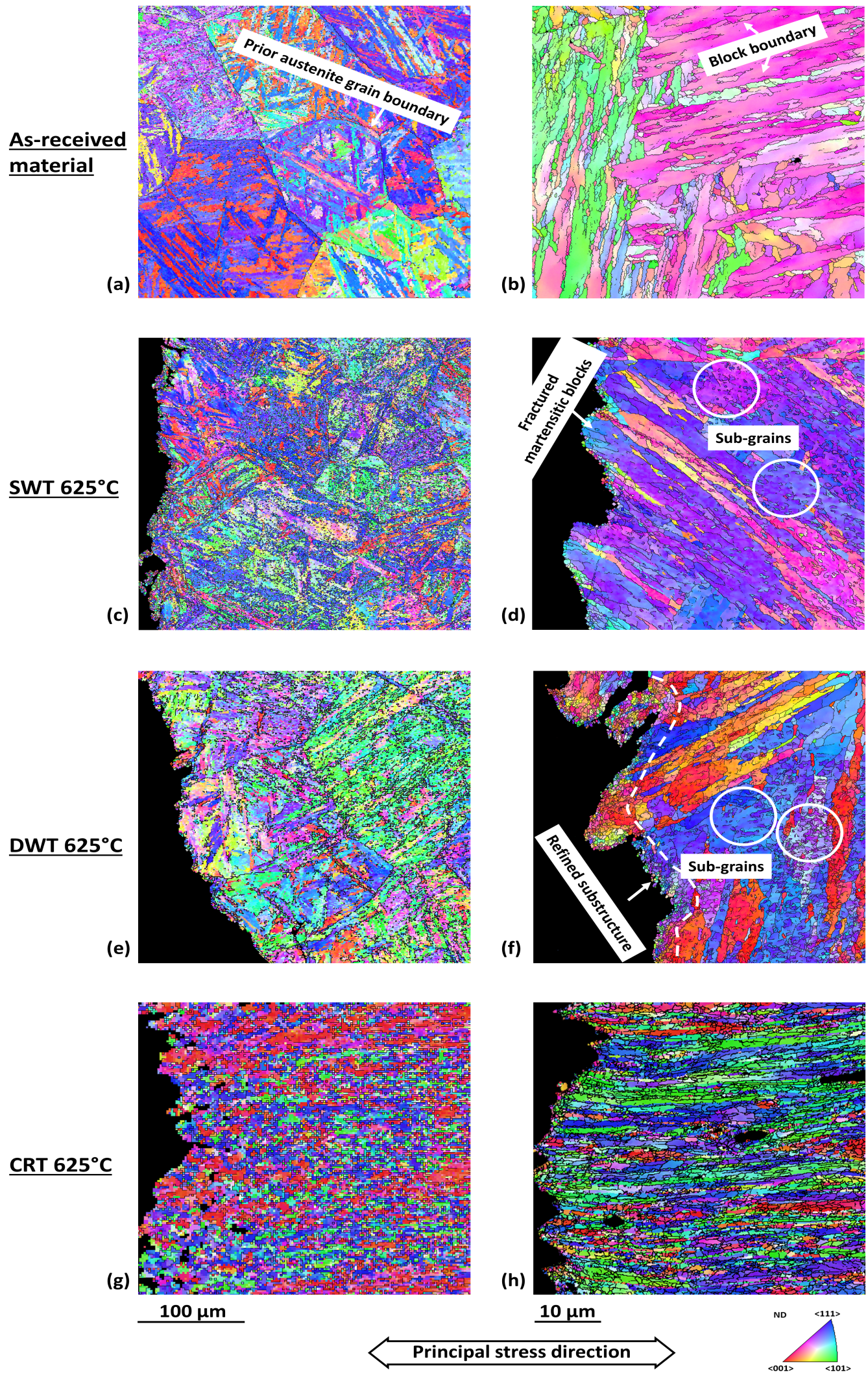

Figure 9: EBSD maps showing ( $a$ and $b$ ) the initial microstructure in the as-received state and the microstructure in the regions adjacent to the fracture surfaces after (c and d) SWT, (e and f) DWT and ( $g$ and h) CRT at $625^{\circ} \mathrm{C}$. Typical regions demonstrating a refined grain structure are indicated by white circles in (d) and (f). 
The initial microstructure in the as-received state is composed of Prior Austenite Grains (PAGs) that are $>200 \mu \mathrm{m}$ in diameter (Figure 9(a)) and elongated martensitic blocks with a width between 2 and $5 \mu \mathrm{m}$, Figure 9(b). Figure 9(c and e) demonstrate that the original PAG structure was not significantly changed during SWT and DWT, whereas the formation of sub-grains that are $<1 \mu \mathrm{m}$ in diameter was extensively observed within the martensitic blocks, Figure 9(d and f). This is consistent with existing observations from similar $9-12 \% \mathrm{Cr}$ steels demonstrating similar resultant microstructures after LCF exposure (Mishnev et al., 2016; Verma et al., 2016). The extensive formation of sub-grains within the martensitic substructure was attributed to the transformation from an unstable martensitic lath structure to a cellular substructure via the rearrangement of pre-existing dislocations at the elevated temperatures (Mishnev et al., 2016). The formation of sub- grains is therefore considered to result in a decrease in dislocation density and cause cyclic softening as observed in Figure 5.

In addition, significant structural refinement has been observed in the region $<5 \mu \mathrm{m}$ from the fracture surface in the DWT specimen (Figure 9(f)), whereas the refinement of the martensitic substructure was not evident in the SWT specimen. The presence of structural refinement in martensitic steels has been previously reported as a consequence of significant plastic deformation at a high strain rate (Huang et al., 2012; Zhang et al., 2015). This further suggests that the deformation and rupture of the specimen experiencing DWT is involved with plasticity related mechanisms.

The specimen experiencing CRT demonstrates a significantly refined microstructure in the region close to the fracture surface, Figure $9(\mathrm{~g}$ and $\mathrm{h})$. The original PAG structure and the martensitic substructure were both refined to an equiaxed morphology, with the vicinities corresponding to the original martensitic blocks distorted along the principal stress direction, Figure 9(h). The significant refinement of the original martensitic microstructure has been observed from similar materials upon rapid plastic deformation at elevated temperature (Huang et al., 2012; Zhang et al., 2015; Benaarbia et al., 2018b). The CRT specimen was therefore considered to experience significant plastic deformation prior to rupture.

\subsubsection{Hardness mapping}


Hardness measurement was firstly performed in the as-received MarBN steel prior to LCF testing at a loading weight of $10 \mathrm{~kg}$ and $0.2 \mathrm{~kg}$. The values of hardness obtained from the as-received material are measuring $249 \pm 2 \mathrm{HV} 10$ and $261 \pm 8 \mathrm{HV} 0.2$ at different testing conditions. Hardness measurement was further conducted close to the boundary between gauge and head portions of SWT and DWT specimens at a loading weight of $10 \mathrm{~kg}$. The hardness values obtained from the specimens experiencing SWT and DWT at $625^{\circ} \mathrm{C}$ are $271 \pm 3$ and $260 \pm 8$ HV10, respectively. The variation of hardness in the region close to fracture surface was further characterised using hardness mapping analysis at a loading weight of $0.2 \mathrm{~kg}$ after SWT and DWT at $625^{\circ} \mathrm{C}$, Figure 10 .

Figure 10(a) demonstrates that hardness varies between 198 and 229 HV0.2 in the region < $4 \mathrm{~mm}$ away from fracture surface in the specimen experiencing SWT at $625^{\circ} \mathrm{C}$. The hardness in the regions closer to the head portion (i.e. $>4 \mathrm{~mm}$ from fracture surface) is higher and in the range between 242 and 291 HV0.2 in the same specimen, Figure 10(a). The variation of hardness is not evident without a clear trend in the specimen experiencing DWT, Figure 10(b). Hardness varies between 218 and 247 HV0.2 in the gauge portion of the specimen experiencing DWT. The hardness values measured from the gauge portion are considerably lower than the values measured from the as-received material (i.e. $261 \pm 8$ HV0.2). The lower hardness in the gauge regions close to the fracture surface has further confirmed the deterioration of matrix properties upon LCF exposure at both the SWT and DWT conditions. The transformation of martensitic substructure and the decrease of dislocation density accompanied by the formation of sub-grains may cause a decrease in the hardness and the stress amplitude measured from cyclic fatigue testing, Figure 10. The value of hardness as measured from the region close to the fracture surface of the CRT specimen is evidently higher than the region further away. This can be attributed to a higher volume density of dislocations in the region close to the fracture surface upon the occurrence of necking due to localised plasticity instability (Benaarbia et al., 2018b). This is further evidenced by the observation of significantly distorted and refined martensitic microstructure as shown in Figure 9. 


\section{SWT $625^{\circ} \mathrm{C}$}

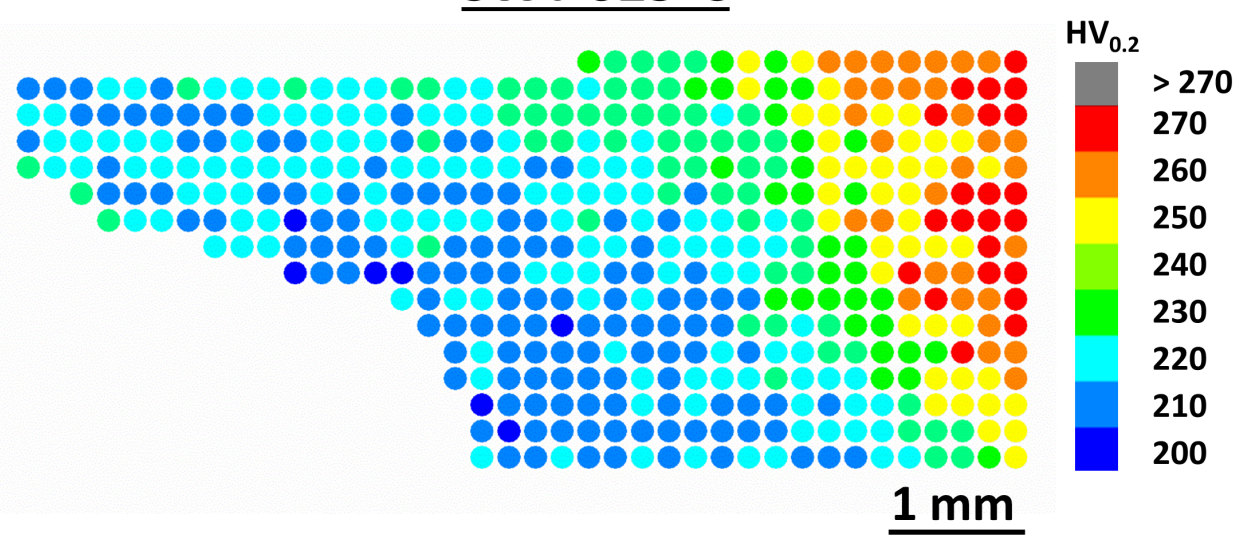

\section{DWT $625^{\circ} \mathrm{C}$}

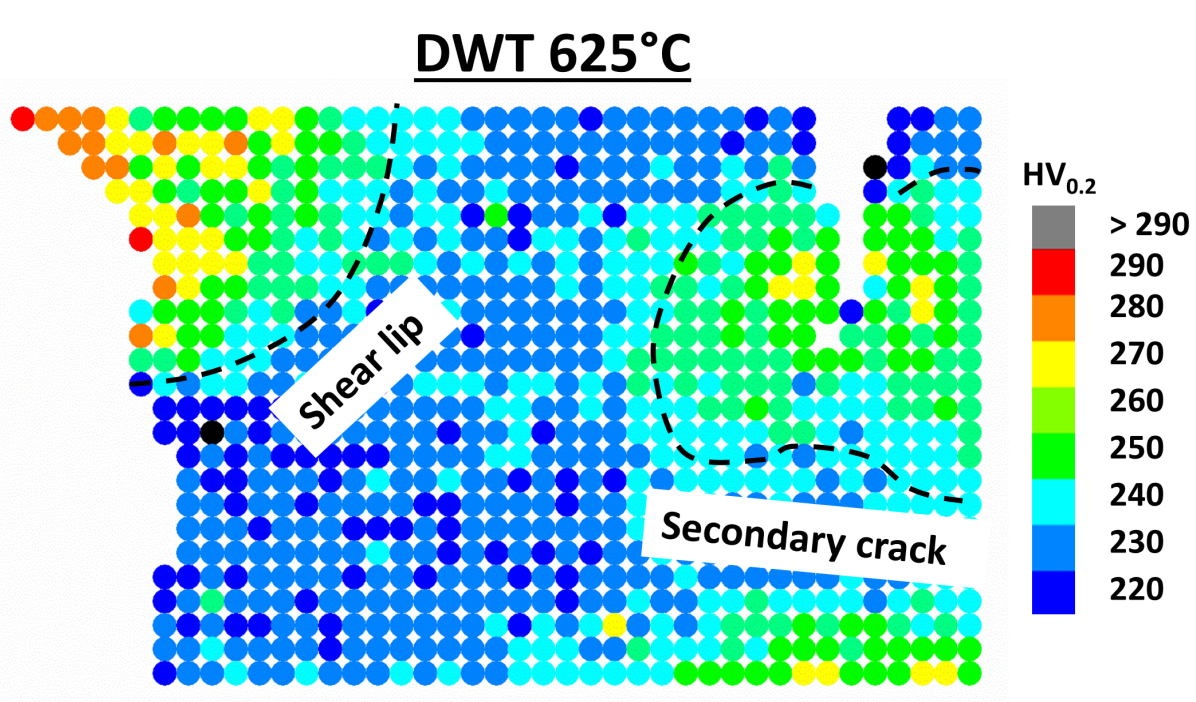

(b)

$1 \mathrm{~mm}$

\section{CRT $625^{\circ} \mathrm{C}$}

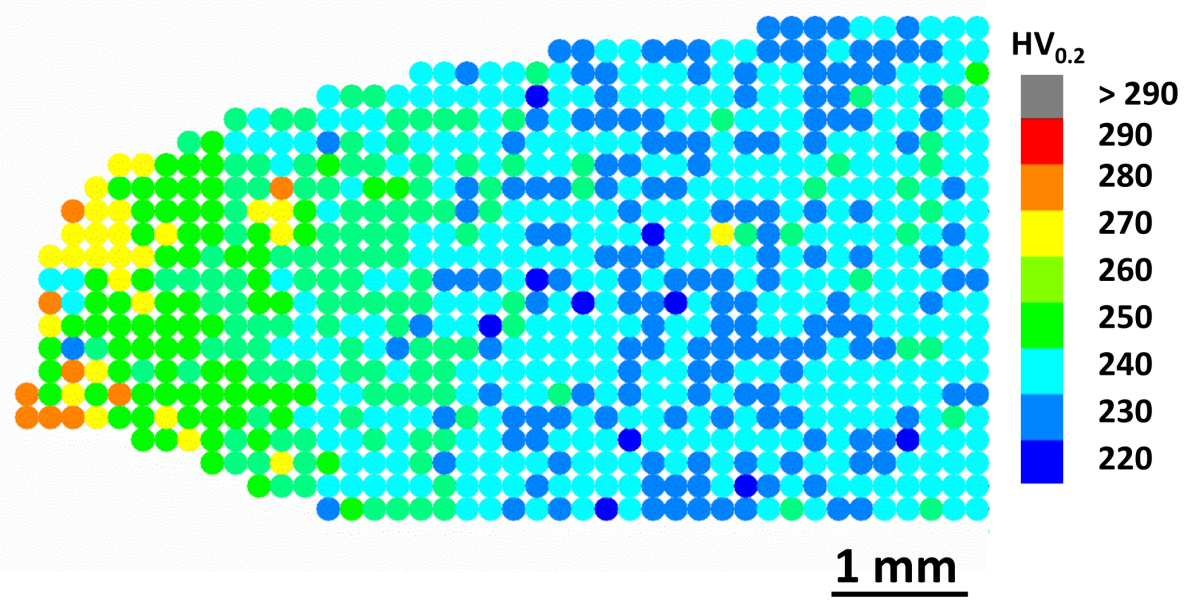

Principal stress direction

Figure 10: Hardness maps collected from the regions close to fracture surfaces in the specimens experiencing (a) SWT, (b) DWT and (c) CRT at $625^{\circ} \mathrm{C}$. 


\section{Conclusions and future work}

Extensive experimental work has been conducted to investigate the high temperature low cycle fatigue behaviour of MarBN steel at bulk and micro-scales. Fully-reversed tests with zero- and hold-tensile periods, anhysteretic tests with hold- tensile periods at ascending strain levels, and cyclic creep-recovery tests at different stress ranges, were conducted. The mechanical investigations were combined with microstructural analyses (through SEM, EBSD and hardness mapping) to further emphasize the leading deformation mechanisms. The main conclusions are listed below:

- A continuous accelerated cyclic softening and a decelerated stress relaxation behaviour were observed for all test temperatures. The first was attributed to the accumulated inelastic transformation from the creep mechanism during the dwell period at the peak tensile strain of the fatigue cycle, while the second was ascribed to the reduction in the viscous stress due to the continuous cyclic softening.

- Large amounts of irrecoverable strains below and above the yield were highlighted through AHT, while the viscous effects were found to occur on a long time-scale. The irreversible strains were attributed to either viscoplastic and/or long-term viscous effects.

- Time-dependent effects at low stress levels were pronounced with inelastic strain partially recovered (see the cyclic creep-recovery tests). At higher stress levels large amounts of irrecoverable strains appeared.

- Specimens experiencing SWT were ruptured as a result of fatigue crack propagation. The rupture for specimens experiencing DWT and CRT was considered to take place in a transgranular and ductile manner (evidenced by a dimpled surface) via the coalescence of plasticity induced micro-voids during the hold duration.

- An extensive formation of sub-grains within the martensitic substructure was observed for all test conditions. This was further related with a decrease in dislocation density that causes cyclic softening. A significant structural refinement for the martensitic substructure 
was also observed for both DWT and CRT conditions. This refinement was attributed to the plastic deformation.

- Same hardness variations for both SWT and DWT conditions were reported. The decrease in hardness values was essentially due to the transformation in martensitic substructure.

Based on the conclusions drawn above, future work will focus on the modelling of the viscoplastic behaviour of the MarBN steel at high temperature conditions. This should be undertaken focusing on the incorporation of microstructural features in the model constitutive equations. The inclusion of such microstructural information will undoubtedly enhance the fundamental understanding that the model can provide. Models based on dislocation density should have an enhanced physical meaning. Dislocation densities can thus be incorporated as internal state variables, and their evolution can be modelled based on the storage and annihilation processes for dislocations.

\section{Acknowledgments}

This work is supported by the Engineering and Physical Sciences Research Council (grant numbers: EP/N509991/1 and EP/N509942/1).

The authors gratefully acknowledge the following partners for their valuable contributions: Doosan Babcock, GE Power, Uniper Technologies, Metrode Products, Goodwin Steel Castings and Wyman-Gordon. Specific acknowledgments to GE Power for providing the test material and to Mr. Shane Maskill (University of Nottingham) for his support in the experimental testing.

\section{References}

\section{References}

Abe, F., Tabuchi, M., Semba, H., Igarashi, M., Yoshizawa, M., Komar, N., Fujita, A., 2008. Feasibility of marbn steel for application to thick section boiler components in usc power plant at $650^{\circ} \mathrm{C}$. 5th International Conference on Advances in Materials Technology for Fossil Power Plants, Marco Island, FL, Oct. 3-5 , 92-106. 
Bassi, F., Foletti, S., Conte, A.L., 2015. Creep fatigue crack growth and fracture mechanisms of t/p91 power plant steel. Materials at High Temperatures 32, 250-255.

Batista, M., Marinelli, M., Herenu, S., Alvarez-Armas, I., 2015. The role of microstructure in fatigue crack initiation of $9-12 \% \mathrm{cr}$ reduced activation ferritic-martensitic steel. International Journal of Fatigue 72, $75-79$.

Benaarbia, A., Rouse, J., Sun, W., 2018a. A thermodynamically-based viscoelastic-viscoplastic model for the high temperature cyclic behaviour of $9-12 \%$ cr steels. International Journal of Plasticity 107, $100-121$.

Benaarbia, A., Xu, X., Sun, W., Becker, A., Jepson, M.A., 2018b. Investigation of short-term creep deformation mechanisms in marbn steel at elevated temperatures. Materials Science and Engineering: A 734, $491-505$.

Chaboche, J., 2008. A review of some plasticity and viscoplasticity constitutive theories. International Journal of Plasticity 24, 1642 - 1693. Special Issue in Honor of Jean-Louis Chaboche.

Chen, R., Armaki, H.G., Maruyama, K., Igarashi, M., 2011. Long-term microstructural degradation and creep strength in gr.91 steel. Materials Science and Engineering: A 528, $4390-$ 4394.

Cortellino, F., Rouse, J.P., Cacciapuoti, B., Sun, W., Hyde, T.H., 2017. Experimental and numerical analysis of initial plasticity in p91 steel small punch creep samples. Experimental Mechanics $57,1193-1212$.

Fournier, B., Dalle, F., Sauzay, M., Longour, J., Salvi, M., Caës, C., Tournié, I., Giroux, P.F., Kim, S.H., 2011. Comparison of various $9-12 \%$ cr steels under fatigue and creep-fatigue loadings at high temperature. Materials Science and Engineering: A 528, 6934- 6945.

Fournier, B., Sauzay, M., Caës, C., Noblecourt, M., Mottot, M., Bougault, A., Rabeau, V., Pineau, A., 2008. Creep-fatigue-oxidation interactions in a 9cr-1mo martensitic steel. part i: Effect of tensile holding period on fatigue lifetime. International Journal of Fatigue 30, 649 - 662 . 
Gianfrancesco, D., 2017. Materials for ultra-supercritical and advanced ultra- supercritical power plants. Woodhead Publishing , 1-49.

Guguloth, K., Sivaprasad, S., Chakrabarti, D., Tarafder, S., 2014. Low-cyclic fatigue behavior of modified 9cr-1mo steel at elevated temperature. Materials Science and Engineering: A 604, $196-206$.

Huang, X., Morito, S., Hansen, N., Maki, T., 2012. Ultrafine structure and high strength in cold-rolled martensite. Metallurgical and Materials Transactions A 43, 3517-3531.

Lin, J., Liu, Y., Dean, T.A., 2005. A review on damage mechanisms, models and calibration methods under various deformation conditions. International Journal of Damage Mechanics 14, 299-319.

Mannan, S., Valsan, M., 2006. High-temperature low cycle fatigue, creep-fatigue and thermomechanical fatigue of steels and their welds. International Journal of Mechanical Sciences 48, 160 - 175. 7th Asia-Pacific Symposium on Advances in Engineering Plasticity and its Applications (AEPA 2004).

Mishnev, R., Dudova, N., Kaibyshev, R., 2016. Low cycle fatigue behavior of a 10cr-2w-mo-3conbv steel. International Journal of Fatigue 83, 344 - 355.

Pineau, A., 2014. High temperature fatigue - a comprehensive review. Creep fatigue crack development symposium .

Pineau, A., Antolovich, S.D., 2015. High temperature fatigue: behaviour of three typical classes of structural materials. Materials at High Temperatures 32, 298-317.

Rae, Y., Benaarbia, A., Hughes, J., Sun, W., 2019. Experimental characterisation and computational modelling of cyclic viscoplastic behaviour of turbine steel. International Journal of Fatigue 124, $581-594$.

Saad, A., Hyde, T., Sun, W., Hyde, C., Tanner, D., 2013. Characterization of viscoplasticity 
behaviour of p91 and p92 power plant steels. International Journal of Pressure Vessels and Piping 111-112, $246-252$.

Shankar, V., Bauer, V., Sandhya, R., Mathew, M., Christ, H.J., 2012. Low cycle fatigue and thermomechanical fatigue behavior of modified $9 \mathrm{cr}-1 \mathrm{mo}$ ferritic steel at elevated temperatures. Journal of Nuclear Materials 420, $23-30$.

Shankar, V., Valsan, M., Rao, K.B.S., Kannan, R., Mannan, S., Pathak, S., 2006. Low cycle fatigue behavior and microstructural evolution of modified 9cr-1mo ferritic steel. Materials Science and Engineering: A 437, $413-422$.

Swindeman, R., Santella, M., Maziasz, P., Roberts, B., Coleman, K., 2004. Issues in replacing cr-mo steels and stainless steels with 9cr-1mo-v steel. International Journal of Pressure Vessels and Piping 81, 507 - 512. The 7th International Conference on Operating Pressure Equipment.

Verma, P., Srinivas, N.S., Singh, S., Singh, V., 2016. Low cycle fatigue behavior of modified 9cr-1mo steel at room temperature. Materials Science and Engineering: A 652, $30-41$.

Viswanathan, R., Henry, J.F., Tanzosh, J., Stanko, G., Shingledecker, J., Vitalis, B., Purgert, R., 2005. U.s. program on materials technology for ultra-supercritical coal power plants. Journal of Materials Engineering and Performance 14, 281-292.

Wang, X., Zhang, W., Gong, J., Wahab, M.A., 2018. Low cycle fatigue and creep fatigue interaction behavior of $9 \mathrm{cr}-0.5 \mathrm{mo}-1.8 \mathrm{w}-\mathrm{v}-\mathrm{nb}$ heat-resistant steel at high temperature. Journal of Nuclear Materials 505, $73-84$.

Yan, W., Wang, W., Shan, Y.Y., Yang, K., 2013. Microstructural stability of 9-12\%cr ferrite/martensite heat-resistant steels. Frontiers of Materials Science 7, 1-27.

Zhang, S.L., Xuan, F.Z., 2017. Interaction of cyclic softening and stress relaxation of 9-12\% cr steel under strain-controlled fatigue-creep condition: Experimental and modeling. International Journal of Plasticity 98, $45-64$. 
Zhang, S.L., Xuan, F.Z., Guo, S.J., Zhao, P., 2017. The role of anelastic recovery in the creep-fatigue interaction of $9-12 \% \mathrm{cr}$ steel at high temperature. International Journal of Mechanical Sciences $122,95-103$.

Zhang, Z., Mishin, O., Tao, N., Pantleon, W., 2015. Microstructure and annealing behavior of a modified $9 \mathrm{cr}-1 \mathrm{mo}$ steel after dynamic plastic deformation to different strains. Journal of Nuclear Materials 458, $64-69$.

Zhu, X., Chen, H., Xuan, F., Chen, X., 2019. On the creep fatigue and creep rupture behaviours of 9-12\% cr steam turbine rotor. European Journal of Mechanics - A/Solids 76, 263 - 278. 